\title{
MACHINING ASSESSMENT OF NANO-CRYSTALLINE HYDROXYAPATITE BIO-CERAMIC
}

by

\section{SANKET S. KULKARNI}

B.E., University of Pune, India, 2007

\begin{abstract}
A THESIS
Submitted in partial fulfillment of the requirements for the degree MASTER OF SCIENCE

Department of Industrial and Manufacturing Systems Engineering College of Engineering

KANSAS STATE UNIVERSITY

Manhattan, Kansas
\end{abstract}

2011

Approved by;

Co- Major Professor

Dr. Shuting Lei

Approved by; Co- Major Professor Dr. Malgorzata Rys 


\begin{abstract}
The demand of synthetic implants for good quality of life is high and increasing continuously due to limitations of autogenous bone grafting. Development of various synthetic bio materials and their manufacturing methods in the fields of orthopedics and dentistry has been done and still under way. Close physical properties with human bone make sintered hydroxyapatite (HAP) a suitable bioceramic material for hard tissue replacement. Newly developed fully dense nanocrystalline hydroxyapatite (nHAP) bioceramic has better mechanical properties than porous hydroxyapatite and has potential to be used alone, without metallic support in certain applications. When being used as implant devices in the human body, the nHAP bioceramic needs to be machined to the closest possible configuration with minimal surface roughness. This study investigates the machinability of nHAP bioceramic in milling operations. Efforts are focused on the effects of various machining conditions on surface integrity. Surface roughness is measured using a surface profilometer and the machined surface is observed using an optical microscope and a scanning electron microscope (SEM). Chip morphology and tool wear are examined using an optical microscope. Machined surface analysis showed that the surface integrity was good and the required surface roughness value $\left(R_{a}\right)$ of $1-1.5 \mu$ was achieved in many experiments. It was found that material removal is caused by brittle fracture without plastic flow. A first order surface roughness model for the end milling of nHAP under dry condition has been described. The mathematical model for surface roughness has been developed based on the cutting parameters: cutting speed, feed and depth of cut. The effects of these parameters on surface roughness have been studied using factorial designs and response surface method. Model analysis showed that all three cutting parameters have significant effect on surface roughness. However the current model has limited statistical power for prediction purposes and it demands a higher order model for accurate prediction of surface roughness value.
\end{abstract}




\section{Table of Contents}

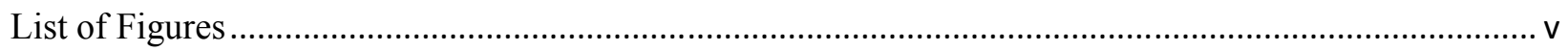

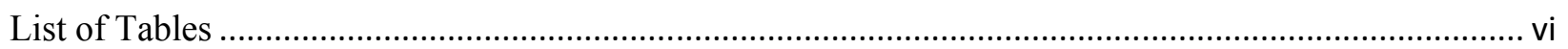

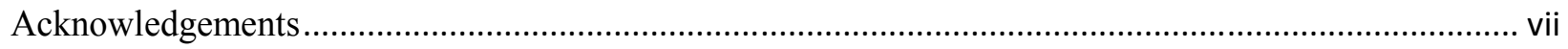

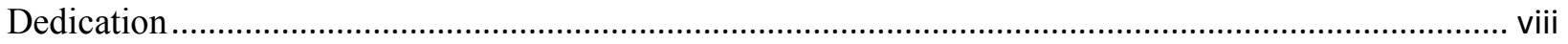

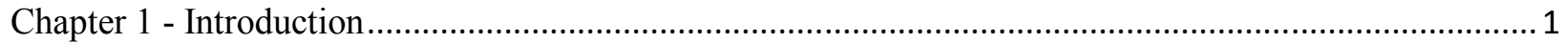

Chapter 2 - Synthetic Materials Used in Engineered Bone Tissue ........................................................ 5

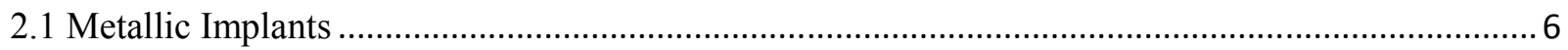

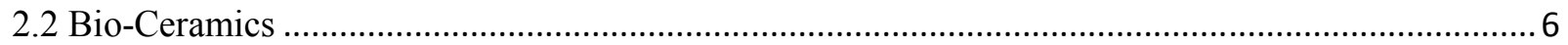

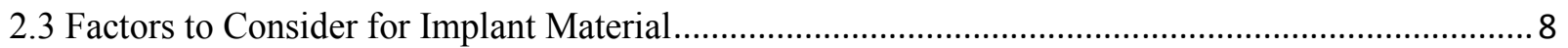

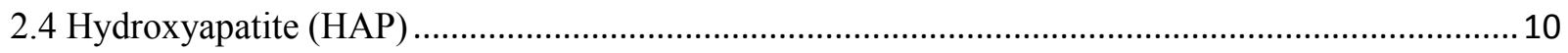

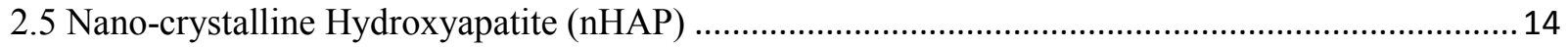

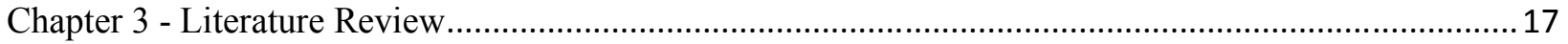

3.1 Limitations of Current HAP Implant's Fabrication Methods ...................................................... 17

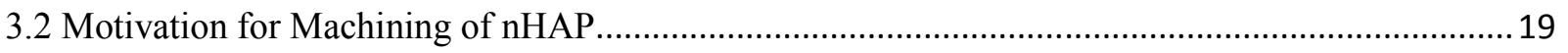

3.3 Literature Review - Machining of Ceramics ............................................................................. 21

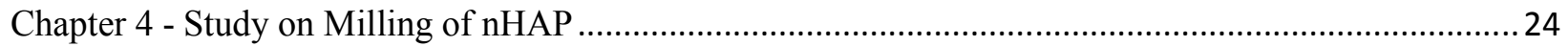

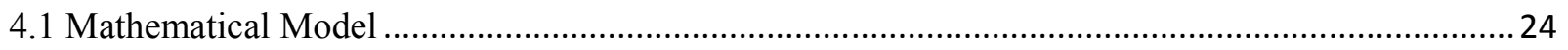

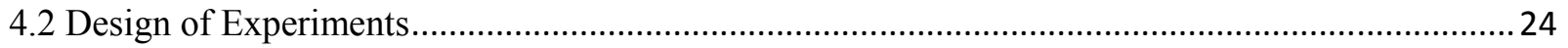

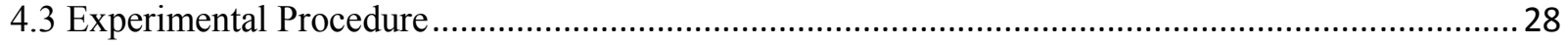

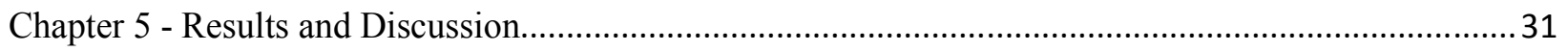

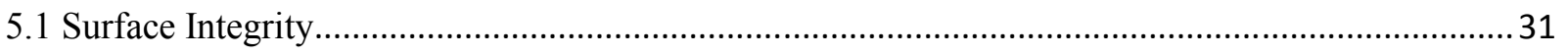

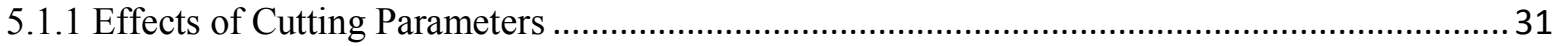

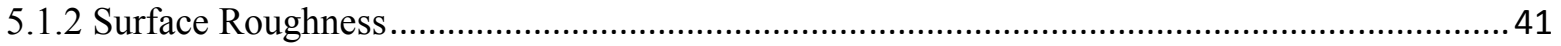

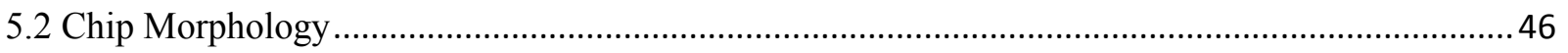

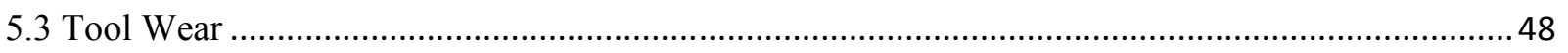

Chapter 6 - Conclusions and Future Work........................................................................................ 53

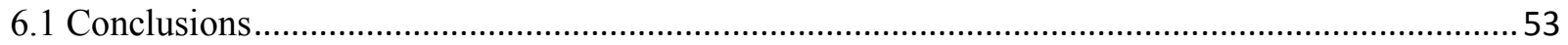

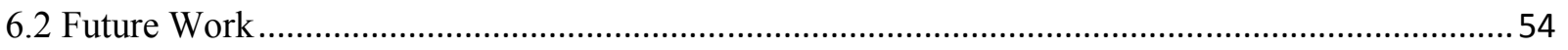

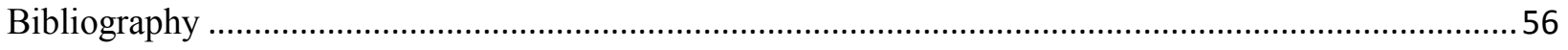




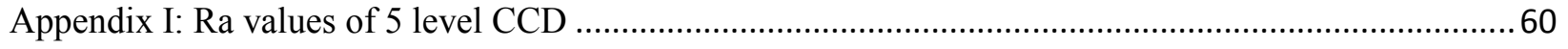

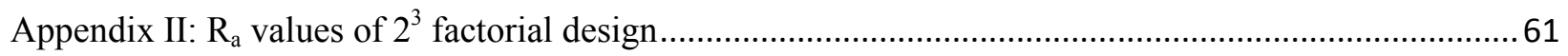

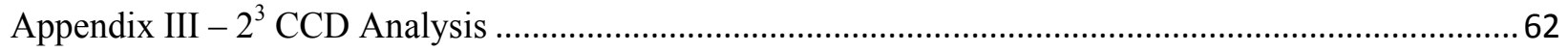

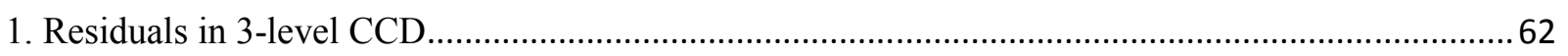

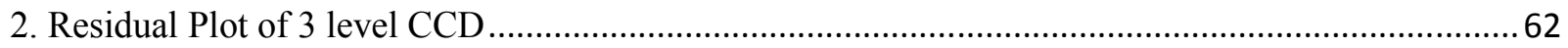

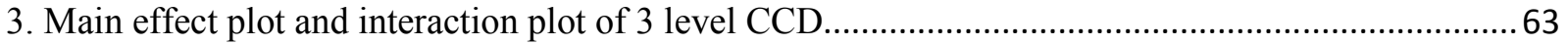

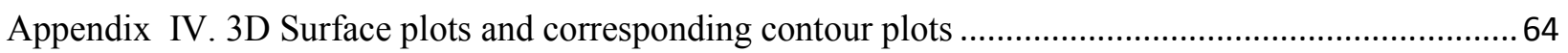




\section{List of Figures}

Figure 1: Total number of total knee (A) and hip (B) replacements with year....................................... 2

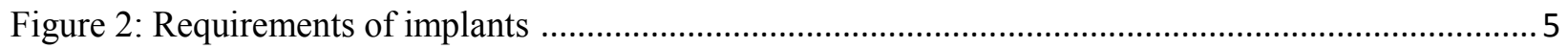

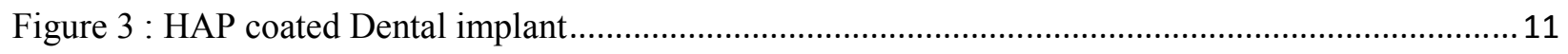

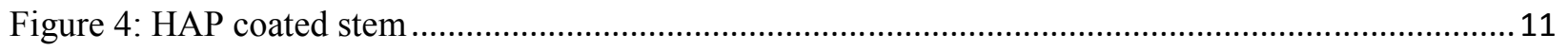

Figure 5: Applications of HAP in various body parts....................................................................... 13

Figure 6: Scanning Electron Micrograph (SEM) of a nHAP bioceramic provided by PST ...................... 15

Figure 7: Potential use of nHAP; Spinal Fixation............................................................................ 16

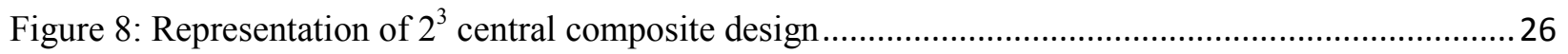

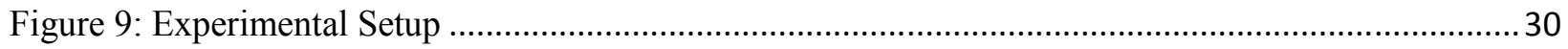

Figure 10: Surface plot of Ra v/s cutting speed and feed ................................................................... 32

Figure 11: Main effect plot of Ra v/s cutting speed, feed and depth of cut ............................................34

Figure 12: Main effect plot of Ra v/s cutting speed, feed and depth of cut ..............................................35

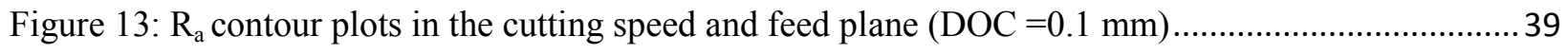

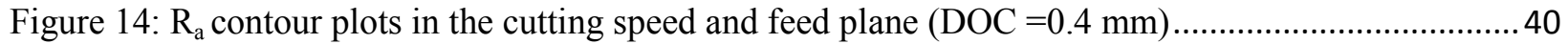

Figure 15: (A) surface profile of polished surface (B) surface profile of machined surface (machining run

2) (C) surface profile of machined surface (machining run 3) ............................................................. 42

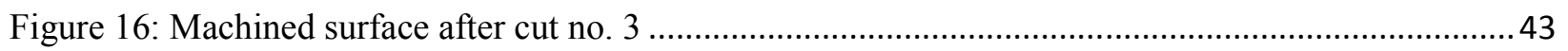

Figure 17: SEM image of machined surface after cut no. 1................................................................. 44

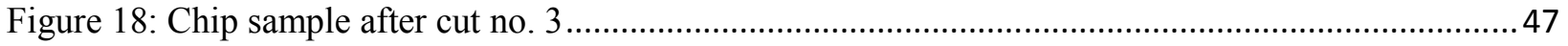

Figure 19: (A) Unused tool (B) Tool after cut 1............................................................................ 50 


\section{List of Tables}

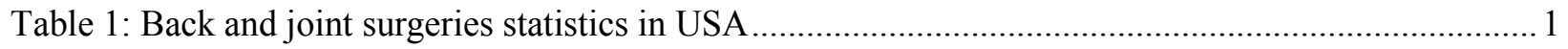

Table 2: Metallic materials used in orthopedics and their mechanical properties ................................... 6

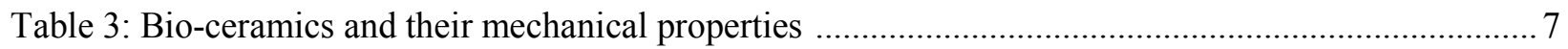

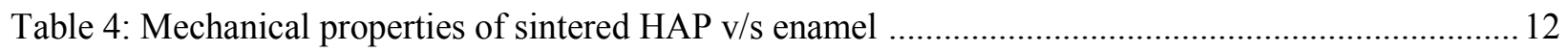

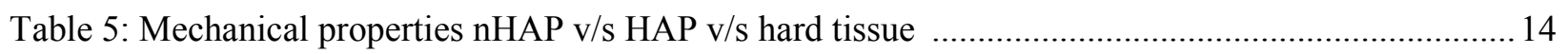

Table 6: Mechanical properties comparison of nHAP with other counter-parts....................................... 19

Table 7: Surface roughness values of commercially available dental implants.......................................2 20

Table 8: Levels of independent machining parameters and their coding for CCD with 5 levels ...............27

Table 9: Levels of independent machining parameters and their coding for $2^{3}$ factorial DOE..................2 27

Table 10: Levels of independent machining parameters and their coding for $2^{3}$ CCD of 3 levels ............ 28

Table 11: Analysis of variance for 5 - level CCD (quadratic model)..................................................... 31

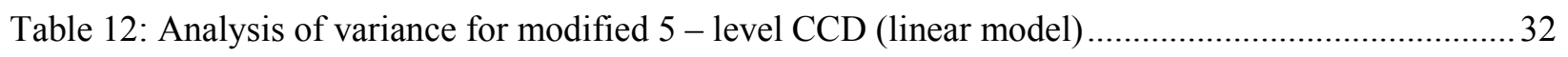

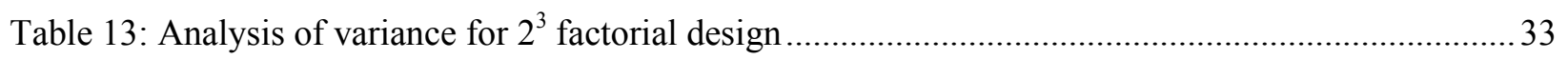

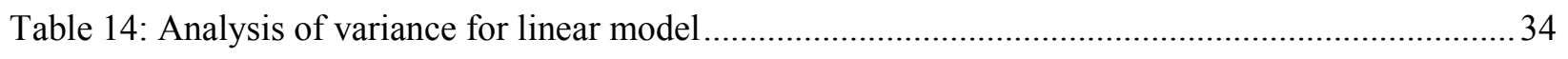

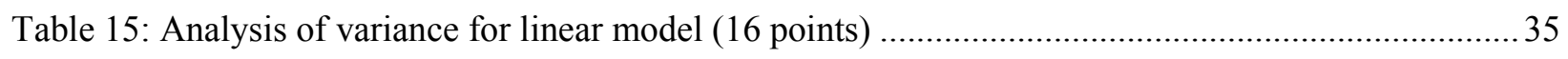

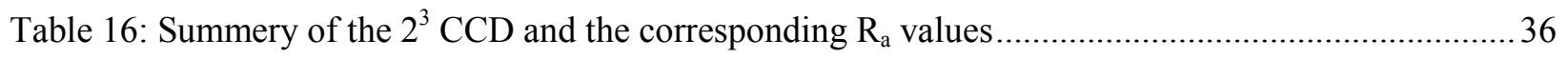

Table 17: Analysis of variance for the prediction model ........................................................................ 37

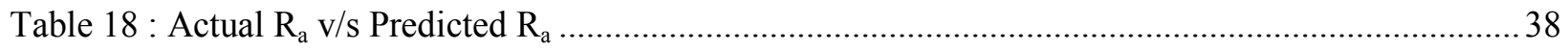

Table 19: Machined surface under respective machining conditions ....................................................45

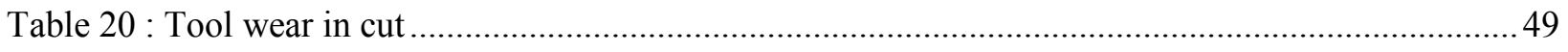

Table 21: Comparison of tool wear (left flank) ................................................................................. 51 


\section{Acknowledgements}

I am indebted to my advisors Dr. Shuting Lei and Dr. Malgorzata Rys for all their encouragement, guidance and time throughout the duration of this research. I would really like to express my sincere thanks to them for giving me opportunity to work in my area of interest. I would also like to thank Dr. Gurpreet Singh for his help with SEM. I am grateful to my research colleague Yaowei Yong, who spent countless hours and assisted in conducting experiments. The contributions of all the above mentors with whom I worked have been invaluable and I appreciate time and resources they invested in current research study.

I would like to express my appreciation to Dr. Bradley Kramer, Head of the Department, and the entire Industrial and Manufacturing Systems Engineering Department at KSU for giving me an opportunity to pursue my Masters and making my stay a wonderful learning experience. I would like to extend my tanks to Doris and Vicky of Industrial Engineering Dept. who helped me in various official activities.

Finally, I would like to thank my parents, family and friends who have been a source of confidence, guidance, providing me with all their love and support throughout my life in all my endeavors. 


\section{Dedication}

This thesis is dedicated to my mother, late Mrs. Shehal Kulkarni, who always stood behind me and knew I would succeed. Gone now but never forgotten. It is also dedicated to my father Mr. Shriniwas Kulkarni who taught me value of hard work, persistence and personal sacrifices, and who instilled in me the inspiration to set high goals and the confidence to achieve them. 


\section{Chapter 1 - Introduction}

Bone and joint problems/diseases are serious health conditions which affects millions of people worldwide. It has been reported that they account for half of all the chronic diseases in people over 50 years of age in developed countries (26).

Table 1 reflects the back and joint procedure statistics informed by National Center for Health Statistics (17). This statistic reflects the need of implants in the upcoming years, to avoid the discomfort, affecting the quality of life.

Table 1: Back and joint surgeries statistics in USA (17)

\begin{tabular}{|c|c|c|c|}
\hline Age & Procedure & $\begin{array}{c}\mathbf{1 9 9 6 - 1 9 9 7} \\
\text { (no/10,000 } \\
\text { population ) }\end{array}$ & $\begin{array}{c}\mathbf{2 0 0 6 - 2 0 0 7} \\
\text { (no/10,000 } \\
\text { population) }\end{array}$ \\
\hline \multirow{4}{*}{$\begin{array}{c}45-64 \\
\text { yrs. }\end{array}$} & $\begin{array}{l}\text { Excision of intervertebral disc and spinal } \\
\text { fusion }\end{array}$ & 27 & 27.2 \\
\hline & Total knee replacement & 11.9 & 25.9 \\
\hline & Total hip replacement & 6.5 & 11.7 \\
\hline & Partial hip replacement & 1.3 & 9.4 \\
\hline \multirow{4}{*}{$\begin{array}{l}65 \text { yrs. } \\
\& \\
\text { above }\end{array}$} & $\begin{array}{l}\text { Excision of intervertebral disc and spinal } \\
\text { fusion }\end{array}$ & 17 & 28.4 \\
\hline & Total knee replacement & 51.2 & 82.1 \\
\hline & Total hip replacement & 28.5 & 33.3 \\
\hline & Partial hip replacement & 28.2 & 35.8 \\
\hline
\end{tabular}

In most cases treatment includes surgery for total/partial joint replacement if deterioration of natural bone occurred. In addition to bone fracture, low back pain, osteoporosis and other musculoskeletal problems need to be resolved using biodegradable materials. These biomaterials are intended to be implanted in human body to perform certain biological functions by replacing or supporting various tissues such as bone, cartilage, tendons etc. Bio-materials are defined as "nonviable material used in a medical device, intended to interact with biological system" (Ratner, 1996). 

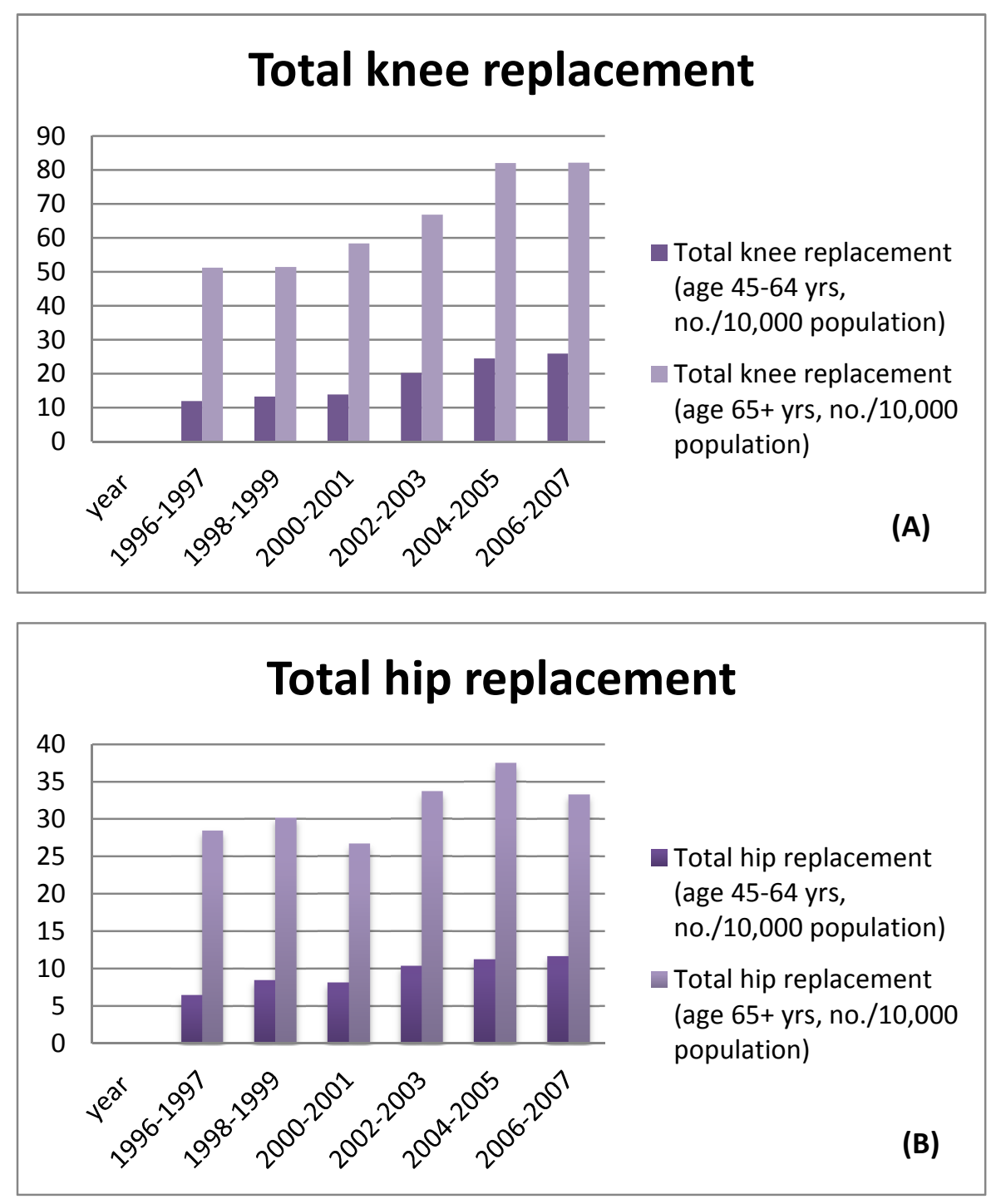

Figure 1: Total number of total knee (A) and hip (B) replacements with year (17)

Bio-materials have one of the following characteristics $(18,24)$

1. osteointegration: it is the capability of forming chemical bond to the surface of bone without an dominating layer of fibrous tissue

2. osteoconduction: it is the capability of supporting the growth of bone over its surface

3. osteoinduction: it is the capability of inducing differentiation of pluripotential stem cells from surrounding tissue to an osteoblastic phenotype

4. osteogenesis: it is the capability of formation of new bone by osteoblastic cells present within the graft material 
It is well known that autogenous bone graft has better osteogenic (formation of bone) potential than allograft (a tissue graft from donor of same species), as it satisfies all the above characteristics. Synthetic bone graft substitutes lack the property of osteogenesis due to lack of live celluler components. Unfortunately autogenous bone grafting has limitations such as morbidity and disability at the site from where the graft was removed and occurrences of late fatigue fractures due to insufficient graft material (13). It has been reported that autografting is a time consuming surgical procedure, which is associated with residual pain. Furthermore it may fail in clinical applications. Autograft harvesting is a complicated process because of nerve injury, blood loss, hernia formation, infection, arterial injury, fracture, cosmetic defects, tumour transplantation, chronic pain at the donor site, limited availability etc. $(14,24)$. Allograft has limitation of diseases transfer. Process to reduce this risk might lead to loss of inherent biological and mechanical properties of allograft (24).

Considering increasing demand of implants for good quality of life and limitations of autogenous bone grafting and allografts, development of various synthetic materials as bone substitute in the fields of orthopedics and dentistry has been done and still under way. This development will insure the no-damage to healthy tissue, no threat of viral/ bacterial risk to patients and unlimited supply without delays.

Hydroxyapatite [HAP] is a widely used and researched bioceramic having great potential to work as a synthetic bio-material. To satisfy the increasing demand of implants, machining processes to shape the HAP need to be developed/identified, which will ensure the affordable and practical supply of implants. But very few studies have been done to assess the machinability of HAP. Existing machining processes and mechanical properties of porous HAP has certain drawbacks which leads to increased machining cost and time. Surface properties of machined HAP play an important role into the quality of implants, which demands good surface integrity. Nano-crystalline hydroxyapatite [nHAP], is a new form of conventional HAP. With nano-scale grains the mechanical properties of nHAP ceramic are improved significantly, and there is a potential for this material to act alone as implants in specific applications. The present study aims to conduct a machining assessment of nHAP in the end milling operation. Conventional machining is the most economical and essential way to shape the ceramics, although selection of optimal machining conditions is essential. For studying the effects of different cutting parameters on the surface roughness, end milling operations were performed on the given nHAP samples. 
Surface integrity was assessed for the roughness and microcracks. Efforts were made to build the surface roughness prediction model to achieve Ra value of 1-1.5 $\mu \mathrm{m}$ in case of end milling operations of nHAP using response surface methodology (RSM). Chip samples and tool wear was studied for the nHAP machinability assessment. 


\section{Chapter 2 - Synthetic Materials Used in Engineered Bone Tissue}

It would be excessive to provide a comprehensive list of all biomaterials used in orthopedics and dentistry. We will classify the materials in three major classifications: metallic, ceramic and polymers. Figure 2 shows the requirements of implants.
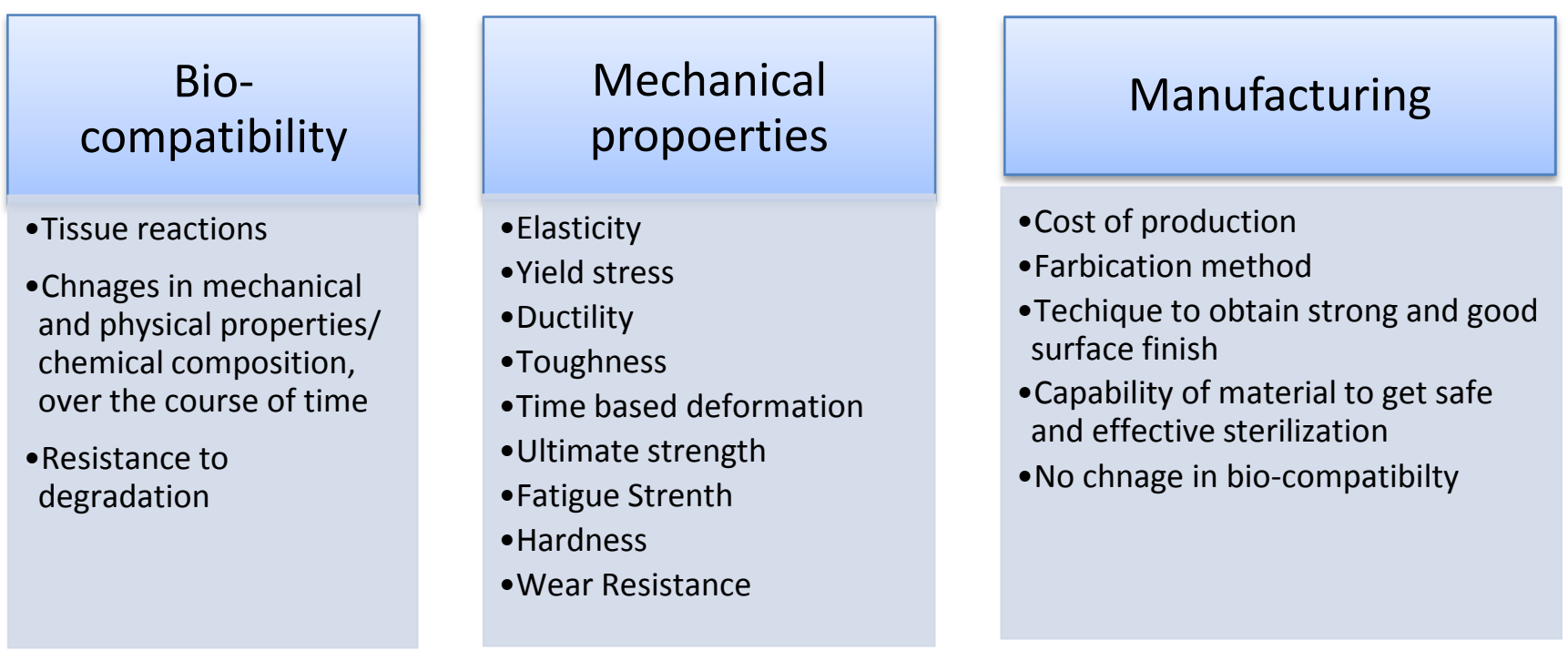

Figure 2: Requirements of implants (Davis, 2003)

The required properties of any bio-material are:

a. High bio-compatibility and non-toxicity: material should have chemical composition to avoid adverse tissue reactions.

b. Good mechanical properties: material should have enough strength to sustain cyclic loading endured by joints and acceptable wear resistance to minimize wear debris generation.

c. Resistance to degradation: metallic implants should have high corrosion resistance to survive in body environment; polymer implants should have resistance to biological degradation 


\subsection{Metallic Implants}

Metallic materials have high modulus and yield point along with ductility, which allows them to be commonly used for load bearing implants and internal fixation devices. Processing method and purity of the metal determines its properties. Some of the desirable properties of a metallic implant are bio-compatibility, high tensile strength, high yield strength, resistance to cyclic loading (fatigue), resistance to time dependent deformation (creep) and its corrosion resistance. Applications of metals include fabrication of implant devices such as hip joint prosthesis, knee joint prosthesis, dental implants, cardiovascular devices, surgical instruments, etc. Table 2 shows different metallic materials used for orthopedic applications along with their mechanical properties. The major difficulty with metals and alloys to be used as implant is corrosion in body environment.

Table 2: Metallic materials used in orthopedics and their mechanical properties (26)

\begin{tabular}{|c|c|c|c|}
\hline Material & $\begin{array}{l}\text { Elastic Modulus } \\
\qquad(\mathrm{GPa})\end{array}$ & $\begin{array}{l}\text { Yield Strength } \\
(\mathrm{MPa})\end{array}$ & $\begin{array}{c}\text { Ultimate Strength } \\
(\mathrm{MPa})\end{array}$ \\
\hline stainless steel $316 \mathrm{~L}$ & $205-210$ & $170-750$ & $465-950$ \\
\hline CoCrMoF75 & \multirow{2}{*}{$220-230$} & \multirow{2}{*}{$275-1585$} & \multirow{2}{*}{$600-1785$} \\
\hline MP35N & & & \\
\hline Ti Grade 4 & 105 & 692 & 785 \\
\hline Ti4A16V & 110 & $850-900$ & $960-970$ \\
\hline Ti6Al7Nb & 105 & 921 & 1024 \\
\hline Ti35Nb5Ta7Zr & 55 & 530 & 590 \\
\hline NiTi & $20-70$ & $50-300$ & $755-960$ \\
\hline $\mathrm{TiNb}$ & $60-85$ & - & - \\
\hline
\end{tabular}

\subsection{Bio-Ceramics}

Bio-ceramics can be defined as synthesized inorganic solid, crystalline materials, excluding metal. Ceramics are popularly being used in various orthopedic applications such as, to fix the bone grafts, to replace the diseased tissue etc. Ceramics can be classified in to three major groups:

1. Bioinert ceramics: These materials do not influence the surrounding tissue biochemically. Bioinert ceramics also includes some oxide ceramics for formation of some kind of a coating with the body's own molecules. The reactions of bony tissue adjacent to implants of such 
ceramics are biomechanically controlled. They can lead to a stable osseo-integration of these implants under certain conditions. They have high chemical stability and high mechanical strength.

2. Bioactive ceramics: They have character of osteocondustion and capability of chemical bonding with living bone tissues. So when bioactive ceramics are implanted in living bone they are incorporated into bone tissue in accordance with pattern of "bonding osteogensis". The mechanical strength of these materials is less than that of bioinert ceramics.

3. Bioresorbable / biodegradable ceramics: These ceramics are gradually absorb in vivo and replaced by bone in bone tissue. Process of their incorporation into bone tissue was comparable to contact osteogenesis although interface between bioresorbable ceramics and bone is unstable as that observed in bioinert ceramics.

Bio-Ceramics have limited range of formulation and their microstructure is highly dependent of manufacturing processes, which affects their mechanical and biological properties. Though bioceramics, holds good chemical and corrosion-resistant properties, they are extremely brittle. The poor fracture toughness of ceramics severely limits their use for load-bearing applications. Therefore efforts were made for combining desirable ceramics with other materials to tailor the properties such as strength and elasticity to meet bio-system requirements. Table 3 shows the mechanical properties of different bio-ceramics.

Table 3: Bio-ceramics and their mechanical properties (19)

\begin{tabular}{|l|c|c|c|c|}
\hline \multicolumn{1}{|c|}{ Material } & $\begin{array}{c}\text { Compressive } \\
\text { Strength (MPa) }\end{array}$ & $\begin{array}{c}\text { Bending } \\
\text { Strength (MPa) }\end{array}$ & $\begin{array}{c}\text { Young's } \\
\text { Modulus } \\
(\mathrm{GPa})\end{array}$ & $\begin{array}{c}\text { Fracture } \\
\text { Toughness } \\
\left(\mathrm{MPam}^{1 / 2}\right)\end{array}$ \\
\hline Bioglass (15S5) & - & 42 & 35 & - \\
\hline Hydroxyapatite & $500-1000$ & $115-200$ & $80-110$ & 1 \\
\hline Glass-ceramic & 1080 & 220 & 118 & 2 \\
\hline Alumina & $1900-2000$ & $200-600$ & 380 & $4-5$ \\
\hline Zirconia & 2000 & 1000 & 205 & 9.5 \\
\hline
\end{tabular}




\subsection{Factors to Consider for Implant Material}

\subsubsection{Mechanical forces acting on implant}

Based on the activities of an individual implants are subjected to both static and dynamic loading. An induced implant should have enough strength to sustain and transmit the load from joints and muscular forces. Mudali et al. (25) has suggested that simple calculation of static loading can be done to evaluate the typical loading. Furthermore the mechanical properties of "fatigue," "creep," and "stress relaxation" indicate time-dependent behavior of a material and are important mechanical parameters in the selection process. Implant materials should possess a high degree of fatigue resistance to perform over the long term. Non-crystalline materials such as polymers, have weak Van der Waals bonds between chains, and are particularly prone to timedependent form of deformation (creep). Creep phenomena can be minimized in the design process by utilizing metal/alloys having a high melting point and face-centered cubic crystalline structure to inhibit dislocation movement. Russias et al. (34) pointed out important conditions for bone substitute, which are used for load-bearing applications. According to them implant material should have mechanical properties that match those of the bone tissue that they are intended to substitute. Matching the elastic modulus is an important factor which limits the implant life. Mismatch of elastic modulus in case of metallic implant with the surrounding bone and the resulting stress shielding, and lead to osteoporosis and implant failure.

\subsubsection{Biological environment}

Biological environment is an oxygenated saline solution with salt content of about $0.9 \%$ and $\mathrm{pH}$ $\sim 7.4$ with temperature of $98.4^{0} \mathrm{~F}$, with dissolved gases (oxygen), electrolytes, cells and proteins. Even highly corrosion-resistant metallic implantable materials undergo chemical and electrochemical dissolution at some finite rate, due to the complex and corrosive nature of blood plasma (25). It has been reported that surgically implanted material greatly disturbs the body environment: such as disturbance of blood supply to bone, and variation in ionic equilibrium. Initiation of corrosion can be due to various conditions along the implant surface. These conditions might lead to formation of electrochemical cells accompanied by active metal dissolution at favoured localized spots at the implant-body fluid interface, and future implant failure. One of the most important non-mechanical requirements of an implant material is 
inertness. In the ideal situation an implant material should not degrade at all, but practically such a state is unachievable, and therefore a relative degree of implant degradation is acceptable (27). However, the degradation process, must not impair the mechanical strength of the device nor allow the release locally or systemically of by-products that might evoke adverse biologic responses.

\subsubsection{Tissue Implant Corrosion}

Mudali et al. (25) suggested that the material - tissue interaction can induce corrosion/ionization of implanted material. The corrosion phenomena of metals in biologic fluids can be explained as an electrochemical reaction that results in the release of metal ions into the surrounding aqueous electrolyte. This dissolution reaction is coupled with a corresponding reduction reaction of constituents in the aqueous environment to maintain charge neutrality. Implant corrosion may lead to implants weakening or premature failure. Another potential hazard of implant corrosion could be the release of corrosion products into the body. This corrosion release can alter the functions of tissues in the vicinity of implants. Implantation of most alloys may significantly increase the concentration of various ions adjacent to the tissues. Body can react unpredictably to the implanted device. Implant can disturb the body defense mechanism, which causes infection, especially in case of elderly population. Furthermore it was reported that the body response to implant could range from mild edema to chronic inflammation and alteration in bone/tissue structure, demanding implant removal from body. This requires the material used in implants must be inert or tolerated by human body environment.

The alloys currently being used in orthopedics are protected from accelerated corrosion rate by a passivating oxide layer that acts like an electrical resistor to retard the anodic dissolution of metal cations (27). Thus it can safely be assumed that under ideal circumstances of complete passivation, all implant alloys have a finite, although slow, uniform corrosion rate in vivo. Localized corrosion may occur due to factors like metal transfer of materials from surgical tool to implant, differential $i^{2}$ and $\mathrm{H}^{+}$concentration of electrolytes over an implant, etc. Destruction of the protective oxide layer is caused by fretting corrosion or surface abrasion. Mixing of various metals or various metallurgical states leads to galvanic corrosion. Surface irregularities such as crevices or pits cause crevice corrosion. Other corrosion factors to be considered are mechano-chemical phenomena such as stress-corrosion cracking and corrosion fatigue. The 
effect of these corrosion factors can't be eliminated completely by design and manufacturing methodologies. Degradation of nonmetallic materials is more difficult to assess than that of metals. One of the factors to be considered in the degradation process of polymers are type of chemical bonds, steric hindrance and electronegativity effects produced by atoms in close proximity with these chemical bonds, and supermolecular structure (27).

\subsection{Hydroxyapatite (HAP)}

\subsubsection{Introduction}

It is essential to recognize that no one material is suitable for all biomaterial applications, although some of the bio-mimic materials have gained wide acceptance, and Hydroxyapatite is one of them. Hydroxyapatite [HAP, $\left.\mathrm{Ca}_{10}\left(\mathrm{PO}_{4}\right)_{6}(\mathrm{OH})_{2}\right]$ is a widely used and researched bioceramic. HAP is a dense, non-porous surface reactive ceramic, which attaches directly to the bone by chemical bonding, called "bioactive fixation". It is popularly being used as a substitute in bone grafts. Chemical and crystallographic properties of HAP are similar to the mineral component of bones and hard tissues in mammals. HAP is bioactive, i.e. it supports bone ingrowth without breaking down. HAP is stable in aqueous media with $\mathrm{pH}$ range of 4.2-8.0, which lowers the risk of implant corrosion (5). Synthetic HAP comes in ceramic/non-ceramic, porous/non-porous forms. Various manufacturing techniques lead to compact or porous structure of HAP with interconnected macropores that are spatial and structural equivalent of cancellous bone. More crystalline and dense structure of HAP exhibits higher mechanical strength and resistance to dissolution in body environment. Amorphous ultrastructure and greater porosity help improving the tissue/implant material interface activity and bone ingrowth, but this leads to early implant degradation (36).

\subsubsection{Use of HAP}

Most often a layer of hydroxyapatite is applied on metal (titanium or stainless steel alloy) implants to enhance their osteointegration (24). Biocompatibility of HAP enables the metallic implants to be readily accepted in the body. HAP has porous structures that allow the speedy growth of tissues in a grafted area. Tisdel et al. (37) showed that titanium fiber-metal implants, 
coated with hydroxyapatite and tricalcium-phosphate had more rapid and voluminous bone ingrowth than uncoated ones. This study showed that functional outcome of metallic implants can be improved with the help of HAP coating. HAP coated metallic implants are mainly used in hip joints, knee joints and dental implants.

Another popular way to use HAP is using it as a bone filler $(21,41)$. HAP can be used in powder or solid form in bones where a large section of bone mass is missing or when bone augmentations are required. Martinetti et al. (21) developed a porous HAP, which showed the higher speed of bone formation over conventional porous artificial bone fillers, and it did not show any inflammation during grafting operations.
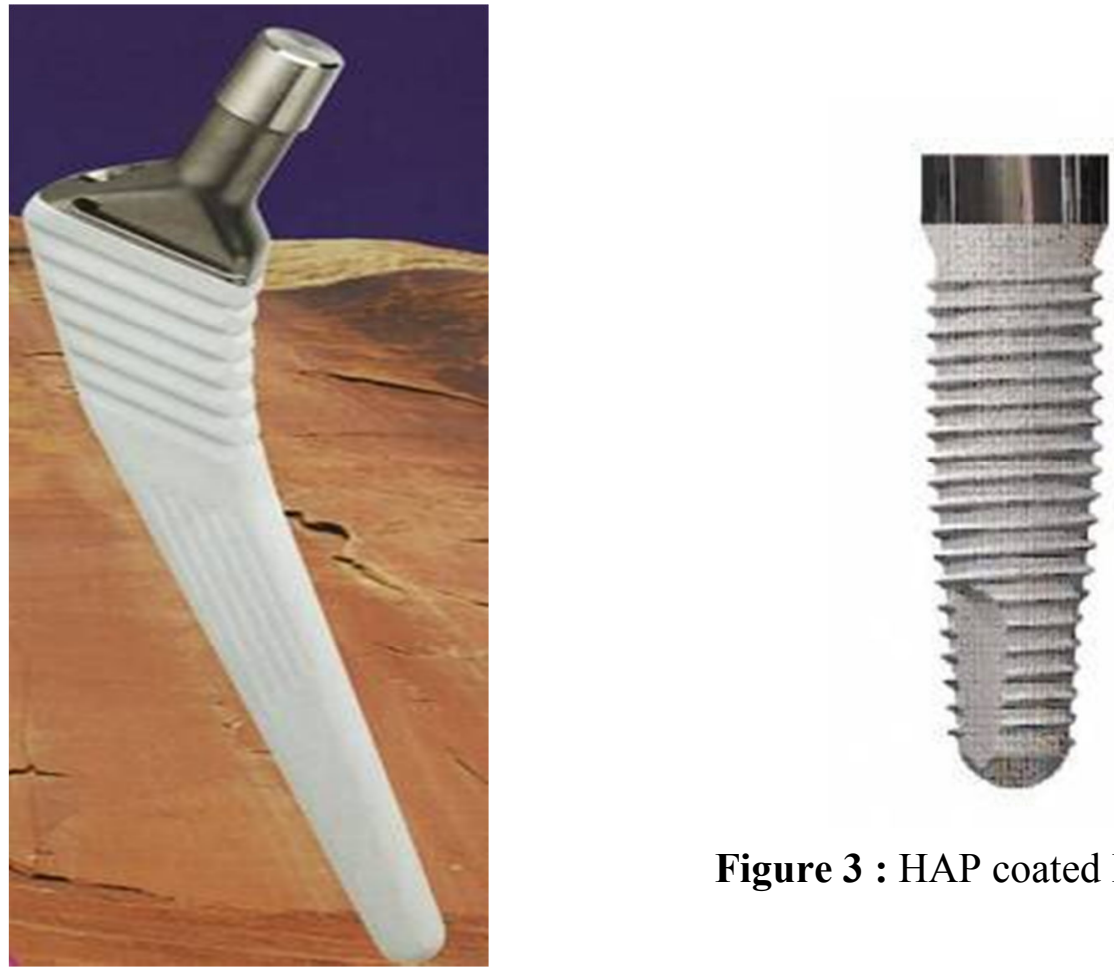

Figure 3 : HAP coated Dental implant (15)

Figure 4: HAP coated stem (1)

Spiveak and Hasharoni (36) evaluated HAP/TCP (tricalcium phosphate) based ceramics for potential use in the range of applications in spine surgery based on vivo animal models and human clinical study. They reported that, porous structure of HAP allows mesenchymal cell migration, adhesion, proliferation and differentiation into osteoblasts in pores. This structure possesses osteoconductive properties. In vivo animal studies reveled efficiency of HAP/TCP ceramic as bone graft substitutes in interbody fusions and as a bone graft extender. Human 
clinical studies showed that HAP can be effective as bone graft extender in posterior spinal fusion surgery and as a structural bone graft substitute in anteriror cervical spine fusion. Furthermore injectable HAP material, used as cement, holds good biocompatibility and bioresorbility. This has applications in spinal screw fixation strength augmentation.

Yoshikawa et al. developed a fully porous HAP using "form-gel" technique (41). The intended use of porous HAP is scaffolds for cell-based or cytokine based bone/cartilage tissue engineering. Also the same product can be used for articular cartilage repair. Figure 5 illustrates the current use and potential use of HAP in various parts of human skeleton.

Unfortunately, low mechanical strength made porous HAP difficult to use as a bone implant (2). It has good compressive strength but it is weak in tension and shear. HAP is brittle and has low fracture toughness, which restricts its clinical orthopedic and dental applications. Some of the body areas generate quite massive static and cyclic force concentrations and the variance in such characteristics among individuals might be enormous. The brittle nature of HAP bio-ceramic is characterized by high strength ionic bonds (12). As a result there is no plastic deformation prior to failure. Furthermore if a crack is initiated, its propagation will not be restricted by deformation of material, as in case of ductile materials. HAP has been reported as brittle polycrystalline materials for which the mechanical properties are governed by crystallinity, grain size, grain boundaries, porosity and composition. Due to high brittleness (associated to a low crack resistance), biomedical applications of HAP are limited to non-load-bearing implants. The properties of HAP and human enamel are compared in Table 4.

Table 4: Mechanical properties of sintered HAP v/s enamel (33)

\begin{tabular}{|c|c|c|}
\hline & Sintered HAP $\left(1200^{\circ} \mathrm{C}\right)$ & Enamel \\
\hline Compressive Strength $(\mathrm{MPa})$ & 376 & 400 \\
\hline Young's Modulus $(\mathrm{GPA})$ & 121 & 77.9 \\
\hline Knoop Hardness $\left(\mathrm{kg} / \mathrm{mm}^{2}\right)$ & 450 & 343 \\
\hline Density $\left(\mathrm{g} / \mathrm{cm}^{3}\right)$ & 3.1 & 2.96 \\
\hline Coefficient of friction & 0.239 & 0.365 \\
\hline Coefficient of thermal expansion $\left(10^{-6}{ }^{0} \mathrm{C}\right)$ & $9.2-11.8$ & 11.4 \\
\hline
\end{tabular}




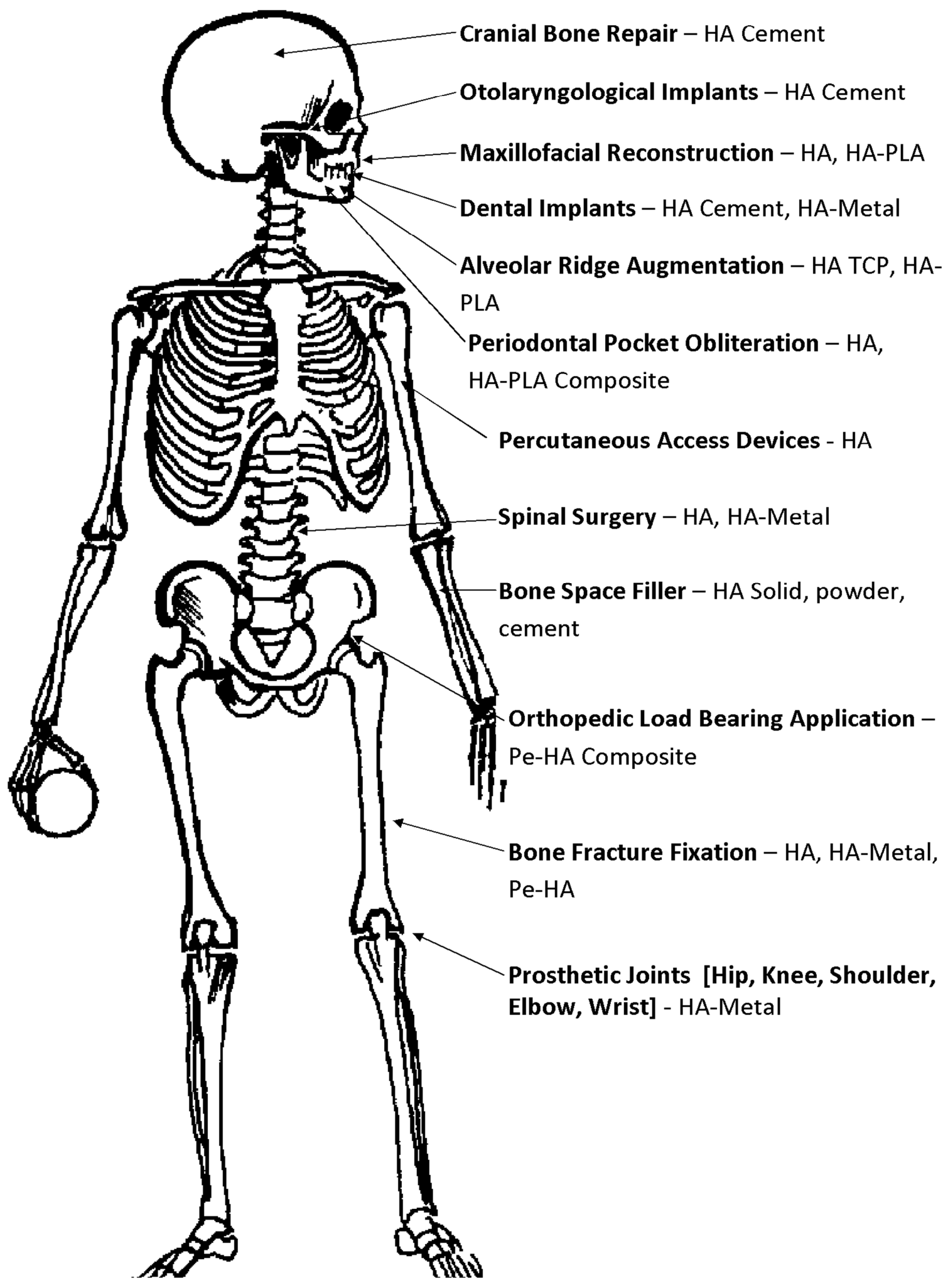

Figure 5: Applications of HAP in various body parts 


\subsection{Nano-crystalline Hydroxyapatite (nHAP)}

HAP considered as a brittle polycrystalline materials, whose the mechanical properties depends on material, crystallinity, grain size, grain boundaries, porosity and composition. For dense HAP, the strength is governed by the grain size. Finer is the grain size, smaller flaws at the grain boundaries occurs, making ceramic stronger compared to ceramics with larger grain sizes. It has been suggested that with increase in the amorphous phase, microporosity and grain size, the mechanical properties decrease significantly. High crystallinity, low porosity and small grain size provide higher stiffness, higher compressive and tensile strength and increased fracture toughness (12). Furthermore Dorozhkin (12) reportd that in the case of HAP the fracture toughness reaches to maximum and decreases rapidly with increasing grain size.

Materials having structures and sizes that fall within the range of 1 to $100 \mathrm{~nm}$ are referred to as nanostructured materials. Pioneer Surgical Technologies (PST) has developed a dense nanocrystalline hydroxyapatite (nHAP) bioceramic for surgically created osseous defects or defects created from traumatic injury to the bone. Figure 6 shows the SEM image of nHAP. Ceramics like HAP having brittle characteristics, fail when stress concentration at a critical flaw is exceeded. Considering this fact, internal company investigation suggested that the reduction in size and density of critical flaws, increases mechanical strength and reducing brittleness. To achieve this, with the help of indigenous processing techniques, nanometer sized grains of HAP were achieved and densified into mechanically stable columns. PST provided comparison of mechanical properties of nHAP and HAP is shown in Table 5.

Table 5: Mechanical properties nHAP v/s HAP v/s hard tissue (provided by PST)

\begin{tabular}{|c|c|c|c|}
\hline & $\begin{array}{c}\text { Compressive } \\
\text { Strength (MPa) }\end{array}$ & $\begin{array}{c}\text { Bending Strength } \\
(\mathrm{MPa})\end{array}$ & $\begin{array}{c}\text { Fracture } \\
\text { Toughness } \\
\left(\mathrm{MPa}^{1 / 2}\right)\end{array}$ \\
\hline nHAP* & $879 \pm 56$ & $330 \pm 18$ & $1.3 \pm 0.2$ \\
\hline HAP & $120-900$ & $38-113$ & 1 \\
\hline Dental Enamel & $95-370$ & 76 & ---- \\
\hline Compact bone & $170-193$ & 160 & $2-12$ \\
\hline
\end{tabular}

$*$ Density $=3160 \mathrm{~kg} / \mathrm{m}^{3}$, shear strength in distal femur $=2.58 \pm 0.03 \mathrm{MPa}$

Table 5 shows that the newly developed nHAP has superior compressive and bending strength than HAP and hard tissues. The fracture toughness of nHAP lacks compared to that of compact 
bone. PST reported that the mechanical properties of nHAP are function of diameter in cylindrical geometry, which acts as blank for screws. Bio-absorbable screws have applications in anterior cruciate ligament surgery. PST claimed that the $7 \mathrm{~mm}$ X $30 \mathrm{~mm}$ cylindrical pin has the largest mechanical properties: tensile force up to $5500 \mathrm{~N}$ and torque up to $1250 \mathrm{~N}-\mathrm{cm}$. During surgical insertion, screws undergo torque of $0.35 \mathrm{~N}-\mathrm{m}$. Thus screws made from nHAP have potential to replace conventional metallic screws as they can sustain the torque experienced during surgical process. Figure 7 shows the potential use of nHAP implants. On the other hand there is need to identify optimal fabrication method, to shape the nHAP into the required shape. Various fabrication methods and assessment of conventional machining of nHAP, for economic processing is discussed in the subsequent sections.

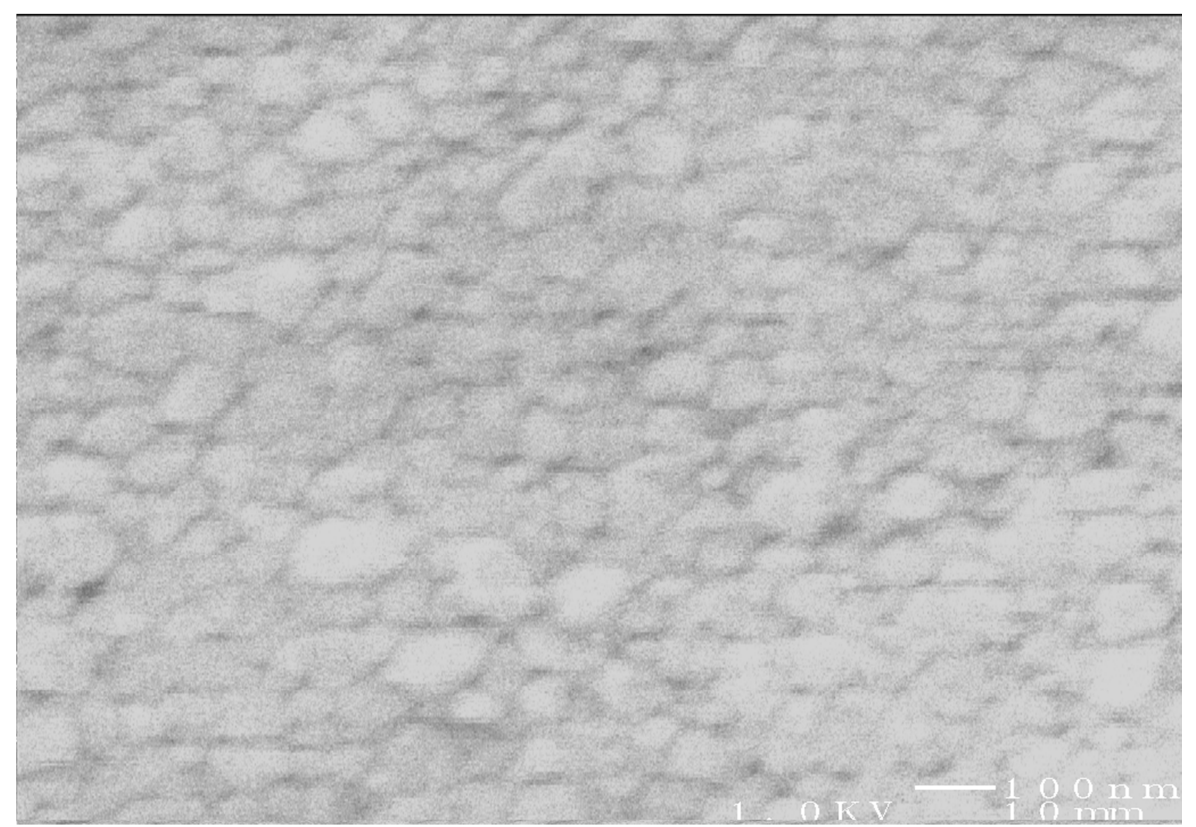

Figure 6: Scanning Electron Micrograph (SEM) of a nHAP bioceramic provided by PST 


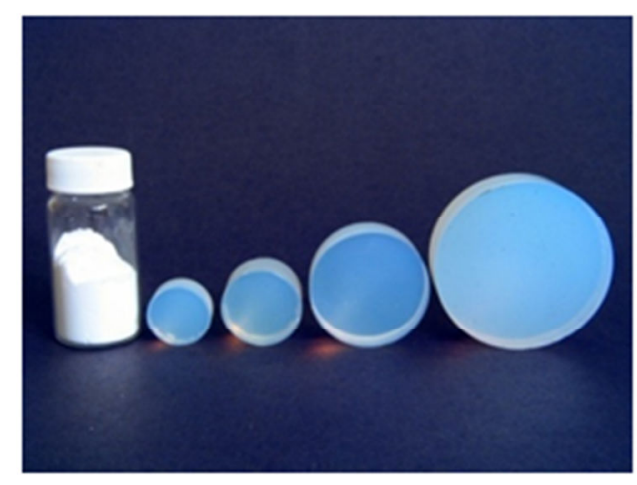

Raw cylinders
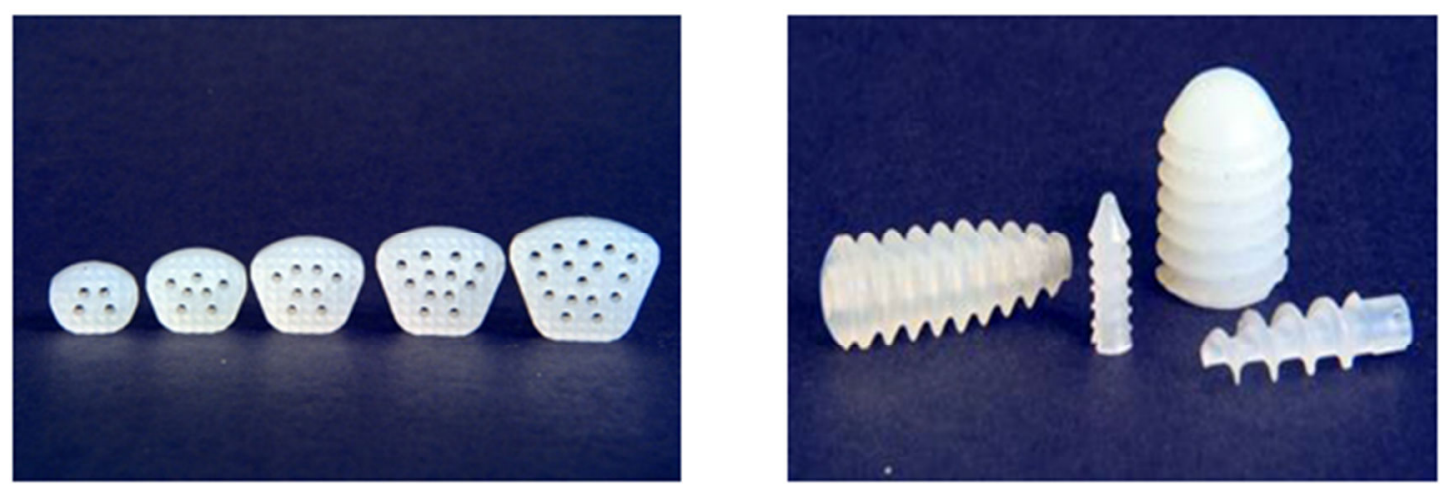

Spinal Disc Spacers

Screws

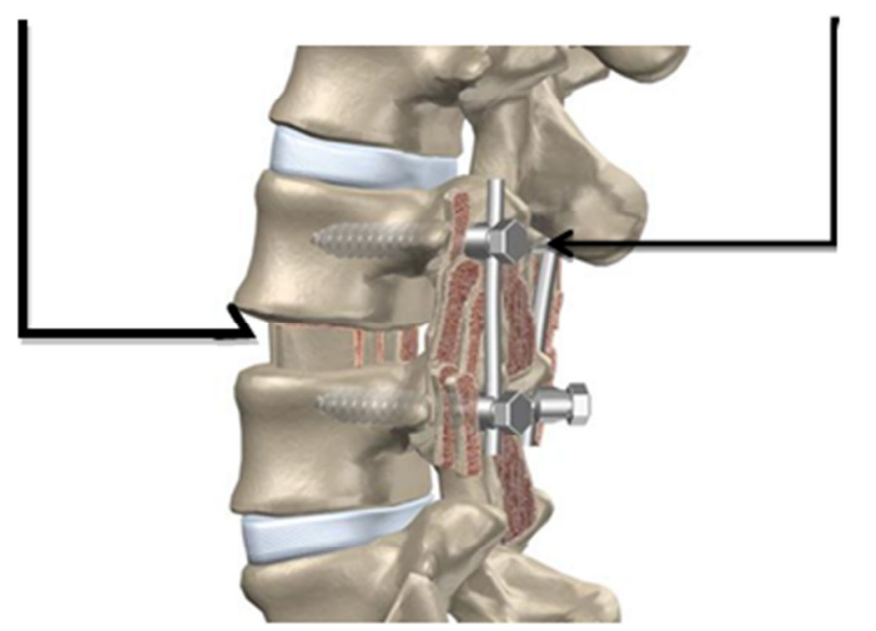

Figure 7: Potential use of nHAP; Spinal Fixation*

(*Credit: Pioneer Surgical Technologies and www.holidayparkphysicalrehab.com) 


\section{Chapter 3 - Literature Review}

\subsection{Limitations of Current HAP Implant's Fabrication Methods}

\section{Metallic Coating}

Hydroxyapatite has been widely used to restore bone tissue and to decrease the negative consequence of surgical operation. Because of its limited mechanical strength, HA is often used as coating on surfaces of more resistant metallic prostheses made of, e.g., Ti-6Al-4V alloy. The environment rich of calcium and phosphate at the surface of prosthesis favors development of bone cells and enhances its adhesion to the bone.

There are various processes studied to apply HAP over metallic implant such as, thermal spraying, sputter coating, sol-gel coating, dip-coating, electrophoretic coating, electrochemical deposition etc. (20). Singh et al. (35) reported that plasma spray technique is the only process which is clinically recommended by Food and Drug Administration (FDA), USA due to superior coating properties obtained by this process over other coating techniques. Though primarily used, plasma spraying has some inherent shortcomings. During the rapid cooling of coated biometal, formation of some amorphous phases like try-calcium phosphate ( $\alpha$ and $\beta$ TCP) and tetracalcium phosphates (TTCP) takes place. These phases are speedily dissolvable in human blood plasma, exposing the metal part to body tissues. This leads to implant instability in later years of implantation. Layer of pure HAP coating exhibits poor mechanical properties, and post heat treatments are used to improve the mechanical properties of HAP coating, increasing processing cost and time.

\section{Net-shape Sintering}

The sintering process consists of solid particle bonding or neck formation, and subsequently continuous closing of pores from a large open porosity to basically pore-free bodies. Though free sintering has been considered as a most economical way to induce strength into powder bodies, it has inherent drawback. Sintering of macroscopically inhomogeneous materials results in distortion because of non-uniform shrinkage of different powder elements (22). This makes netshape sintering of nHAP difficult. Furthermore criteria of complex geometry and custom demand require special purpose dies, which increases the cost and time of overall operation. 


\section{Laser Machining}

It has been reported that laser processing (sintering/melting) of ceramic powders is less practical mainly due to low availability of machines appropriate for laser ceramics processing(4). Various efforts were made to machine HAP based material. Benga et al. (3) reported laser micromachining of HAP based bioceramics. They suggested that the quality of the machined surface was significantly affected by the laser parameters and detailed studies need to be performed to choose the appropriate parameters. The phenomena of vaporization, melt expulsion, thermal cracking should be further reviewed to determine their impact on the machined surface. Initial experiments performed at Kansas State University revealed that the nHAP is transparent to a simple diode laser i.e. it does not absorb enough energy for material removal. Literature suggests Nd-YAG laser can be utilized for machining of HAP/Ti implants, especially for small/limited cutting, drilling and welding. Work efficiency of laser processing is low due to low power and energy efficiency. Furthermore heating nHAP samples induced cracks in the material (due to low thermal conductivity), which are suggestive of limited scope of laser machining.

\section{Grinding}

It is possible to sinter nHAP, and the final shape can be achieved by grinding process. It is well known that excessive grinding forces acting on surface causes defect during grinding of brittle ceramics. Oblak and Jevnikar (29) studied the effect of dental grinding on biaxial flexural strength of tetragonal zirconia ceramics, which is widely used in dental applications. During the dry grinding process, they observed the intensive sparking, indicating excessive stresses and temperature. SEM image of ground surface showed the heavy surface damage and plastic deformation. Dental grinding lowered the mean strength and Weibull modulus; furthermore there was a grain-size dependency of damage tolerance after grinding. Internal company work was performed to analyze reduction in material strength due to typical grinding process of nHAP, and subsequent change in mechanical performance. In case of nHAP grinding studies, similar results were observed as that of literature; there were small localized areas with surface defects. Equibiaxial test of ground specimen showed a $48 \%$ reduction in intrinsic strength of material (75.99 MPa), which is the effect of change in surface conditions. Various post grinding 
treatments such as polishing, glazing, and annealing are needed to regain or increase the strength of material. These post treatments adds excessive cost and are time consuming processes.

\subsection{Motivation for Machining of nHAP}

Manufacturing of miniaturized parts are more widespread in the field of biomedical, automobile, telecommunication etc. Literature suggests utilization of new technologies such as lithography, beam etching and electrical discharge machining for the manufacturing of miniature parts (32). Considering economics, application of these processes are practical for mass production under the limitation of machinable materials and formable geometries. On the other hand conventional machining methods which include end milling, drilling and turning etc. are the most important processes in machining, and can be modified easily to handle the complex geometry of complex shapes such as implants. Popular way used in industry to produce ceramic components starts with taking impression of desired part. It is then followed by preparation of mold, and then casting/sintering processes. The obtained blank is ground and polished to desired shape. This sequence of processes is costly and time consuming. An efficient alternative to this sequence will be conventional machining operations, under required conditions such as tool geometry and machining parameters.

nHAP has shown improved mechanical properties which enables it to perform alone at certain applications as shown in Figure 7. nHAP has inherent properties of chemical inertness, resistance to corrosion even at constantly elevated body temperature. Machining of nHAP in desired shape can avoid use of metals inside the body and will help avoiding disadvantages associated with it such as need of second surgery to remove/replace implant, stress shielding, implant poisoning due to corrosion or allergies etc. Table 6 compares the mechanical properties of nHAP with other popular biomaterials.

Table 6: Mechanical properties comparison of nHAP with other counter-parts

\begin{tabular}{|c|c|c|c|c|}
\hline & nHAP & HAP & $\begin{array}{c}\text { Cortical bone } \\
\text { allograft }\end{array}$ & $\begin{array}{c}\text { Reabsorbable } \\
\text { Polymers }\end{array}$ \\
\hline 3-pt bending strength (MPa) & $330-356$ & $113-195$ & $124-174$ & $150-270$ \\
\hline Tensile Strength (MPa) & $112-179$ & N/A & N/A & $26-140$ \\
\hline $\begin{array}{c}\text { Compressive Strength } \\
(\mathrm{MPa})\end{array}$ & $877 \pm 42$ & $509-917$ & $100-230$ & 124 \\
\hline
\end{tabular}


It has been suggested that tissue-biomaterial interactions are governed by surface properties and the important interactions between the two occur within around $1 \mathrm{~nm}$ of the biomaterial surface. Thus surface properties and the surface roughness is one of the important factors that significantly affect the quality of machined components. In the PST investigation nHAP has shown good biocompatibility over other bio-materials such as glass, Ti6Al4V, PLLA in vivo. This suggests that machining does not hamper bio/chemical properties of nHAP. But the surface integrity needs to be observed after machining, as any small crack might lead to failure of implant or freed chip from surface which might get into blood stream and/or block small blood vessel.

Wennerberg et al. (40) reported that although rough surface is preferable for bone absorption, there could be negative consequences of surface irregularities; increased surface area increases the risk of simultaneous ion release. Furthermore stability of dental implant is negatively affected by increased surface roughness value. Furthermore rough surface increases the torque requirement to fix the implant. Most oral implants have a screw-shaped design. Therefore, minimum torque is always desirable. Wennerberg et al. (40) compared the design and surface characteristics of 13 commercial oral implants (usual shape is cylindrical with grooves). Six HAP -coated implants had highest surface roughness, and they are shown in Table 7.

Table 7: Surface roughness values of commercially available dental implants (40)

\begin{tabular}{|c|c|c|}
\hline name & $\mathrm{R}_{\mathrm{a}}(\mu \mathrm{m})$ & $\begin{array}{c}\mathrm{R}_{\mathrm{t}}(\mu \mathrm{m}) \text { max peak-valley } \\
\text { height }\end{array}$ \\
\hline Osteobond & 2.94 & 32.52 \\
\hline IMZ & 2.76 & 38.41 \\
\hline Micro-Vent & 1.89 & 22.08 \\
\hline Bio-Vent & 1.76 & 20.68 \\
\hline Impla-Med & 1.69 & 20.09 \\
\hline Calcitek & 1.59 & 16.26 \\
\hline
\end{tabular}

It has been suggested that only a very specific surface topography with a Ra value between 1 and $1.5 \mu \mathrm{m}$ provides an optimal surface for bone integration and reduced torque during implant processing (40). Limitations of spraying HAP on metal surface have been discussed in section 
5.1. In addition to that achievable surface roughness values obtained with this process are quite high. Surface roughness values are important in case of bio implants. Roughness values of as sprayed coating of pure HAP was $5.36 \mu \mathrm{m}$, and of reinforced HAP was $6.32 \mu \mathrm{m}$. Heat treatment at $700^{\circ} \mathrm{C}$ was $4.20 \mu \mathrm{m} \& 4.45 \mu \mathrm{m}$ and at $800^{\circ} \mathrm{C}$ were $3.4 \mu \mathrm{m}$ and $3.52 \mu \mathrm{m}$. Roughness might decrease due to refinement of grains in sintering (35).

Considering potential use as implant devices inside the human body, smooth and strong nHAP components with high dimensional and geometrical accuracy are necessary. Current HAP implant fabrication processes have certain limitations. If basic machining processes are able to achieve tight tolerances with smooth, crack free and strong surface, then finishing processes like grinding and following surface treatments will be reduced which directly impacts the manufacturing cost and time. These processes are easy to quickly mold into different configuration to satisfy highly personalized demands of implants with high dimensional accuracy.

Newly developed nHAP has better mechanical properties and has potential to be used alone, without metallic support in certain applications. Taking advantage of these increased properties, this study tries to assess the machinability of nHAP. The targeted surface roughness value is considered as 1-1.5 $\mu \mathrm{m}$. Milling is the important machining processes in manufacturing which can be utilized to obtained many desired shapes and are being used to machine various ceramics. Furthermore though near net shape sintering process strategy is incorporate popularly for mass production of implants, final complex shapes of implants can be economically achieved by processes of milling. It is therefore essential to investigate the machinability of nHAP so as to optimize the machining parameters, leading to minimized machining cost and process time, with good surface integrity. Considering these issues, end milling operations were performed to assess the machinability of nHAP. Efforts were directed towards the development of $1^{\text {st }}$ order surface roughness prediction model, in end milling operations.

\subsection{Literature Review - Machining of Ceramics}

Very few attempts were done to assess the machining performance of solid HAP Chelule et al. (8), investigated into the machinability of "CATPOL-90" HAP in milling operations. They used sintered porous HAP for machining purpose. Results were focused on surface integrity, tool wear 
and chip fragments. The $2^{3}$ design of experiments methodology was utilized, under chosen range of three machining parameters; feed rate, depth of cut and cutting speed. The analysis revealed that the effect of machining parameters was minimal on surface roughness value, and the machinability of the HAP material was poor. Milled surfaces were adversely affected by the grains pull-out. SEM examinations revealed that the HAP structure was highly porous with cavity channels between grains, leading to brittle fracture along the grain boundary interface during the machining. The observed surface topography was irregular and surface roughness values $\left(\mathrm{R}_{\mathrm{a}}\right)$ obtained were in the range of $88.04 \mu \mathrm{m}$ to $100.04 \mu \mathrm{m}$. Cutting conditions had no significant effect on the average chip size. A major concern was considerable fracture or cracks at the tip of cutting tool, along with occurrence of abrasive wear. Furthermore they suggested that smaller grain size will densify the material, improving its mechanical strength. To assess the machining of new ceramics under CAM applications, Chelule et al. (8) performed milling operation of "CATPOL-90" HAP. Surface roughness value $\left(\mathrm{R}_{\mathrm{a}}\right)$ was $90.30 \mu \mathrm{m}$. Their study concluded that the HAP structure was highly porous and of low strength. HAP needed more modifications to improve its strength for better structural performance and machinability. They further suggested that cutting parameters in case of ceramic machining has large effect on rate of machining, tool wear and properties of ceramic; furthermore machining procedures should be chosen considering material limitations, microstructure and tool used.

Brehm et al. (7) studied single point turning of optical glass, to evaluate the optimal operating conditions for obtaining transparent surface. Turning operation at ambient temperature could only achieve matt surface finish which depends on glass type and tool used. Also tool wear was high and continuous chips were not observed. They further suggested that it is hard to identify the properties that will help achieving continuous chips, as it depends on the combination of material hardness, fracture toughness, local inhomogeneity and viscosity. A solution suggested to achieve the continuous chips and to optimize the machining parameters was machining at elevated temperature. Turning at elevated temperature can be achieved by supplying extra energy at the tool tip, which will locally and momentarily predominate the viscous phenomena. The objective of the study was to obtain the transparent surface finish, with optimized combination of mechanical-abrasive and surface viscous-flow process. The chosen temperature range was in the range on $30^{\circ} \mathrm{C}$ near the American softening point corresponding to the glass viscosity of $10^{6.6}$ $\mathrm{Nsm}^{-2}$. In this study five different types of optical glasses were used: Fused silica, Borosilicate 
(pyrex), Borosilicate (G28), AR, Lead glass and four different types of tools were used; Green $\mathrm{Al}_{2} \mathrm{O}_{3}$, SN 56, SHT, Diamond (single crystal). The surface roughness values $\left(\mathrm{R}_{\mathrm{a}}\right)$ varied between $1.76 \mu \mathrm{m}$ to $0.45 \mu \mathrm{m}$. Lead glass has the least $\mathrm{R}_{\mathrm{a}}$ value, although none of the experiments achieved the transparent surface. Tool wear in case of Mono-crystalline diamond tool was least, but at high temperature diamond turns into graphite, which forced the authors to seek alternative tools. The authors suggested that Borazon can be used as tool material as its wear is low at $900^{\circ}$ C. They further performed work with Hafnium nitride (HfN) tool, at $463^{\circ} \mathrm{C}$. In this case the tangential component of cutting force was less than that of the normal component, and continuous chips were generated. However it was mentioned that $\mathrm{HfN}$ has high wear at $800^{\circ} \mathrm{C}$.

Efforts have been made to develop a surface roughness model for turning operation of machinable glass-ceramic (Macor) (10). A first order predictive surface roughness model for turning was developed, based on machining parameters such as; cutting speed, feed and depth of cut. A $2^{\mathrm{k}}$ factorial design with 4 axial points was utilized. The model covered range for cutting speed of $15-60 \mathrm{~m} / \mathrm{min}$, for feed $0.06-0.025 \mathrm{~mm} / \mathrm{rev}$ and for depth of cut $0.4-1.6 \mathrm{~mm}$ at $95 \%$ confidence interval. An uncoated carbide tool, having grade that can sustain high temperatures without deformation was used in the machining study (TNMG160404-QM, TNMG331- QM). The obtained $1^{\text {st }}$ order model was; $\mathrm{R}_{\mathrm{a}}=17.750\left(\mathrm{~V}^{-0.03028} \mathrm{f}^{0.94372} \mathrm{~d}^{0.1135}\right)$, which suggests that $\mathrm{R}_{\mathrm{a}}$ decreases as cutting speed increases, although it decreases with increase in feed and depth of cut. Feed was the most influential factor affecting $\mathrm{R}_{\mathrm{a}}$.

Reddy et al. (32) developed a surface roughness model for end milling operation of machinable glass-ceramic. They utilized response surface methodology (RSM), to develop the end milling model. Central composite design methodology (CCD) was used to design the experiments. Machining parameters: cutting speed, feed and depth of cut were chosen for the study as they are dominant factors in case of end milling operation, but depth of cut was kept constant and feed rate $(10-30 \mathrm{~mm} / \mathrm{min})$, cutting speed (10000-20000) were varied. A two flute square end micro grain carbide end mill tool was used. Results showed that surface roughness value $\left(R_{a}\right)$ decreased with increase in cutting speed. Although a quadratic model was fitted for prediction purpose, it is hard to judge the influential factor affecting $R_{a}$ value. 


\section{Chapter 4 - Study on Milling of nHAP}

\subsection{Mathematical Model}

The practical relationship between predicted surface roughness and the independent machining variables can be represented as follows:

$$
R_{a}=C V^{l} f^{m} d^{n}
$$

Where $R_{a}$ is predicted surface roughness, $C$ is constant, $1, m, n$ are the model parameters to be determined by experimental data. Cutting speed (V, $\mathrm{m} / \mathrm{min}$ ), feed (f, $\mathrm{mm} / \mathrm{rev} /$ tooth) and depth of cut $(\mathrm{d}, \mathrm{mm})$ were chosen as independent machining parameters as they play important role in end milling operation.

Equation (1) can be written by performing logarithmic transformation as,

$$
\ln R_{a}=\ln C+l \ln V+m \ln f+n \ln d
$$

Equation (2) can be represented by the following linear model as,

$$
y=\beta_{0} x_{0}+\beta_{1} x_{1}+\beta_{2} x_{2}+\beta_{3} x_{3}+\varepsilon
$$

In case of equation (3), $y$ is the true response when $x_{0}=0$ (dummy variable). $x_{1}, x_{2}$ and $x_{3}$ represents the logarithmic transformation of cutting speed, feed and depth of cut respectively. $\varepsilon$ is the error term. $\beta_{0}$ is the intercept of the linear regression model. $\beta_{1}, \beta_{2}$ and $\beta_{3}$ are regression coefficients/ model parameters which represent change in surface roughness value per unit change in cutting parameters. Model parameters need to be estimated experimentally. Values of $\beta_{1}, \beta_{2}$ and $\beta_{3}$ are calculated by method of least squares, using Minitab 16.

\subsection{Design of Experiments}

In the ideal case, to establish a functional relationship between the surface roughness and the cutting parameters: cutting speed, feeds and depth of cut, a large number of tests will be required, with a separate combination of cutting parameters for each test along with separate cutting tool and workpiece. This strategy increases the number of tests and research costs. The present study utilizes the response surface methodology (RSM) and a well-designed experimental method to predict the surface roughness of nHAP bio-ceramic under end milling operations. RSM is a collection of mathematical and statistical tools which enables analysis and 
optimization of response, influenced by many parameters (23). RSM takes into account the simultaneous variation of cutting speed, feed and depth of cut to predict the surface roughness value $\left(\mathrm{R}_{\mathrm{a}}\right)$ or the response of $\mathrm{R}_{\mathrm{a}}$ to the simultaneous change of cutting parameters. In case of the design of machining experiments, knowledge of the range of cutting parameters is really important. In many cases this range is constrained by physical limitations of machine available. If the chosen range of machining parameters is too low then the effect of predictor (cutting conditions) on response (surface roughness) can't be proven statistically. Based on the known range of predictors various types of response surface designs can be developed. The preferred classes of RSM designs are orthogonal first order design and central composite design (CCD) for second order models (23).

The basic mathematical model for predicting surface roughness is,

$$
R_{a}=f(v, f, d)+\varepsilon
$$

The above equation assumes that the three cutting parameters are independent of each other and surface roughness depends on them with some experimental error. This error term accounts for uncertainties in machining experiments. In RSM methodology, the true response of function $f$ is unknown. In order to develop a functional approximation for $f$, experiments should start with a low-order polynomial in a small range of parameters. If the response of Ra can be defined by a linear function of the independent machining parameters, then the approximate function $f$ is a first order model. The first order model for the three independent cutting parameters is shown by Equation (3). The orthogonal first order design minimizes the variance of the coefficients $\beta$ and makes design more efficient. In this study the orthogonal first order design consisting of 12 experiments is used to develop the first order surface roughness predictive model. These 12 experiments are designed using the $2^{3}$ factorial design methodology ( 3 parameters). It has 8 corner points located at the vertices of cube and 4-times repeated center point (for estimation of pure error). Figure 8 represents the $2^{3} \mathrm{CCD}$. All the 8 experiments were replicated to estimate the true effect of cutting parameters on the surface roughness value. Furthermore, the inclusion of replication allowed the estimation of random error independent of any lack of fit error. 
The first order model is generally appropriate for describing a flat surface without tilt. If the first order model has substantial lack of fit, i.e. the response surface has curvature; a more structured second-order model may be needed to find the optimal response (surface roughness).

4.2.1 Cutting Conditions: This study begins with a CCD of 5 levels. This design is an extension of the orthogonal first order design and able to provide with a second order model. The second order model has all the terms in the first order model, plus it also includes quadratic terms and cross product terms. The target surface roughness value $R_{a}$ was $1 \mu \mathrm{m}$. Based on initial runs of experiments and machine capability, 5 levels of all the three parameters were chosen, which are shown in Table 8. A total of 20 experiments were performed and the $R_{a}$ values for all the surfaces were recorded and analyzed. Appendix I shows the DOE and the corresponding $R_{a}$ values.

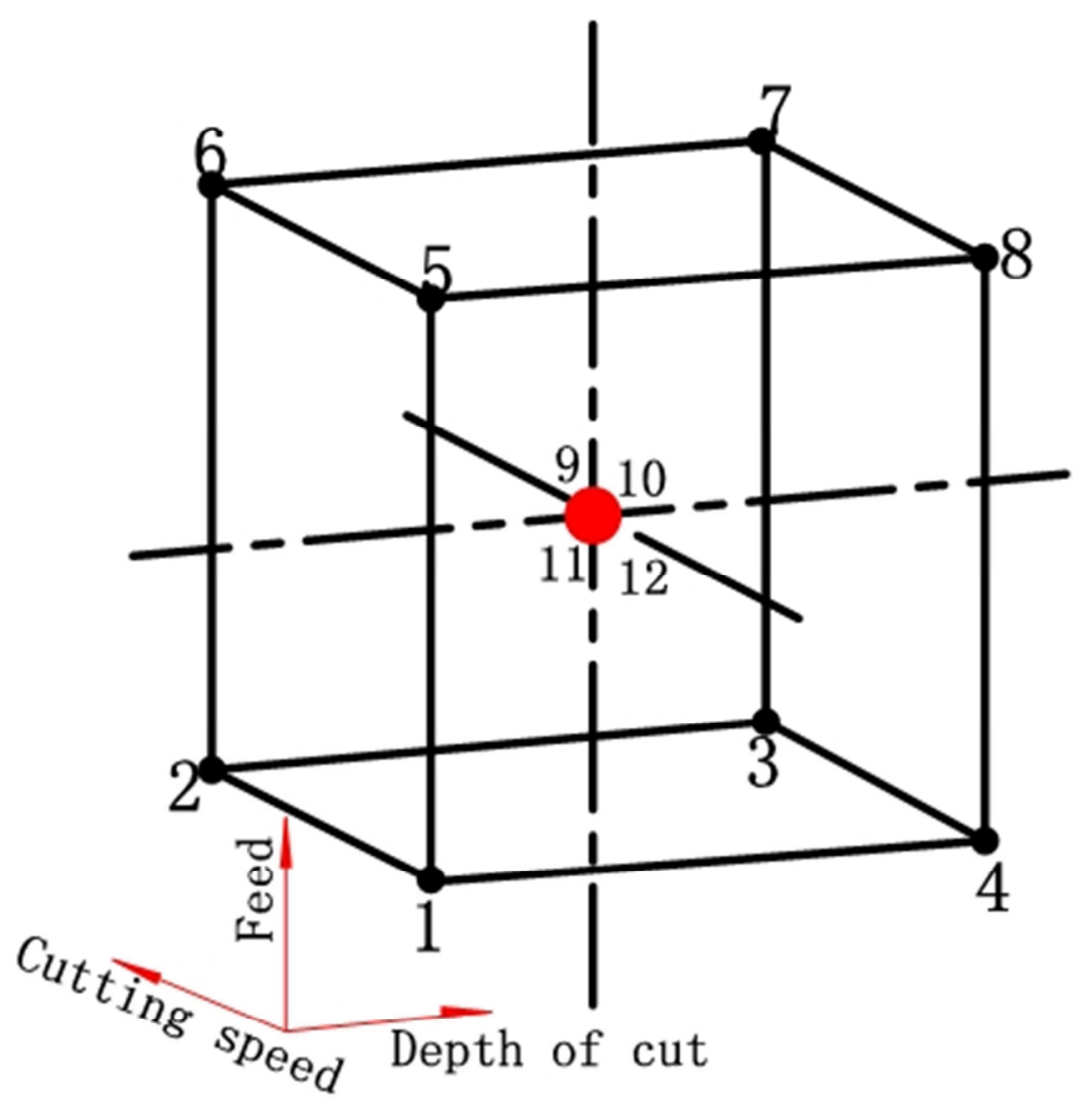

Figure 8: Representation of $2^{3}$ central composite design 
Table 8: Levels of independent machining parameters and their coding for CCD with 5 levels

\begin{tabular}{|l|ccccc|}
\hline \multirow{2}{*}{\multicolumn{1}{|c|}{ Parameter }} & \multicolumn{5}{|c|}{ Levels in coded form } \\
\cline { 2 - 6 } & Lowest & Low & Center & High & Highest \\
& $\mathbf{( - 1 . 6 3 3 )}$ & $\mathbf{( - 1 )}$ & $\mathbf{( 0 )}$ & $\mathbf{( 1 )}$ & $\mathbf{( 1 . 6 3 3 )}$ \\
\hline Cutting speed (mm/min) & 77.5 & 98 & 135.5 & 171 & 193.5 \\
Feed (mm/rev/tooth) & 0.45 & 0.89 & 1.26 & 1.72 & 2.47 \\
Depth of cut (mm) & 0.015 & 0.036 & 0.068 & 0.1 & 0.12 \\
\hline
\end{tabular}

The results of the central composite design (developed based on a total of 5 levels) were not found statistically significant to identify the effects of the parameters on the $R_{a}$ value. They are discussed in subsequent sections in details. As RSM is a sequential process based on chosen range of parameters, the range of parameters (feed and depth of cut) was increases and the basic $2^{3}$ factorial design with new ranges was designed. The cutting conditions are recorded in Table 9. For the new experiments care was taken to use new tool for each of the first 8 experiments, to reduce the source of variability into the experiments. All the 8 experiments were replicated for the estimation of random error. A total of 16 experiments were performed and $R_{a}$ values for all the surfaces were recorded and analyzed. Furthermore tool wear data was recorded. Appendix II shows the DOE and the corresponding $\mathrm{R}_{\mathrm{a}}$ values.

Table 9: Levels of independent machining parameters and their coding for $2^{3}$ factorial DOE

\begin{tabular}{|l|cc|}
\hline \multirow{2}{*}{\multicolumn{1}{|c|}{ Parameter }} & \multicolumn{2}{|c|}{$\begin{array}{c}\text { Levels in coded } \\
\text { form }\end{array}$} \\
\cline { 2 - 3 } & Low & High \\
& $\mathbf{( - 1 )}$ & $\mathbf{( 1 )}$ \\
\hline Cutting speed $(\mathrm{m} / \mathrm{min})$ & 98 & 171 \\
Feed $(\mathrm{mm} / \mathrm{rev} /$ tooth $)$ & 0.00053 & 0.00147 \\
Depth of cut $(\mathrm{mm})$ & 0.1 & 0.2 \\
\hline
\end{tabular}

Although the results obtained using the $2^{3}$ factorial DOE were positive, statistically they were not significant. To develop a surface roughness model with more statistical significance, the ranges of feed and depth of cut were further increased and a new $2^{3}$ factorial design was developed. All the 8 experiments were performed with a new tool for each experiment and the $R_{a}$ 
values for all the surfaces were analyzed. The results were found statistically significant. For the confirmation of results all the experiments were repeated and the data was analyzed. All the results were found statistically significant. An addition of central point was done to create the first order CCD. The center point was repeated four times to calculate the pure error. A total of 20 experiments were performed, and the machining conditions are recorded in Table 10. Based on this CCD of three levels, the surface roughness model for the end milling operation is proposed and discussed in later sections.

Table 10: Levels of independent machining parameters and their coding for $2^{3} \mathrm{CCD}$ of 3 levels

\begin{tabular}{|l|ccc|}
\hline \multirow{2}{*}{\multicolumn{1}{|c|}{ Parameter }} & \multicolumn{3}{|c|}{ Levels in coded form } \\
\cline { 2 - 4 } & Low & Center & High \\
& $\mathbf{( - 1 )}$ & $\mathbf{( 0 )}$ & $\mathbf{( 1 )}$ \\
\hline Cutting speed (m/min) & 98 & 135.5 & 171 \\
Feed (mm/rev/tooth) & 0.0015 & 0.005 & 0.018 \\
Depth of cut (mm) & 0.1 & 0.2 & 0.4 \\
\hline
\end{tabular}

The parameters were coded considering the machine capability and other uncontrollable variables. The transformation from the natural values in the Table 10 to the coded values and to be used in equation 3 are obtained by following equations:

$$
\begin{aligned}
& x_{1}=\frac{\ln v-\ln 135.5}{\ln 171-\ln 135.5} \\
& x_{2}=\frac{\ln f-\ln 0.005}{\ln 0.018-\ln 0.005} \\
& x_{3}=\frac{\ln d-\ln 0.2}{\ln 0.4-\ln 0.2}
\end{aligned}
$$

\subsection{Experimental Procedure}

Machine Tool: End milling experiments were conducted on an indigenously built precision CNC milling machine, under dry conditions. Single cut (10 mm length of cut) strategy was used for the testing purpose. It is well known that machining ceramics needs higher cutting speeds than that of metals. While building the CNC mill, care has been taken to keep the spindle speed 
in the range of 8000-23000 rpm. A fixture was designed to constraint all the degrees of freedom of the nHAP workpiece during the machining. The experimental setup for the milling operation is shown in Figure 8.

Workpiece: The nHAP samples were circular disks with a diameter of $\sim 35 \mathrm{~mm}$ and a thickness ranges 6-10 $\mathrm{mm}$. Samples were randomly chosen from the given batch and polished before starting the actual cutting experiments to make sure the initial surface in all the experiments was similar. Average $\mathrm{R}_{\mathrm{a}}$ for polished samples was $\sim 0.24 \mu \mathrm{m}$. For each experiment, the flatness of workpiece surface was tested by a dial indicator so that the uniformity in the depth of cut was controlled. Mechanical properties of workpiece material are depicted in Table 5 and 6.

Cutting Tool: Micro-grain Tungsten carbide two flute endmill cutting tools, were used in all the experiments. Micro-grain structure enables the sharp cutting edges. These cutting tools were uncoated with a diameter of endmill of $3.178 \mathrm{~mm}\left(1 / 8^{\prime \prime}\right)$ and helix angle of $30^{\circ}$ (Kennametal HEC 125S2025 K600). The tool profile before and after each cut was observed using optical microscope, and tool wear in each run was recorded.

Surface Observation: Surface roughness of the machined workpiece was measured using a Mitutoyo SJ-4000 profilometer. For numerical description of surface roughness $\mathrm{R}_{\mathrm{a}}$ parameter was used under 2D profile evaluation, obtained with the help of profilometer. The machined surface was measured at center (of length of cut) four times (at different location in width of cut). The measuring length in each case was $4 \mathrm{~mm}$ long. For the analysis purpose average value of all the four readings was considered as it represents $R_{a}$ of the entire machined surface as whole. At the end of the experiments, the surface conditions of the nHAP samples were observed using a SEM and optical microscope.

Chip Samples: During the experiments, the nHAP chips were collected. It was observed that the chips were ejected in all the directions during cutting. With the help of an adhesive tape chip samples were collected. The chip fragments ware examined using an optical microscope. 


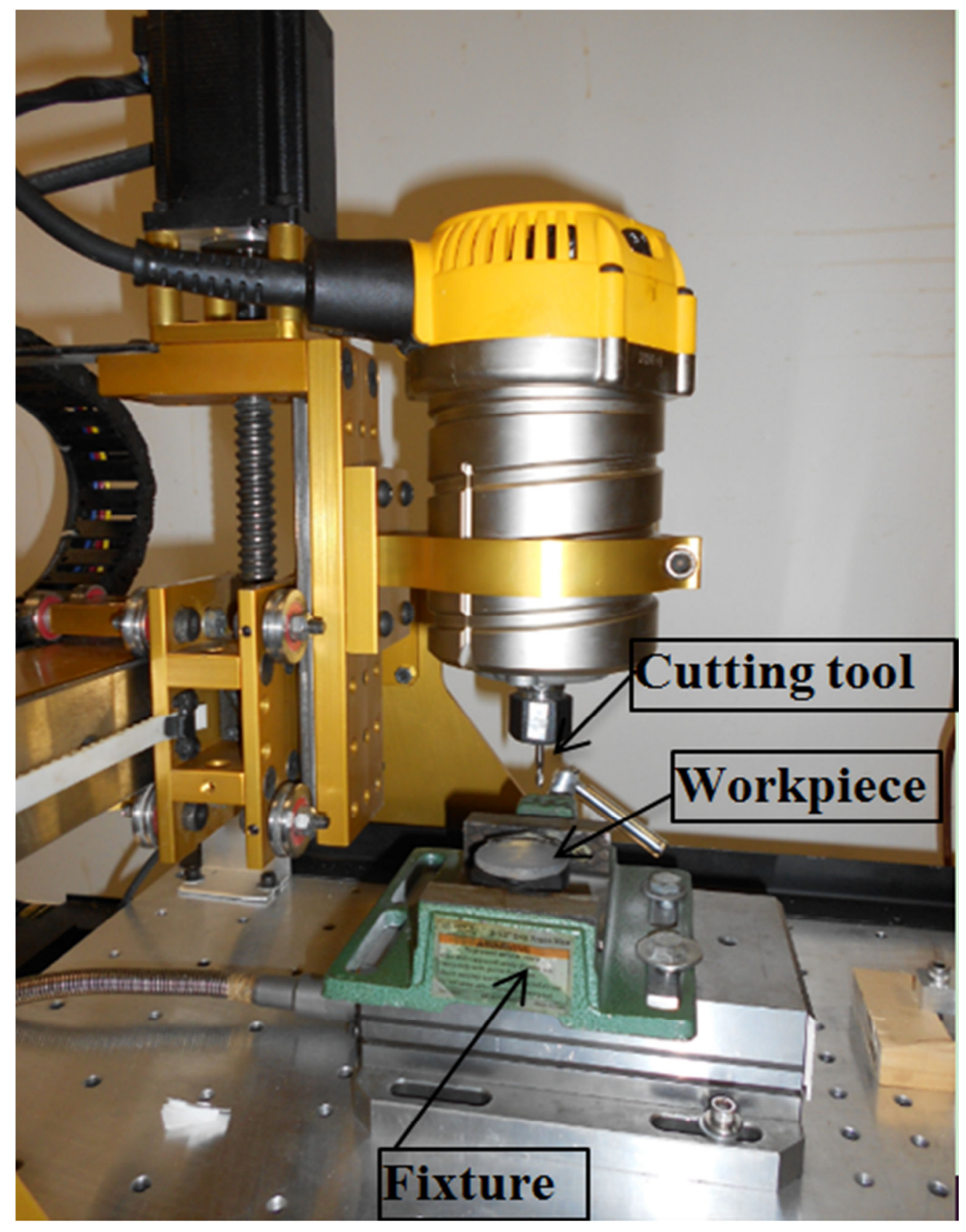

Figure 9: Experimental Setup 


\section{Chapter 5 - Results and Discussion}

\subsection{Surface Integrity}

\subsubsection{Effects of Cutting Parameters}

\section{Central composite design of five levels:}

Statistical analysis of the $\mathrm{R}_{\mathrm{a}}$ values obtained using the CCD did not provide satisfactory relationship between $\mathrm{R}_{\mathrm{a}}$ and cutting parameters. Neither first order nor second order model had enough statistical power to suggest the functional relationship between $\mathrm{R}_{\mathrm{a}}$ and any of the cutting parameter, although all the $\mathrm{R}_{\mathrm{a}}$ values were around or below $1 \mu \mathrm{m}$. This suggests that the chosen range of parameters can achieve the target surface roughness. Major reasons for the weak statistical results could be the chosen range of machining parameters and high noise in the experiments. The ranges chosen for the feed and depth of cut might be too small. Control over such small depths of cut throughout the cut length could be difficult considering the vibrations, brittle nature of material and flatness of workpiece. Table 11 shows the analysis of variance provided by Minitab 16 for the full quadratic model. None of the p-values are in the acceptable range at the $95 \%$ confidence level $(\mathrm{p} \leq 0.05)$.

Table 11: Analysis of variance for 5 - level CCD (quadratic model)

\begin{tabular}{|c|c|c|c|c|c|c|}
\hline Source & $\mathrm{DF}$ & Seq SS & Adj SS & Adj MS & $\mathbf{F}$ & $\mathrm{P}$ \\
\hline Regression & 9 & 0.391122 & 0.391122 & 0.043458 & 1.25 & 0.367 \\
\hline Linear & 3 & 0.170451 & 0.061784 & 0.020595 & 0.59 & 0.635 \\
\hline Speed (m/min) & 1 & 0.074340 & 0.006744 & 0.006744 & 0.19 & 0.670 \\
\hline feed (mm/rev) & 1 & 0.050333 & 0.025635 & 0.025635 & 0.73 & 0.411 \\
\hline $\mathrm{DOC}(\mathrm{mm})$ & 1 & 0.045779 & 0.005780 & 0.005780 & 0.17 & 0.693 \\
\hline Square & 3 & 0.209055 & 0.209055 & 0.069685 & 2.00 & 0.179 \\
\hline Speed $(\mathrm{m} / \mathrm{min}) *$ Speed $(\mathrm{m} / \mathrm{min})$ & 1 & 0.013792 & 0.002449 & 0.002449 & 0.07 & 0.796 \\
\hline feed $(\mathrm{mm} / \mathrm{rev}) *$ feed $(\mathrm{mm} / \mathrm{rev})$ & 1 & 0.179567 & 0.151755 & 0.151755 & 4.35 & 0.064 \\
\hline $\mathrm{DOC}(\mathrm{mm}) * \mathrm{DOC} \quad(\mathrm{mm})$ & 1 & 0.015695 & 0.015695 & 0.015695 & 0.45 & 0.518 \\
\hline Interaction & 3 & 0.011616 & 0.011616 & 0.003872 & 0.11 & 0.952 \\
\hline Speed $(\mathrm{m} / \mathrm{min}) *$ feed $(\mathrm{mm} / \mathrm{rev})$ & 1 & 0.005188 & 0.005188 & 0.005188 & 0.15 & 0.708 \\
\hline Speed $(\mathrm{m} / \mathrm{min}) * \mathrm{DOC}(\mathrm{mm})$ & 1 & 0.004672 & 0.004672 & 0.004672 & 0.13 & 0.722 \\
\hline feed $(\mathrm{mm} / \mathrm{rev}) * \mathrm{DOC} \quad(\mathrm{mm})$ & 1 & 0.001755 & 0.001755 & 0.001755 & 0.05 & 0.827 \\
\hline Residual Error & 10 & 0.349014 & 0.349014 & 0.034901 & & \\
\hline Lack-of-Fit & 5 & 0.235503 & 0.235503 & 0.047101 & 2.07 & 0.221 \\
\hline Pure Error & 5 & 0.113511 & 0.113511 & 0.022702 & & \\
\hline Total & 19 & 0.740136 & & & & \\
\hline
\end{tabular}


The above analysis also suggested that $\mathrm{R}_{\mathrm{a}}$ obtained in run 1 is outlier (residual analysis is attached in appendix III). Repeating the experiment for run 1 value of $R_{a}$ was assessed and new value was considered for the analysis purpose. The full quadratic model did not prove statistically significant, although the linear model showed that the feed has significant effect on $\mathrm{R}_{\mathrm{a}}$. No other parameter or interaction was statistically significant. Table 12 shows the analysis of variance provided by Minitab 16 for the linear model. Only feed has the significant effect on $\mathrm{R}_{\mathrm{a}}$, but the model lack of fit was acceptable ( $\mathrm{p}>0.05)$.

Table 12: Analysis of variance for modified 5 - level CCD (linear model)

\begin{tabular}{|lrlcccc|}
\hline Source & DF & Seq SS & Adj SS & Adj MS & F & P \\
Regression & 3 & 0.25609 & 0.25609 & 0.08536 & 3.28 & 0.048 \\
$\quad$ Linear & 3 & 0.25609 & 0.25609 & 0.08536 & 3.28 & 0.048 \\
$\quad$ Speed (m/min) & 1 & 0.07434 & 0.07434 & 0.07434 & 2.86 & 0.110 \\
feed (mm/rev) & 1 & 0.13597 & 0.13597 & 0.13597 & 5.23 & 0.036 \\
DoC (mm) & 1 & 0.04578 & 0.04578 & 0.04578 & 1.76 & 0.203 \\
Residual Error & 16 & 0.41578 & 0.41578 & 0.02599 & & \\
$\quad$ Lack-of-Fit & 11 & 0.30227 & 0.30227 & 0.02748 & 1.21 & 0.443 \\
Pure Error & 5 & 0.11351 & 0.11351 & 0.02270 & & \\
Total & 19 & 0.67186 & & & & \\
\hline
\end{tabular}

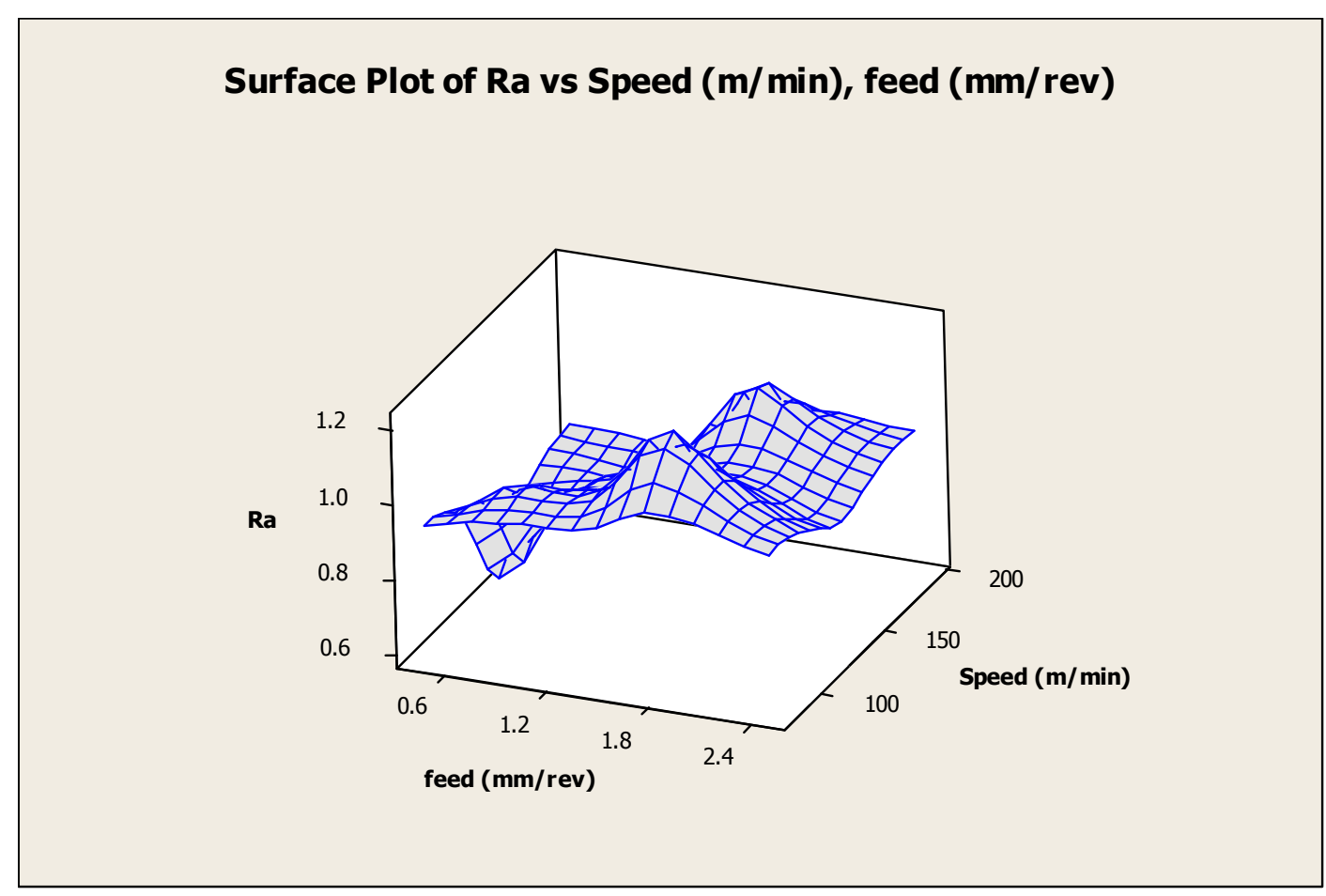

Figure 10: Surface plot of Ra v/s cutting speed and feed 


\section{$2^{3}$ Factorial Design}

The analysis of CCD suggested the need for change in the range of cutting parameters to reveal the effect of cutting parameters on $R_{a}$. Due to machine vibrations and flatness limitations of the workpiece, the small change in the depth of cut (a fraction of a millimeter) might not be picked up in the CCD design. For this purpose the $2^{3}$ factorial design with enlarged range of depth of cut was used. The range of feed was chosen to be the lower end of that of CCD, and the range of cutting speed did not change due to limitations of the spindle speed. In this run of experiments also the linear model shown the statistical significance. Table 13 is the analysis of variance provided by Minitab 16 for the full linear model.

Table 13: Analysis of variance for $2^{3}$ factorial design

\begin{tabular}{|lrrrrrr|}
\hline Source & DF & Seq SS & Adj SS & Adj MS & F & P \\
Main Effects & 3 & 0.49186 & 0.49186 & 0.163952 & 2.80 & 0.085 \\
$\quad$ speed & 1 & 0.28400 & 0.28400 & 0.284000 & 4.85 & 0.048 \\
$\quad$ feed & 1 & 0.14219 & 0.14219 & 0.142192 & 2.43 & 0.145 \\
depth of cut & 1 & 0.06566 & 0.06566 & 0.065664 & 1.12 & 0.311 \\
& & & & & & \\
Residual Error & 12 & 0.70279 & 0.70279 & 0.058566 & & \\
$\quad$ Lack of Fit & 4 & 0.02753 & 0.02753 & 0.006883 & 0.08 & 0.986 \\
$\quad$ Pure Error & 8 & 0.67525 & 0.67525 & 0.084407 & & \\
Total & & & & & & \\
\hline
\end{tabular}

It can be seen that in the chosen range of parameters only cutting speed has shown significant effect on $R_{a}(p<0.05)$. Feed and depth of cut has no significant effect on $R_{a}(p>0.05)$. This is conflicting with the results of CCD, where feed has a significant effect on $R_{a}$. Figure 11 shows the main effect plot for Ra. It shows that feed and depth of cut has effect on $R_{a}$ on chosen range, which is weak in this case. This analysis demands another change in the ranges of parameters. 


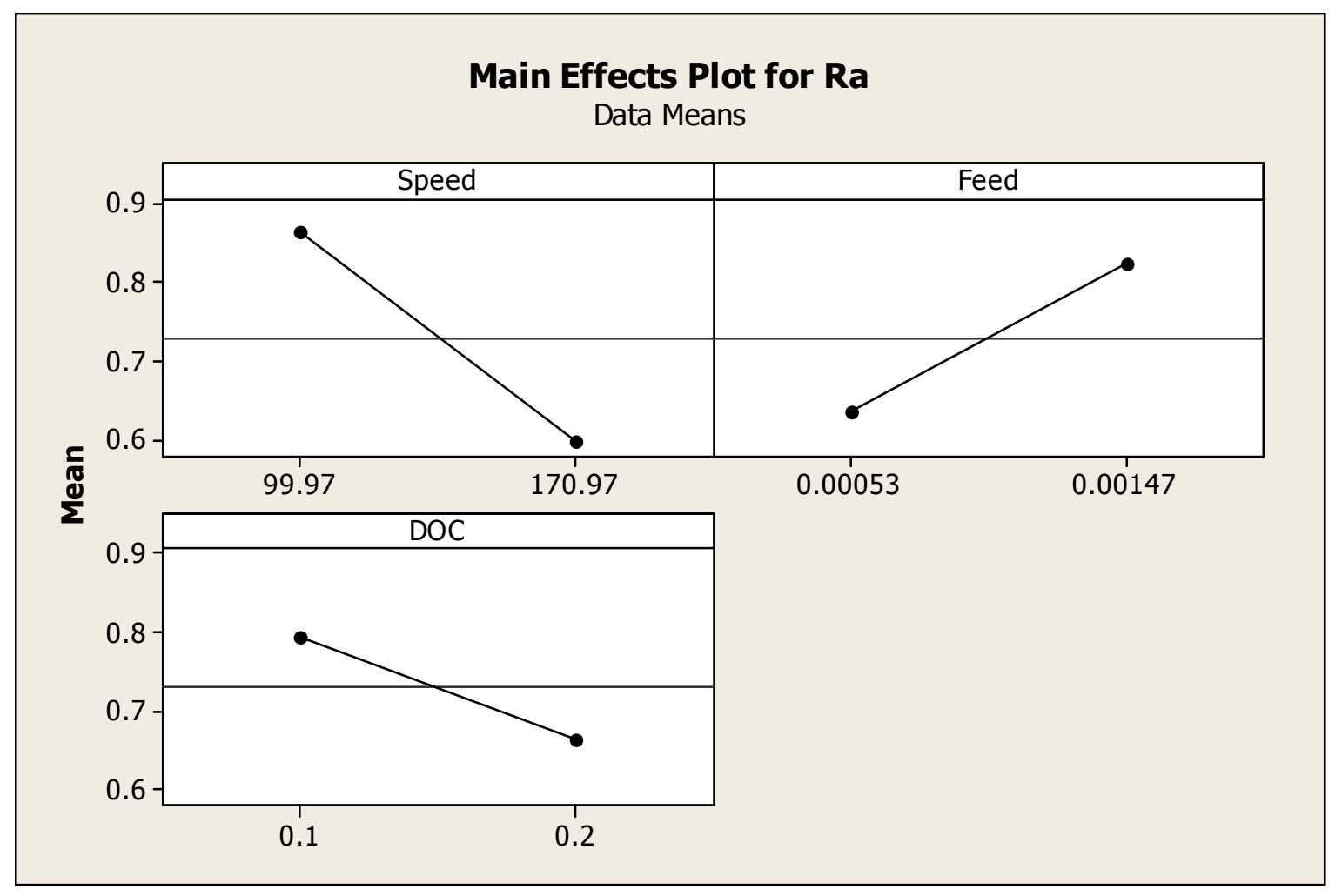

Figure 11: Main effect plot of Ra v/s cutting speed, feed and depth of cut

\section{$2^{3}$ Central Composite Design}

The above analysis of $2^{3}$ factorial design suggested the need for further modifications of the range of feed and depth of cut. These two ranges were increased and eight more experiments were performed. In the chosen range, the cutting speed and feed have statistically significant effect on $R_{a}(p<0.05)$. The analysis suggested that only the linear model is statistically significant. Table 14 shows the analysis of variance provided by Minitab 16 for the linear model.

Table 14: Analysis of variance for linear model

\begin{tabular}{|lrrrrrr|}
\hline Source & DF & Seq SS & Adj SS & Adj MS & F & P \\
Main Effects & 3 & 2.3963 & 2.3963 & 0.79877 & 22.70 & 0.006 \\
$\quad$ Speed & 1 & 0.9853 & 0.9853 & 0.98526 & 28.00 & 0.006 \\
Feed & 1 & 1.2940 & 1.2940 & 1.29404 & 36.78 & 0.004 \\
$\quad$ DoC & 1 & 0.1170 & 0.1170 & 0.11701 & 3.33 & 0.142 \\
& & & & & & \\
Residual Error & 4 & 0.1407 & 0.1407 & 0.03518 & & \\
Total & 7 & 2.5370 & & & & \\
\hline
\end{tabular}


To estimate of the true effects of the cutting parameters on the $R_{a}$, all the 8 experiments were replicated. All the 16 experiments were assessed together. The results showed that all the three cutting parameters have statistically significant effect on $R_{a}(p<0.05)$. In this analysis the interaction between the cutting speed and depth of cut found near significant level $(p=0.6)$. At the same time two observations, 1 and 15 have a large residual. Residuals can be explained by noise in the experiments. This noise might have suggested the significance of the interaction term. For the discussion I have assumed linear model is dominant over interaction model. Table 15 shows the analysis of variance provided by Minitab 16 for the linear model. Figure 12 shows the main effect plot for $\mathrm{R}_{\mathrm{a}}$.

Table 15: Analysis of variance for linear model (16 points)

\begin{tabular}{|lrrrrrr|}
\hline Source & DF & Seq SS & Adj SS & Adj MS & F & P \\
Main Effects & 3 & 4.4855 & 4.4855 & 1.49518 & 53.60 & 0.000 \\
$\quad$ Speed & 1 & 1.4666 & 1.4666 & 1.46662 & 52.57 & 0.000 \\
$\quad$ Feed & 1 & 2.6794 & 2.6794 & 2.67936 & 96.05 & 0.000 \\
$\quad$ DoC & 1 & 0.3395 & 0.3395 & 0.33955 & 12.17 & 0.004 \\
& & & & & & \\
Residual Error & 12 & 0.3348 & 0.3348 & 0.02790 & & \\
$\quad$ Lack of Fit & 4 & 0.1627 & 0.1627 & 0.04067 & 1.89 & 0.206 \\
$\quad$ Pure Error & 8 & 0.1721 & 0.1721 & 0.02151 & & \\
Total & 15 & 4.8203 & & & & \\
\hline
\end{tabular}

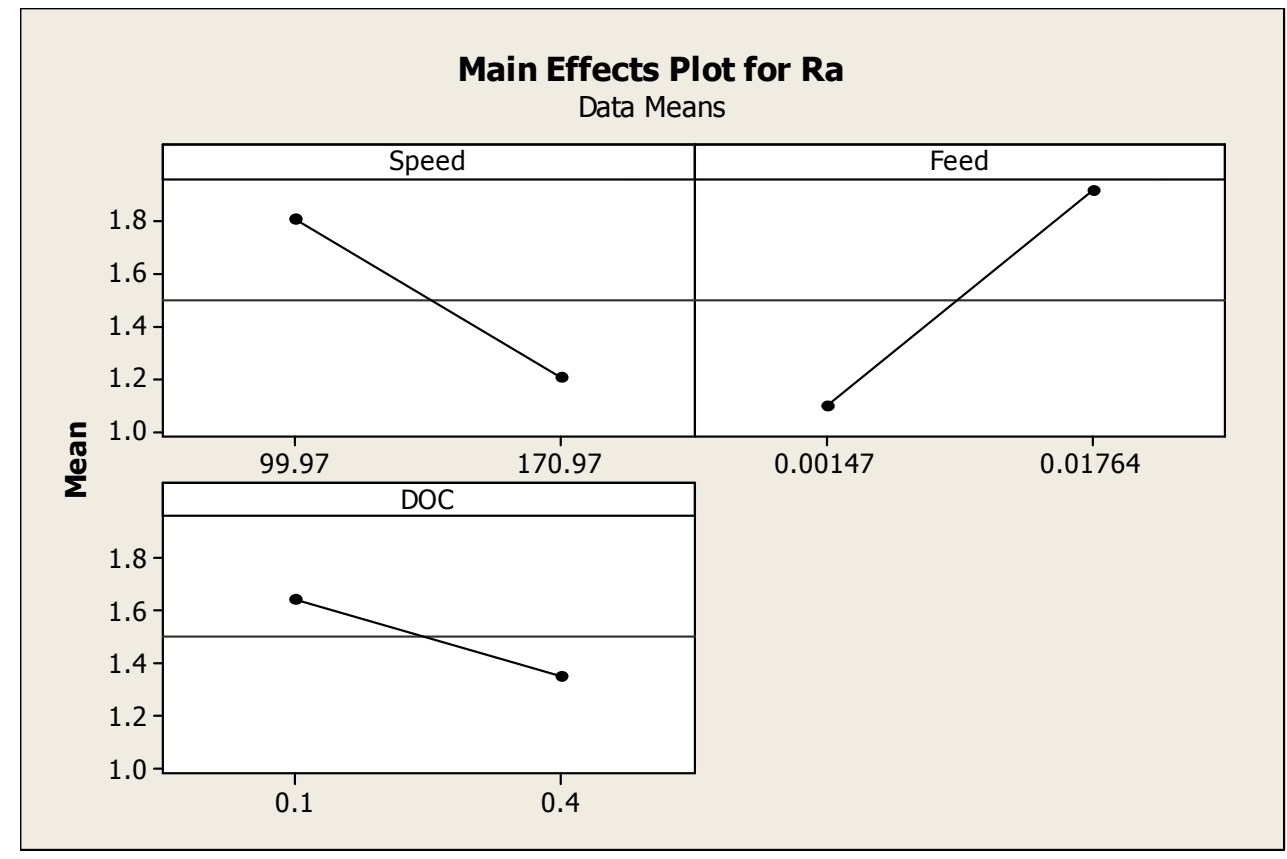

Figure 12: Main effect plot of Ra v/s cutting speed, feed and depth of cut 
The main effect plot suggests some interesting findings. $\mathrm{R}_{\mathrm{a}}$ reduces with increase in cutting speed and depth of cut, but increases with feed. The feed has the most dominant effect on $R_{a}$ in the chosen range. The effect of depth of cut is not very significant.

For the development of the first order surface finish model, the center point was added to the standard $2^{3}$ factorial design. This center point was repeated four times to estimate the pure error. Table 16 summarizes the cutting conditions and the corresponding $\mathrm{R}_{\mathrm{a}}$ values for the $\mathrm{CCD}$. The contrast between the mean of the center points and the mean of the factorial points delivers assessment for the lack of fit in the $2^{3}$ central composite design. The condition of lack of fit for the first order model arises when the model fails to represent the functional relationship between the mean responses and the factor level.

Table 16: Summery of the $2^{3} \mathrm{CCD}$ and the corresponding $\mathrm{R}_{\mathrm{a}}$ values

\begin{tabular}{|c|c|c|c|c|c|c|c|c|}
\hline & $\begin{array}{c}\text { Cutting } \\
\text { Speed } \\
(\mathbf{m} / \mathbf{m i n})\end{array}$ & $\begin{array}{c}\text { Feed } \\
(\mathbf{m m} / \mathbf{r e v})\end{array}$ & $\begin{array}{c}\text { DOC } \\
(\mathbf{m m})\end{array}$ & \multicolumn{3}{|c|}{$\mathbf{R}_{\mathbf{a}}$} & $\begin{array}{c}\text { Average } \\
\mathbf{R}_{\mathbf{a}}\end{array}$ \\
\hline 1 & 99.97 & 0.00147 & 0.1 & 1.97 & 1.9 & 1.7 & 1.78 & 1.838 \\
\hline 2 & 170.97 & 0.00147 & 0.1 & 0.88 & 0.72 & 0.68 & 0.69 & 0.743 \\
\hline 3 & 99.97 & 0.01764 & 0.1 & 2.28 & 2.4 & 2.46 & 2.51 & 2.413 \\
\hline 4 & 170.97 & 0.01764 & 0.1 & 1.68 & 1.71 & 1.7 & 1.78 & 1.718 \\
\hline 5 & 99.97 & 0.00147 & 0.4 & 1.16 & 1.13 & 1.27 & 1.22 & 1.195 \\
\hline 6 & 170.97 & 0.00147 & 0.4 & 0.83 & 0.81 & 0.82 & 0.91 & 0.843 \\
\hline 7 & 99.97 & 0.01764 & 0.4 & 2.22 & 2.12 & 2.21 & 2.19 & 2.185 \\
\hline 8 & 170.97 & 0.01764 & 0.4 & 1.55 & 1.6 & 1.49 & 1.44 & 1.520 \\
\hline & & & & & & & & \\
\hline 9 & 99.97 & 0.00147 & 0.1 & 1.52 & 1.58 & 1.36 & 1.49 & 1.487 \\
\hline 10 & 170.97 & 0.00147 & 0.1 & 0.8 & 0.75 & 0.71 & 0.69 & 0.753 \\
\hline 11 & 99.97 & 0.01764 & 0.1 & 2.53 & 2.27 & 2.31 & 2.28 & 2.370 \\
\hline 12 & 170.97 & 0.01764 & 0.1 & 1.9 & 1.77 & 1.86 & 1.77 & 1.843 \\
\hline 13 & 99.97 & 0.00147 & 0.4 & 1.13 & 1.21 & 1.17 & 1.23 & 1.170 \\
\hline 14 & 170.97 & 0.00147 & 0.4 & 0.8 & 0.65 & 0.64 & 0.6 & 0.697 \\
\hline 15 & 99.97 & 0.01764 & 0.4 & 1.77 & 1.77 & 1.75 & 1.67 & 1.763 \\
\hline 16 & 170.97 & 0.01764 & 0.4 & 1.41 & 1.57 & 1.4 & 1.45 & 1.460 \\
\hline & & & & & & & & \\
\hline 17 & 130.5 & 0.0051 & 0.2 & 1.15 & 0.98 & 1.21 & 1.18 & 1.113 \\
\hline 18 & 130.5 & 0.0051 & 0.2 & 0.98 & 1.18 & 0.94 & 1.14 & 1.033 \\
\hline 19 & 130.5 & 0.0051 & 0.2 & 1 & 0.98 & 1.12 & 0.98 & 1.033 \\
\hline 20 & 130.5 & 0.0051 & 0.2 & 1.01 & 1.05 & 0.97 & 1 & 1.010 \\
\hline
\end{tabular}


The first order model for the surface roughness was developed using 12 values (average of replicated $2^{3}$ and 4 axial points). Regression equation coefficients were obtained using Minitab 16. The surface roughness prediction equation is described as;

$$
y=1.499-0.303 x_{1}+0.409 x_{2}-0.146 x_{3}
$$

By substituting Equations (5), (6), and (7) into Equation (8), the transformed equation of surface roughness value $\left(\mathrm{R}_{\mathrm{a}}\right)$, as a function of cutting speed $(\mathrm{V})$, feed (f), and depth of cut (d) is as follows:

$$
R_{a}=1270.03 V^{-1.12} f^{0.33} d^{-0.21}
$$

This first order equation is valid for end milling of nHAP under dry cutting conditions utilizing uncoated tungsten carbide tool. Extensive tool wear was observed, but it has been not considered under current scope of studies. The model presented in Equation (8) is valid for following ranges of parameters:

Cutting Speed: $100<\mathrm{V}<171 \mathrm{~m} / \mathrm{min}$

Feed: $\quad 0.0015<\mathrm{F}<0.018 \mathrm{~mm} / \mathrm{rev}$

Depth of Cut: $\quad 0.1<$ DOC $<0.4 \mathrm{~mm}$

Table 17 shows the analysis of variance table obtained using Minitab 16.

Table 17: Analysis of variance for the prediction model

\begin{tabular}{|lcccccc|}
\hline Source & DF & Seq SS & Adj SS & Adj MS & F & P \\
Main Effects & 3 & 2.24277 & 2.24277 & 0.74759 & 59.82 & 0.000 \\
$\quad$ Cutting speed & 1 & 0.73331 & 0.73331 & 0.73331 & 58.67 & 0.000 \\
$\quad$ Feed & 1 & 1.33968 & 1.33968 & 1.33968 & 107.19 & 0.000 \\
$\quad \begin{array}{l}\text { Depth of cut } \\
\text { Curvature }\end{array}$ & 1 & 0.16977 & 0.16977 & 0.16977 & 13.58 & 0.008 \\
Residual Error & 7 & 0.54539 & 0.54539 & 0.54539 & 43.64 & 0.000 \\
$\quad$ Lack of Fit & 4 & 0.08748 & 0.08748 & 0.01250 & & \\
$\quad$ Pure Error & 3 & 0.00614 & 0.00614 & 0.00205 & & \\
Total & 11 & 2.87564 & & & & \\
R-Sq = 96.96\% & R-Sq(pred) $=51.25 \%$ & R-Sq(adj) $=95.22 \%$ & & \\
\end{tabular}


The analysis of variance suggests that the data fits the model very well (adjusted R-square value $=95.22 \%$ ). All the machining parameters has significant influence on surface roughness (pvalue $<0.05$ ) under the chosen conditions. Although curvature is significant, suggesting that linear model does not adequately fit the response surface. This demands a higher order model with square and quadratic terms if it is used for the accurate prediction purpose. Also the prediction R-square value is small (51.25\%). The existence of curvature in the model suggests that the $R_{a}$ value at the center points of the cutting parameters is either higher or lower than average Ra value at corner values of cutting parameters. Curvature is usually present when factor settings are near the maximum or minimum response value. The model lack of fit $p$-value is less than 0.05 which suggests that there is need to build a higher order model for prediction purpose. But this statistical lack of evidence is susceptible to uncontrolled variables such as tool wear, which are not considered in the model. Table 18 compares the actual Ra values obtained using profilometer and predicted values by the presented model.

Table 18 : Actual $R_{a}$ v/s Predicted $R_{a}$

\begin{tabular}{|c|c|c|c|c|c|c|}
\hline $\begin{array}{c}\text { Speed } \\
(\mathbf{m} / \mathrm{min})\end{array}$ & $\begin{array}{c}\text { Feed } \\
(\mathrm{mm} / \mathrm{rev})\end{array}$ & $\begin{array}{l}\text { DOC } \\
(\mathrm{mm})\end{array}$ & $\begin{array}{c}\text { Ra after } 1^{\text {st }} \\
\text { cut (new tool) }\end{array}$ & $\begin{array}{c}R_{a} \text { after } 2^{\text {nd }} \\
\text { cut (used tool) }\end{array}$ & $\begin{array}{c}\mathbf{R}_{\mathrm{a}} \\
(\mathrm{Avg})\end{array}$ & $\begin{array}{c}\text { Predicte } \\
\mathbf{d ~ R}_{\mathrm{a}}\end{array}$ \\
\hline 99.97 & 0.00147 & 0.1 & 1.828 & 1.487 & 1.662 & 1.38 \\
\hline 170.97 & 0.00147 & 0.1 & 0.742 & 0.753 & 0.748 & 0.75 \\
\hline 99.97 & 0.01764 & 0.1 & 2.413 & 2.37 & 2.391 & 3.1 \\
\hline 170.97 & 0.01764 & 0.1 & 1.717 & 1.843 & 1.780 & 1.71 \\
\hline 99.97 & 0.00147 & 0.4 & 1.195 & 1.17 & 1.183 & 1.03 \\
\hline 170.97 & 0.00147 & 0.4 & 0.843 & 0.67 & 0.770 & 0.56 \\
\hline 99.97 & 0.01764 & 0.4 & 2.185 & 1.763 & 1.974 & 2.3 \\
\hline 170.97 & 0.01764 & 0.4 & 1.52 & 1.46 & 1.490 & 1.28 \\
\hline \multicolumn{7}{|c|}{ Axial points } \\
\hline 130.5 & 0.0051 & 0.2 & \multicolumn{3}{|c|}{1.113} & \multirow{4}{*}{1.48} \\
\hline 130.5 & 0.0051 & 0.2 & \multicolumn{3}{|c|}{1.033} & \\
\hline 130.5 & 0.0051 & 0.2 & \multicolumn{3}{|c|}{1.033} & \\
\hline 130.5 & 0.0051 & 0.2 & \multicolumn{3}{|c|}{1.010} & \\
\hline
\end{tabular}

The present model is used to analyze the effects of cutting parameters on the surface roughness values and optimize the cutting conditions in the given ranges. It is possible to select the combination of cutting speed and feed which would reduce the machining time, without exceeding the desired surface roughness value of $1-1.5 \mu \mathrm{m}$. Figure 13 and 14 are the contour plots of the surface roughness $\left(R_{a}\right)$ at the lower $(0.1 \mathrm{~mm})$ and higher level $(0.4 \mathrm{~mm})$ of depth of 
cut in the plane containing cutting speed and feed (obtained without considering the axial points). The contour plots suggest that higher level of depth of cut (0.4) can be used, with multiple combinations of cutting speed and feed. Although significant curvature recommends analysis of the 3D surface plots. The analysis of 3D plots and corresponding contour plots suggests the same results. 3D surface plots of surface roughness value $R_{a}$ and cutting parameters are attached in Appendix IV.

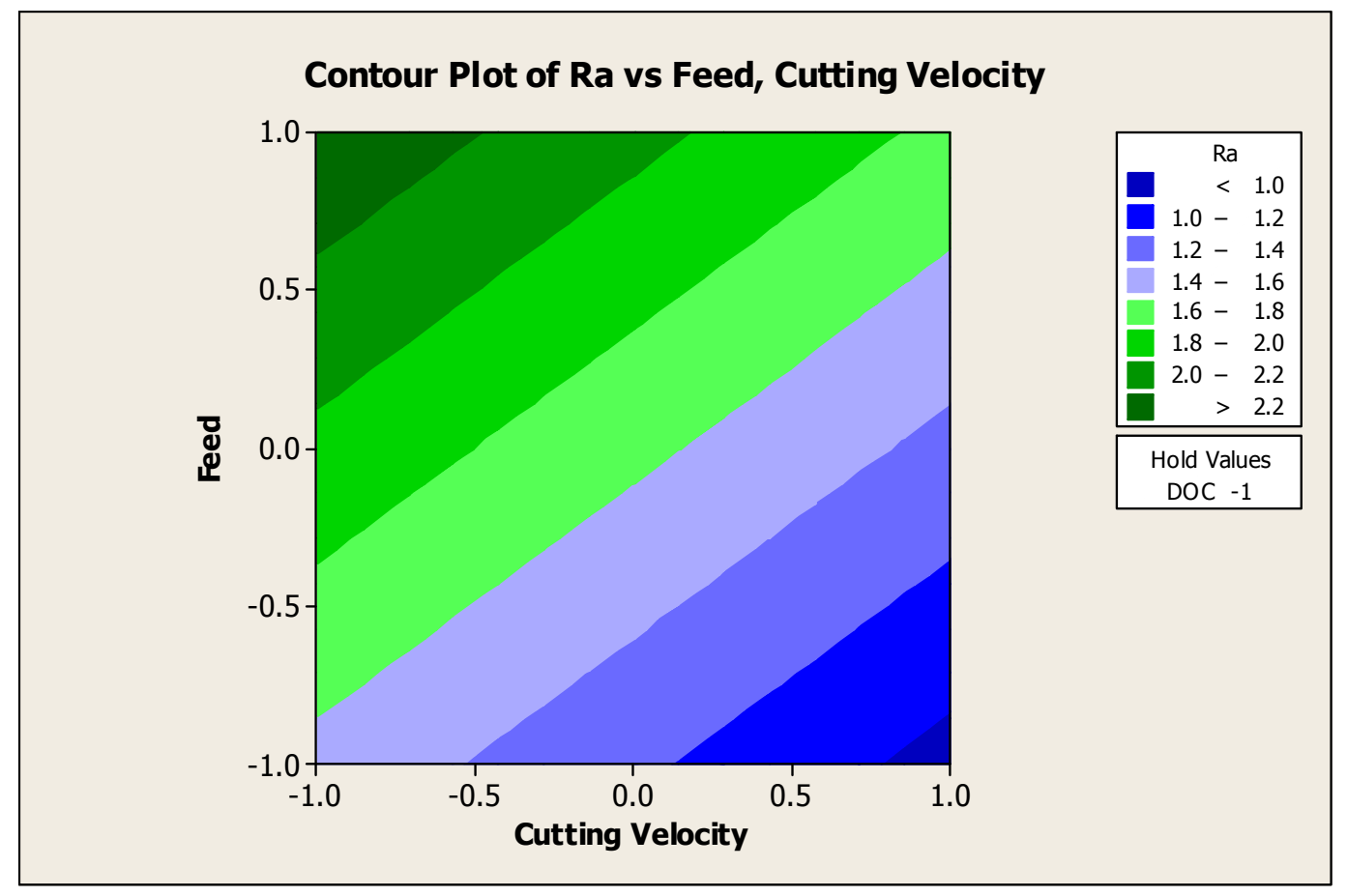

Figure 13: $\mathrm{R}_{\mathrm{a}}$ contour plots in the cutting speed and feed plane $(\mathrm{DOC}=0.1 \mathrm{~mm})$ 


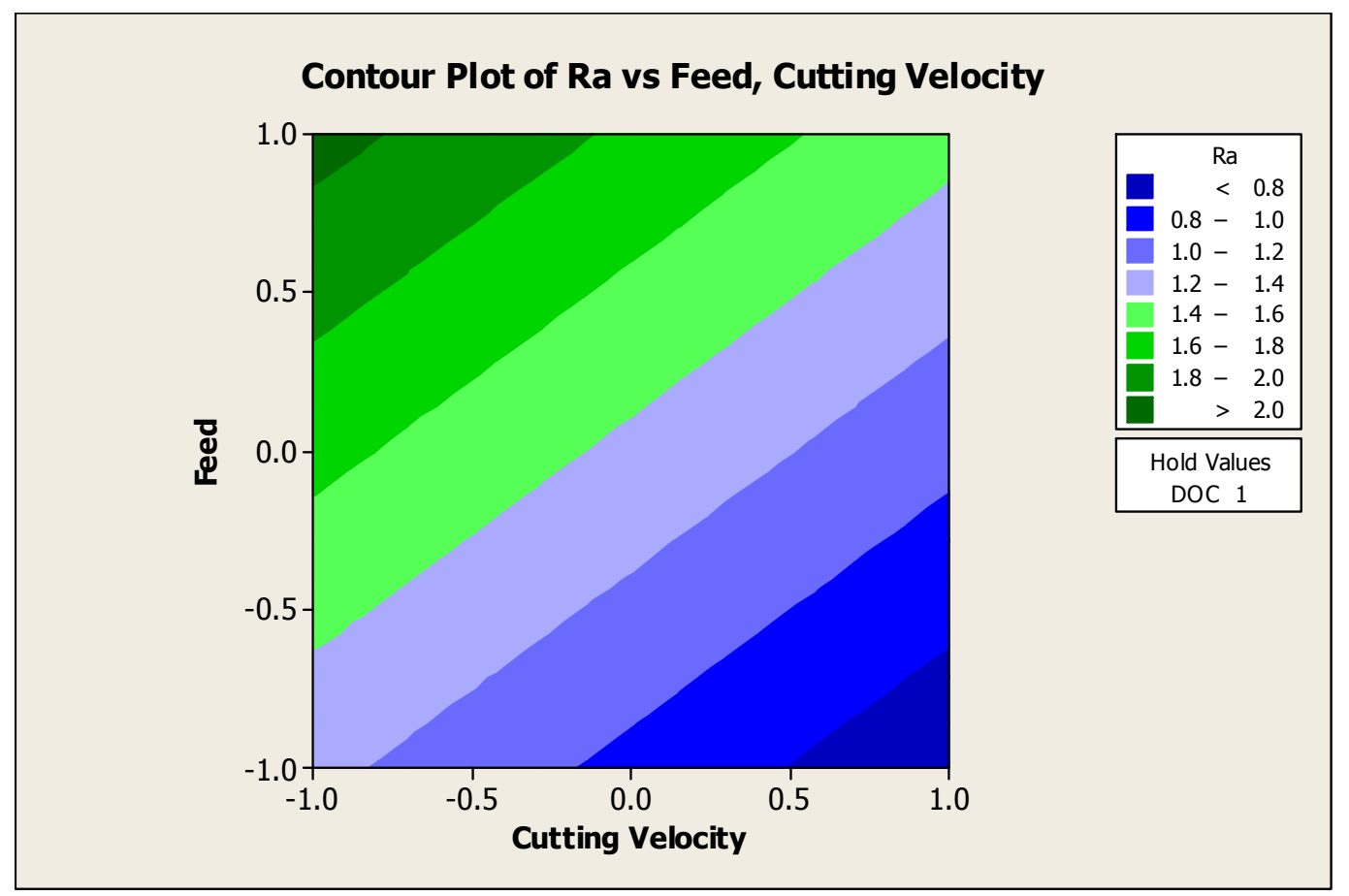

Figure 14: $\mathrm{R}_{\mathrm{a}}$ contour plots in the cutting speed and feed plane $(\mathrm{DOC}=0.4 \mathrm{~mm})$

There is a need to control the variability in the experiments. Experimental variability impedes the data quality, which could be the main reason behind model lack of fit for prediction purposes. The observed tool wear was really high and tool tips were lost in first cut. As tool geometry changes during a cut, non-consistent $\mathrm{R}_{\mathrm{a}}$ values were observed in some of the experiments. It is recommended that superhard cutting tools like polycrystalline cubic boron nitride (PCBN) and diamond end mills should be used to achieve the uniform machined surfaces. In the model development the experimental run no. 2 had large residual, and the primary reason for it could be the changing tool geometry during the cut. nHAP is a highly brittle material, and thus to hold it firmly on the machine bed, a special fixture needs to be developed to hold it firmly during machining without loss of edges or cracks in the material. In the current model all these unstable factors such as tool wear and vibrations are not considered. In the future a second - order model considering tool wear can be built for surface roughness prediction of nHAP. 


\subsubsection{Surface Roughness}

The average roughness, $R_{a}$, of the machined surface was measured using a stylus profilometer. Figure 15 represents the graphs generated by the stylus profilometer in the direction of cut, which represents the surface roughness profile of the polished workpiece, machined surface after run number 2 and machined sample after run number 3. Surface roughness values $\left(R_{a}\right)$ for each experiment are recorded in Table 16. Large variations of peaks and valleys on the machined surface profile suggest severe chipping phenomena. The effects of different machining conditions can be seen in Figure 15-B and 15-C. In case of Figure 15-B which represents the machining run 2, less chipping phenomena can be seen compared to Figure 15-C which represents the machining run 3.

Using optical microscope machined surfaces were assessed. Figure 16 shows the microscopic image of the machined surface that the surface topography is irregular with numerous cavities left by chipping and loss of material, as suggested in the profilometer graphs. The cavities generated by chipping are shiny, which suggests that the microstructure of the nHAP is dense

and the fracture is mainly intragranular in nature. Study of any kind of crack is important as they results into the catastrophic failure in future. Machined surfaces were observed using scanning electron microscope (SEM) for microcracks, and there were no cracks observed on the surface as shown in Figure 17. 

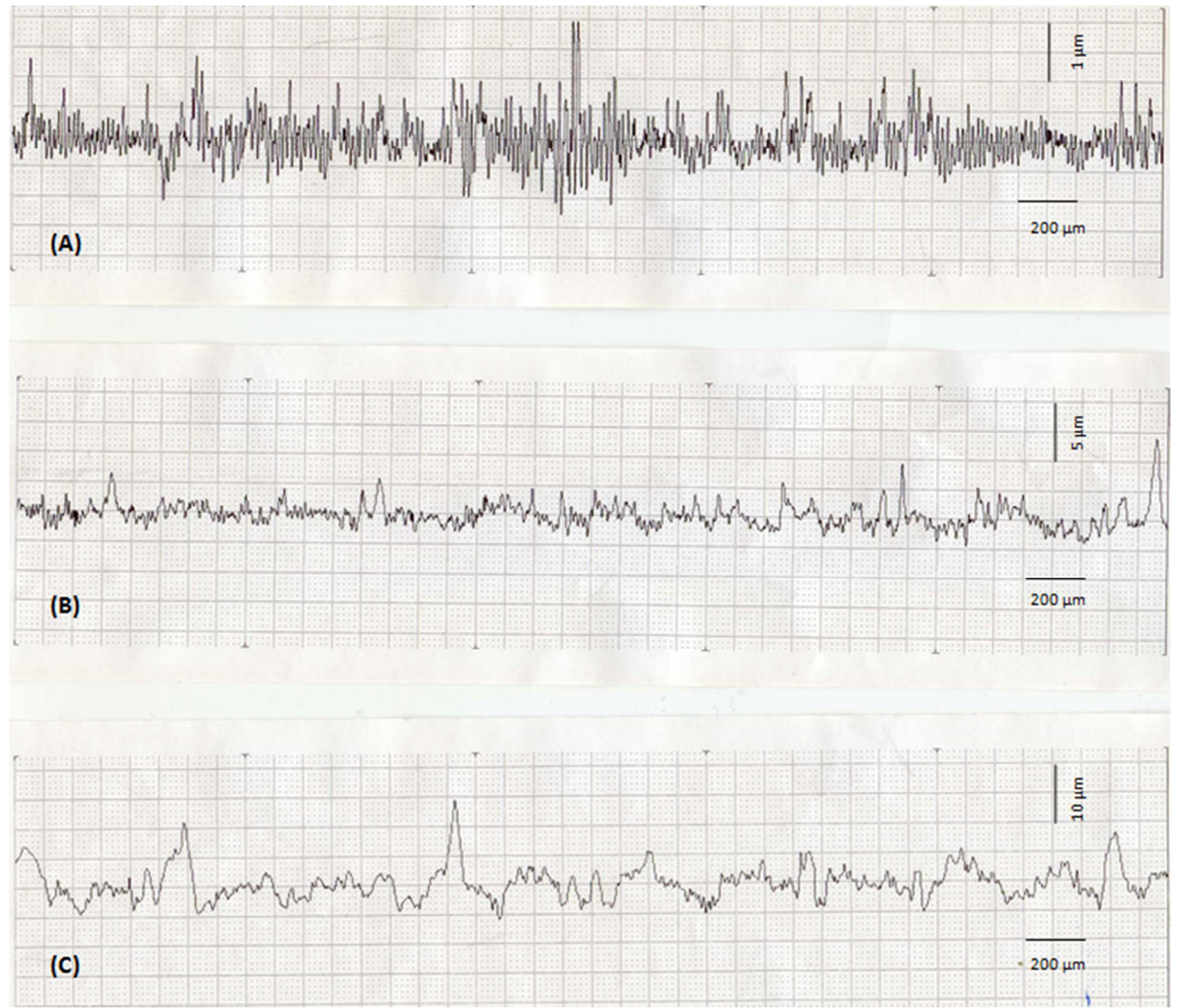

Figure 15: (A) surface profile of polished surface (B) surface profile of machined surface (machining run 2) (C) surface profile of machined surface (machining run 3) 


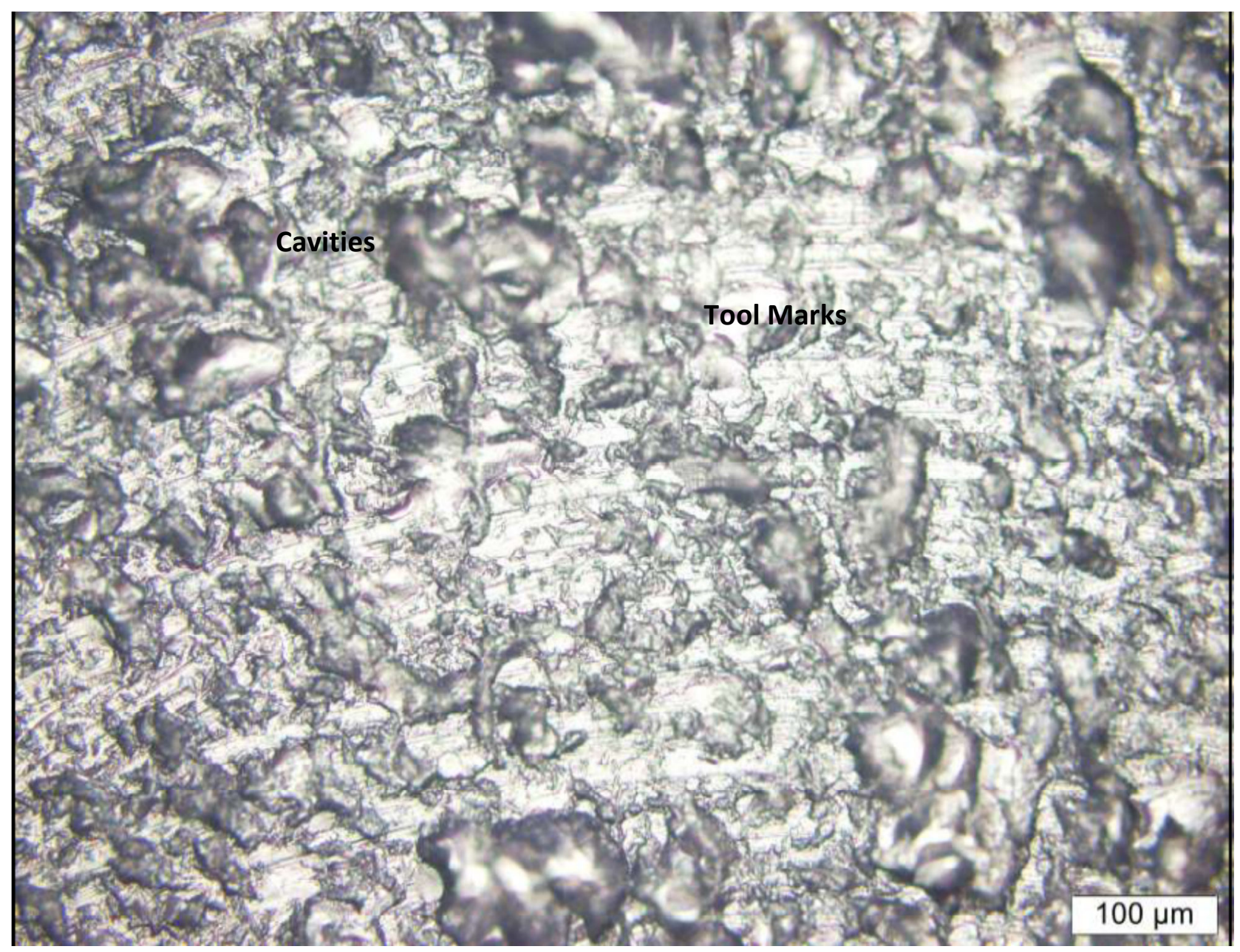

Figure 16: Machined surface after cut no. 3 


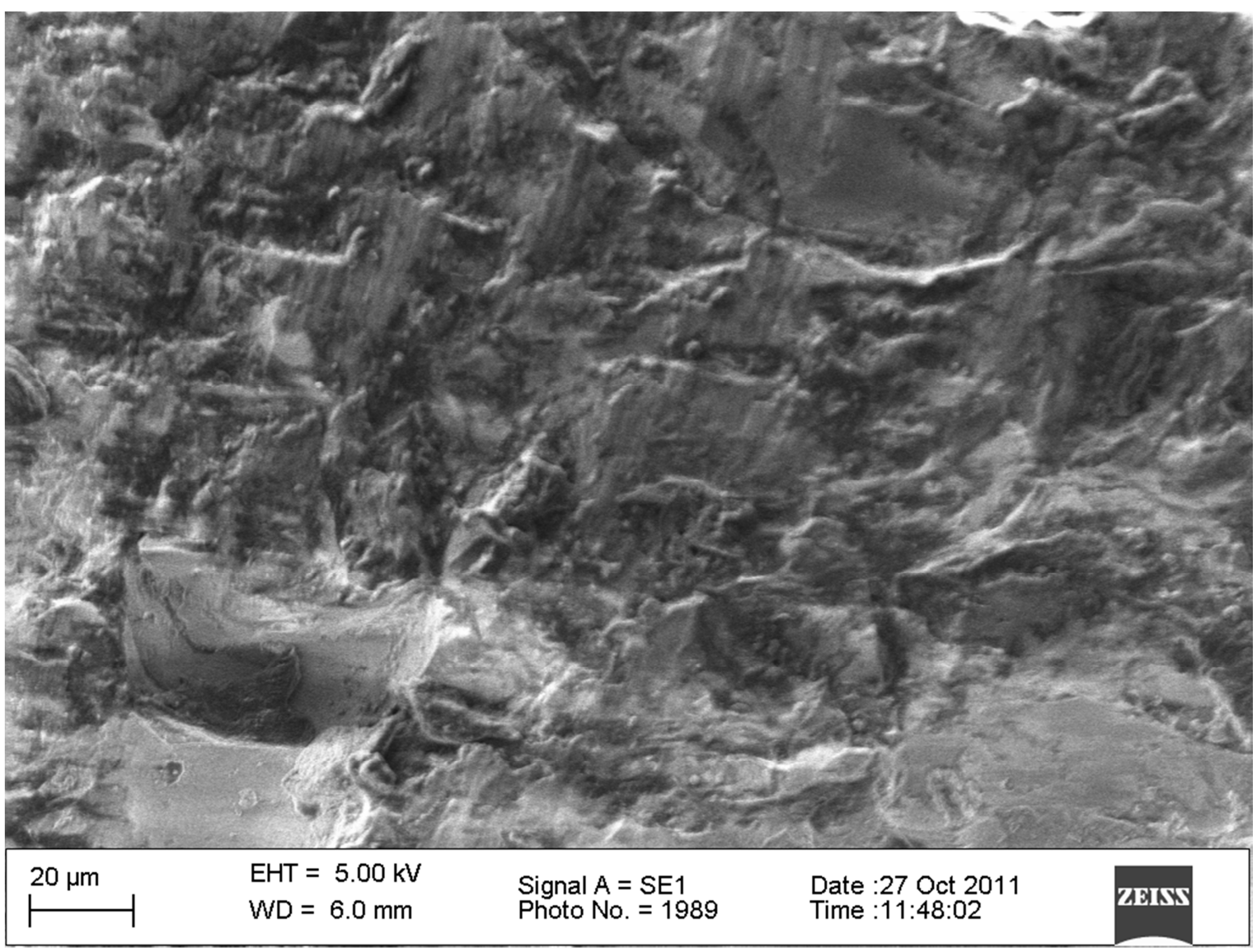

Figure 17: SEM image of machined surface after cut no. 1

Table 19 compares the optical microscopic images for the first 8 runs of experiments, with a new tool for each experiment. Column 1 and column 2 represents the surface conditions at the same feed and cutting speed but different depth of cut. From the Table 19, the effect of different machining conditions on machined surface characteristics can be seen. These surfaces accurately represent the differences in the corresponding $R_{a}$ values represented in Table 16. Images from the Table 19 show that machined surface is largely affected by the change in cutting speed and feed rather than depth of cut. 
Table 19: Machined surface under respective machining conditions

\begin{tabular}{|c|c|c|c|}
\hline 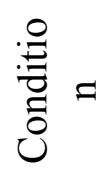 & $\begin{array}{l}\text { Machined Surface } \\
\quad(\text { Column 1) }\end{array}$ & $\overbrace{0}^{\stackrel{\Xi}{0}}=$ & $\begin{array}{l}\text { Machined Surface } \\
\quad(\text { Column 2) }\end{array}$ \\
\hline 1 & 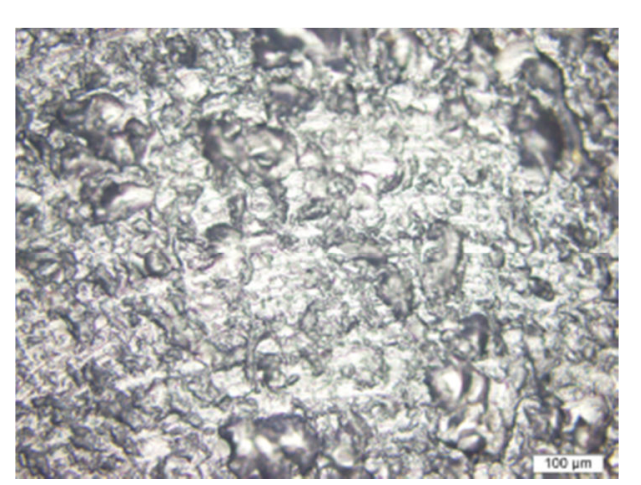 & 5 & 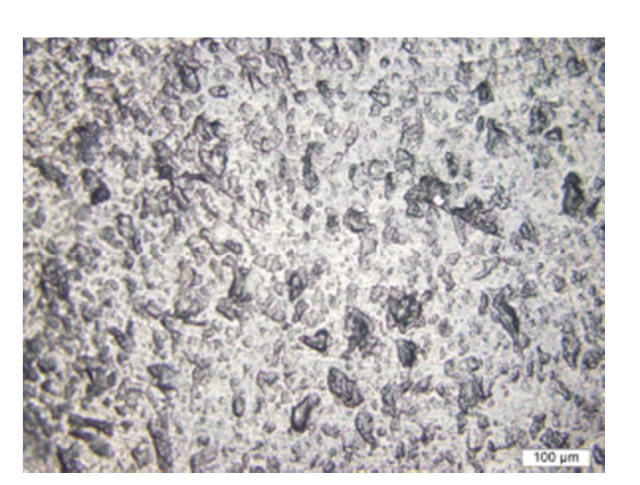 \\
\hline 2 & 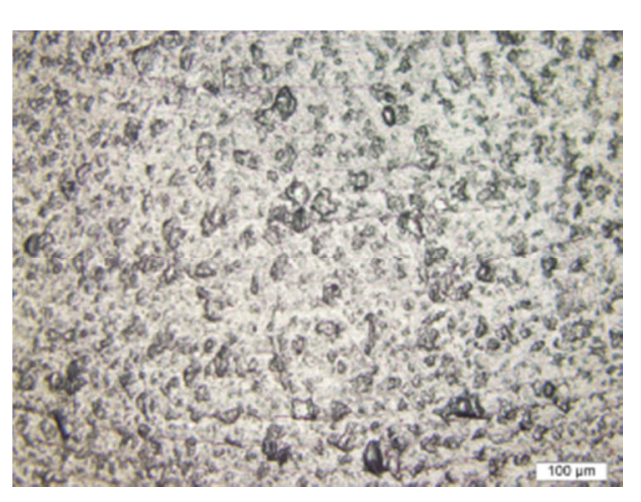 & 6 & 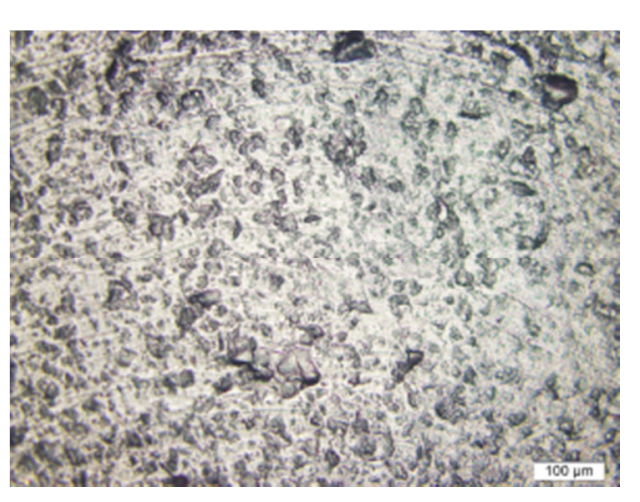 \\
\hline 3 & 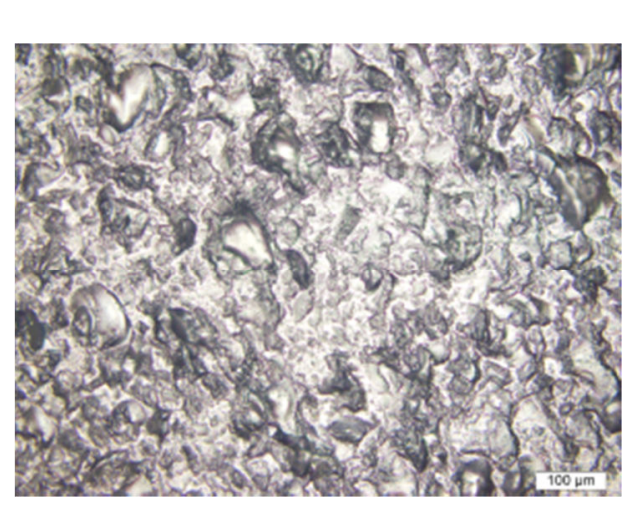 & 7 & 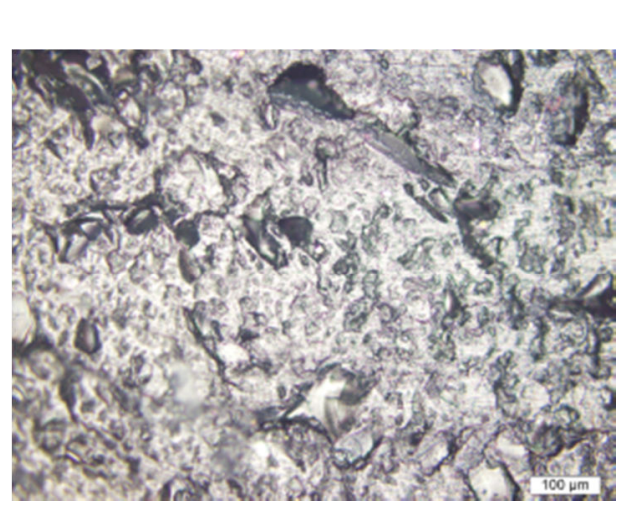 \\
\hline
\end{tabular}




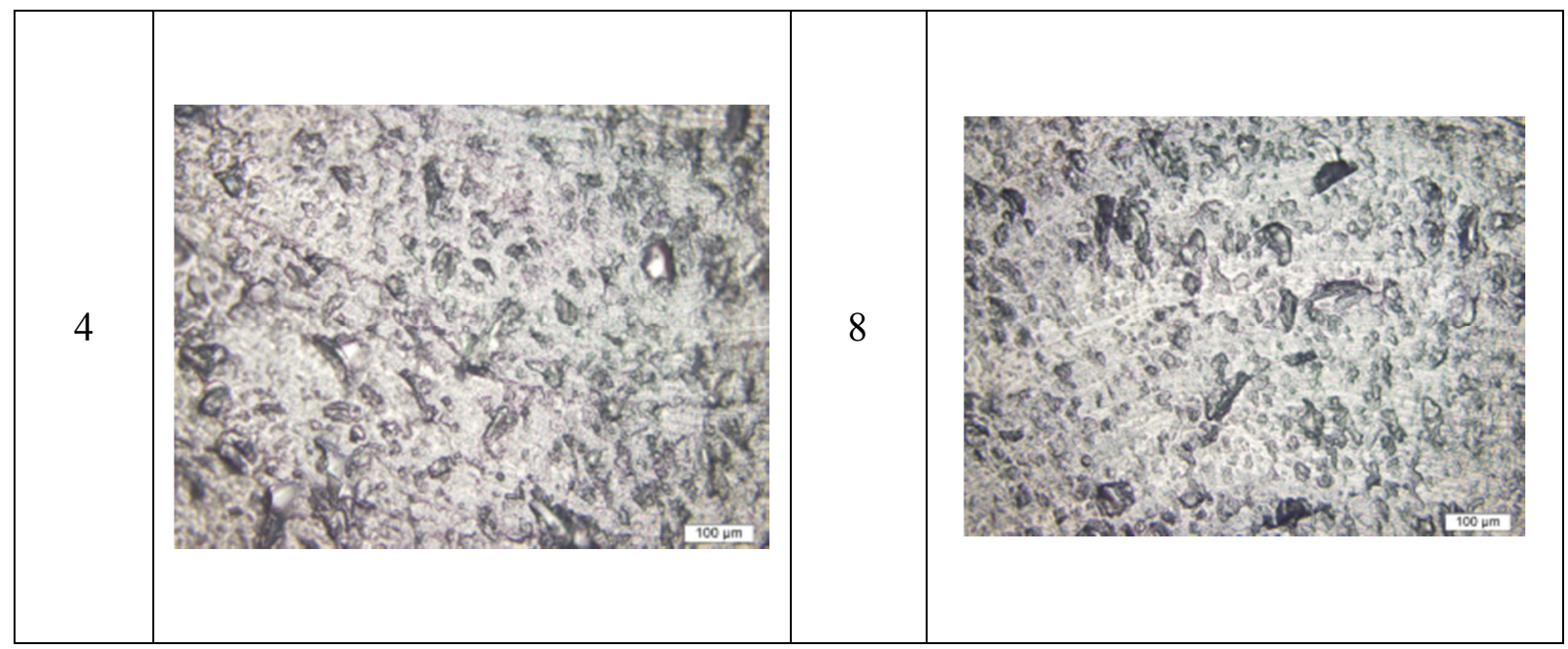

\subsection{Chip Morphology}

Chip fragments were collected using adhesive tape and were analyzed using an optical microscope. The typical sizes and shapes of chip fragments from each experiment were studied. Chip size and shape help understanding the surface topology. Chip sample examination indicates the phenomena of brittle fracture. It should be noted that each cut generates a range of chip fragments from powder-like to relatively large pieces. However, the overall observation suggests that the average chip size increases with increase in cutting parameter: cutting speed, feed and depth of cut. Chip sizes were found coherent with the pitting on the surface. But in case of large chip fragments it is hard to determine if they are from machined surface or they are lost edges. Observation of chip samples suggests the brittle fracture under cyclic loading. Various tool marks are observed on all the chip samples. Figure 18 shows the chip samples collected under cut no. 3 . 


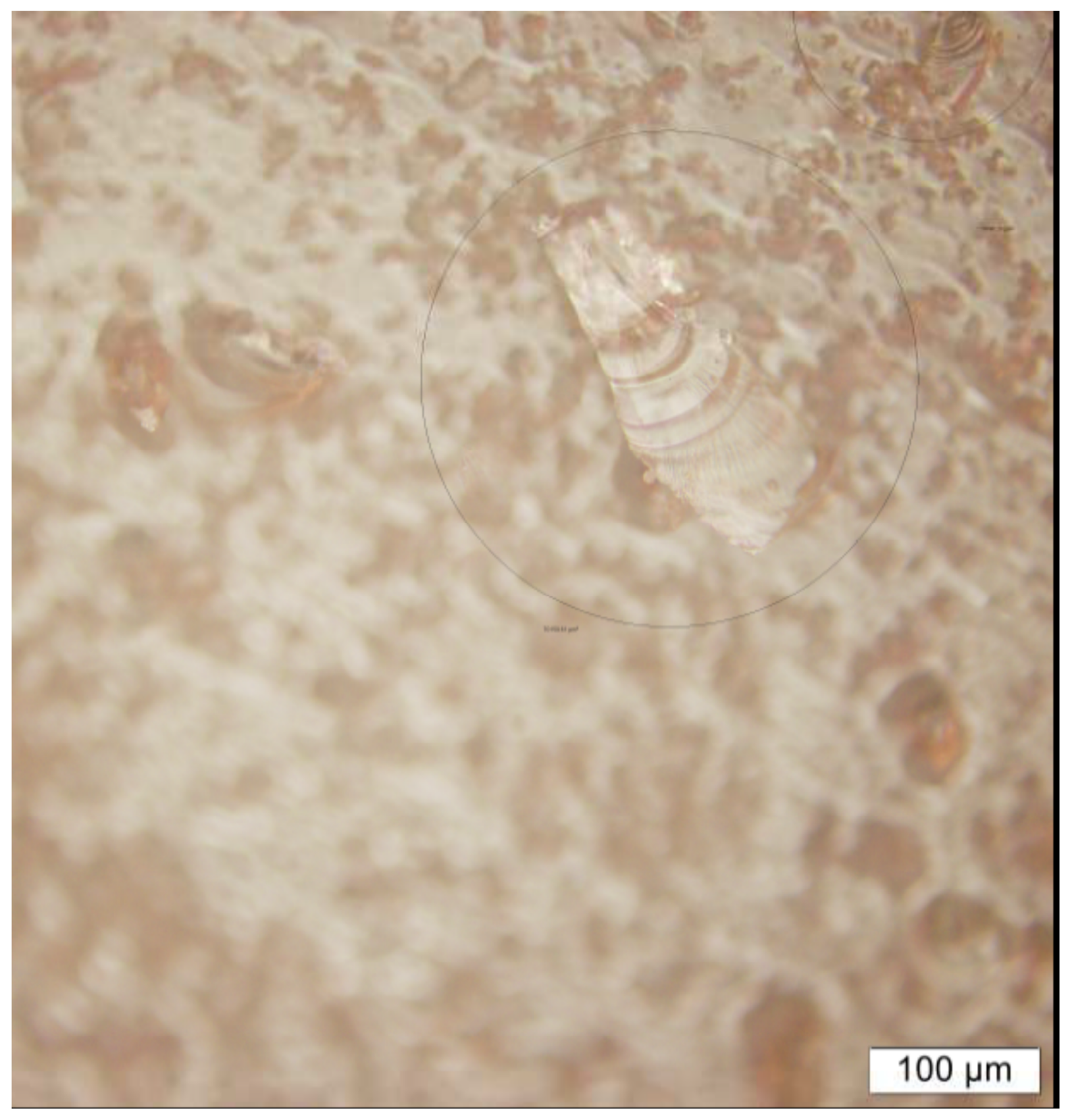

Figure 18: Chip sample after cut no. 3 


\subsection{Tool Wear}

Assessment of tool wear was performed using optical microscope before and after machining operations. The maximum tool wear at the flank of tools are measured after each cut, and the difference between two measurements was considered for the final tool wear. Each tool was used only for the two cuts under similar cutting parameters and similar initial workpiece surface conditions. Study of cutting tool showed that there was large abrasive wear on the cutting tool, although no cracks were observed on cutting edge. Figure 19 shows the tool wear after run no. 8. Table 20 represents the wear in both the flanks in case of each cut. Abrasive tool wear is common phenomena in case of brittle ceramics, which is caused by partials of workpiece furrowing into the surface of tool (8).

Tool wear generally experiences three stages during machining. In the first stage, the tool wear increases rapidly because of the shaper cutting edge. However, tool wear rate will decrease in the second stage, because a cutting tool has passed the rapid wear stage and reached the stable condition, commonly the cutting tool a works in this stage. During the second stage, the generated surface roughness is uniformed across the whole cut with slight tool wear. In the third stage tool wear escalates and the tool is used up very rapidly. Preliminary observation of tool wear in case of nHAP machining showed the same wear pattern. It was observed that cutting tips were lost after the first cut. The loss of tips suggests that tool profile gradually changed during the first cut. Further investigation is required to statistically prove the effect of machining parameters on the tool wear, but under high level of cutting parameters larger tool wear was observed than that under lower level of cutting parameters. An interesting observation was that tool wear for one cutting edge was more than that of the other on the same cutting tool. Further investigation is needed to identify the cause of it. Assessment of tool wear after second set of cuts showed minor incremental wear in tool edge. A general observation is that the surface was smoother in the second set of cuts (performed using used tools from the first set) than that of first set cuts (performed using new tools). The change in tool profile during the first cut could have led to a non-uniform machined surface. In case of the second run of experiments, the tool profile remained nearly the same for the complete cut resulting into a more uniform surface profile. For the machining of nHAP harder tools such as PCBN and diamond tools should be used to avoid 
non-uniformity of the machined surface. Table 21 summarizes the tool wear in each cutting edge after both the runs of cuts.

Table 20 : Tool wear in cut

\begin{tabular}{|c|c|c|c|c|}
\hline Run No. & \multicolumn{2}{|c|}{$\begin{array}{c}\text { Tool wear after cut 1 } \\
(\boldsymbol{\mu m})\end{array}$} & \multicolumn{2}{c|}{$\begin{array}{c}\text { Tool wear after cut 2 } \\
(\boldsymbol{\mu m})\end{array}$} \\
\hline 1 & left & right & left & right \\
\hline 2 & 45.2 & 17.88 & 0 & 0.94 \\
\hline 3 & 98.98 & 47.79 & 12.96 & 39.25 \\
\hline 4 & 9.37 & 32.43 & 19.63 & 19.62 \\
\hline 5 & 140.19 & 79.43 & 3.18 & 16.98 \\
\hline 6 & 0.81 & 134.66 & 28.99 & 0.76 \\
\hline 7 & 88.88 & 240.6 & 201.23 & 20.51 \\
\hline 8 & 171.51 & 25.58 & 9.59 & 112.65 \\
\hline 9 & 366.02 & 100.71 & 4.25 & 152.19 \\
\hline
\end{tabular}



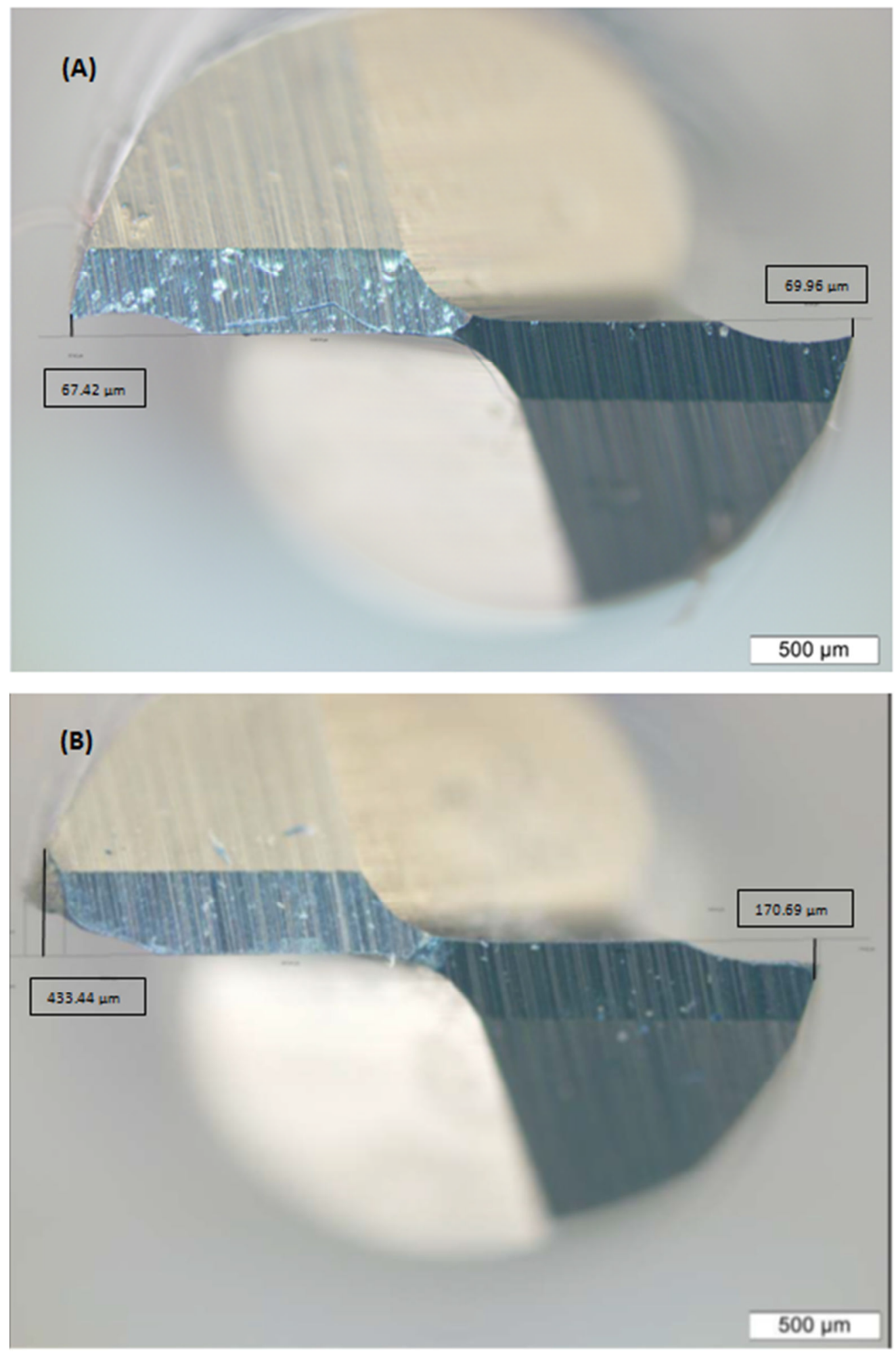

Figure 19: (A) Unused tool (B) Tool after cut 1. Tool wear is calculated as difference between two measurements i.e. left flank wear $=433.4-67.42=\sim 366 \mu \mathrm{m}$. 
Table 21: Comparison of tool wear (left flank)

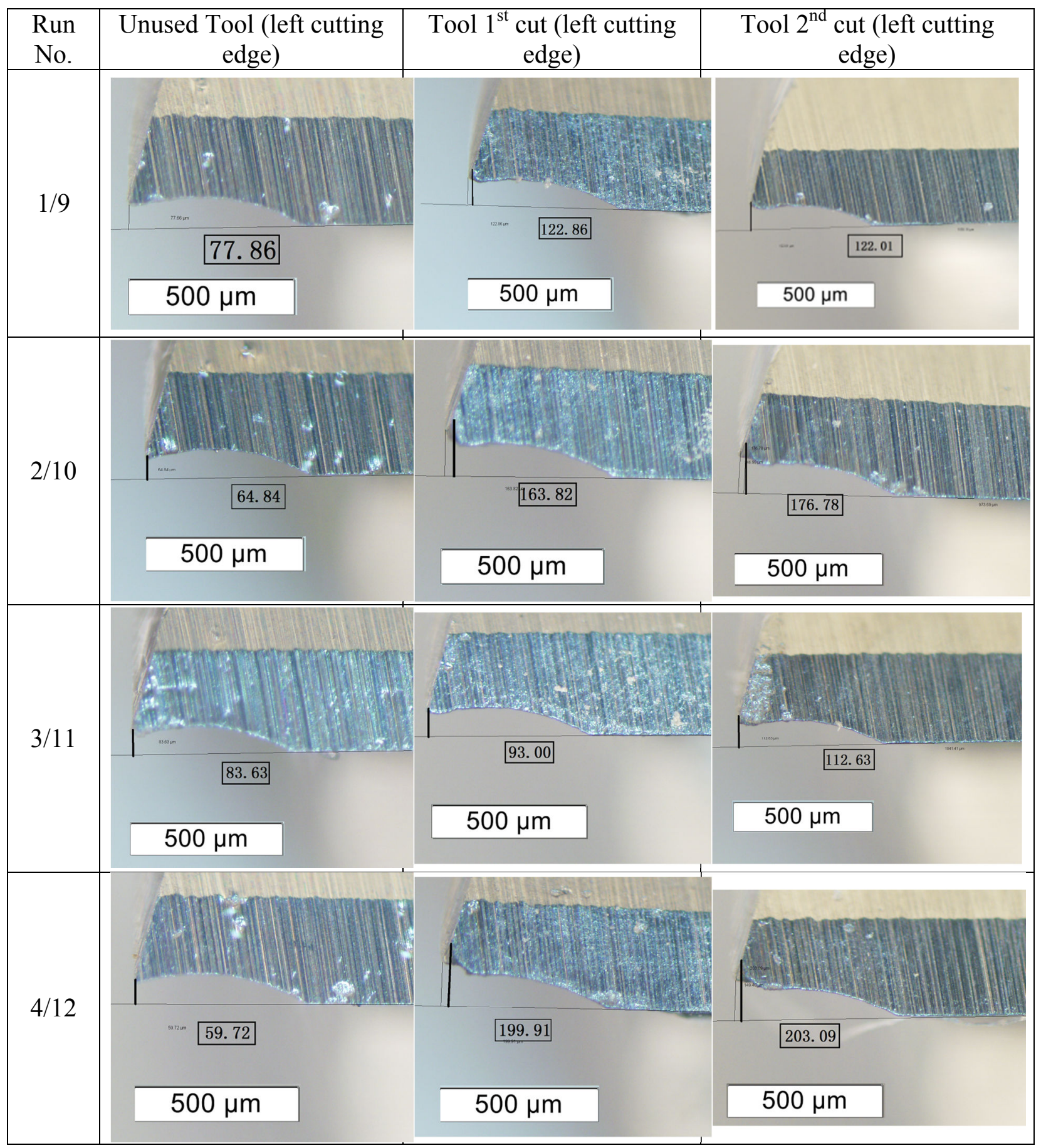




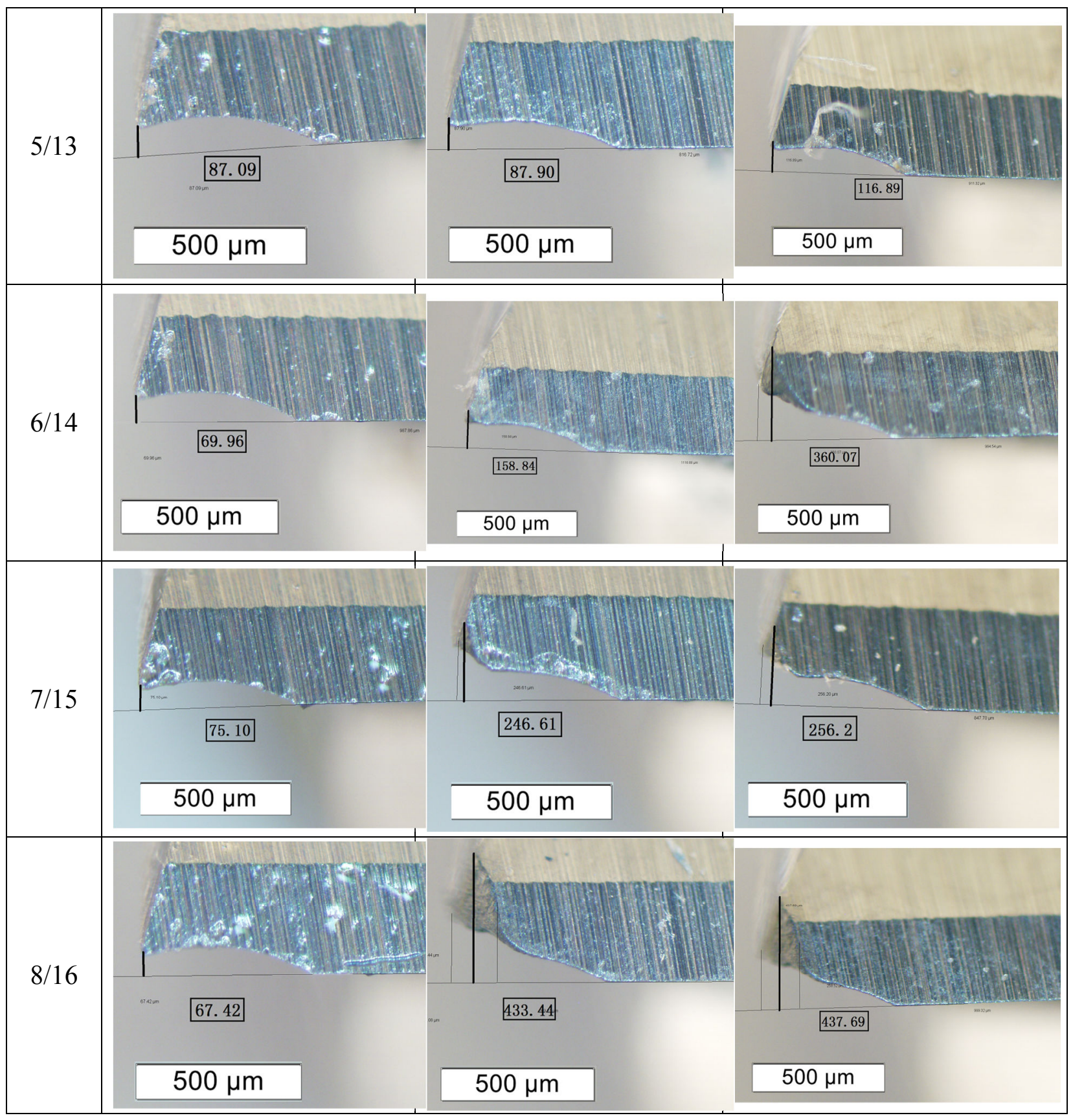




\section{Chapter 6 - Conclusions and Future Work}

\subsection{Conclusions}

Machining of the newly designed nano-crystalline hydroxyapatite bio-ceramic is a novel application in the area of biomedical engineering. The machining setup necessary to facilitate the end milling operations is presented. The experiments are carried out based on a factorial design and the experimental results obtained played a vital role in understanding the effects of the various machining parameters necessary to carry out the end milling operations. Response surface methodology was utilized to develop the first order surface roughness model in end milling operation. Some conclusions from this study are summarized in the following:

1. Milling operation of nHAP is a promising technique in the fabrication of bio-implants that offers benefits of low cost, no special machining setup, high efficiency, faster processing times and good surface finish.

2. Good surface integrity is achieved with required surface roughness value $\left(R_{a}\right)$ of $1-1.5$ $\mu \mathrm{m}$. It was found that material removal is caused by brittle fracture without plastic flow. Observation under SEM and optical microscope suggest that material is very dense and fracturing is believed to be intragranular in nature.

3. The effect of cutting parameters: cutting speed, feed and depth of cut on the surface roughness value $\left(R_{a}\right)$ was studied with the help of factorial design. It was found that under the chosen range of parameters, all three parameters have significant effect on the $R_{a} \cdot R_{a}$ increases with increase in feed, and decreases with increase in cutting speed and depth of cut.

4. Based on the results a linear, first order surface roughness prediction model of nHAP in the end milling operation is proposed. The presence of interaction and significant curvature demands higher order prediction model, for the statistical significance. Causes of variability in the experiments such as tool wear are not considered in the model building process, which affects the $\mathrm{R}_{\mathrm{a}}$ value significantly.

5. The analysis of the chip samples suggests good fit between the chip size and shapes and surface defects. Cavities on the machined surface points out the brittleness of material and need to optimize the machining process to control them. 
6. The observed tool wear was high and mainly occurred due to abrasion.

\subsection{Future Work}

1. This research can be further continued by building more accurate surface roughness prediction models in case of end milling. There is a need to consider a higher order model for prediction purpose. Star point can be added to the current 3 level CCD to make it 5 level CCD.

2. Change in tool material is required. Harder tools should be used for further machining experiments, which will control the variability in the experiments.

3. The nano-crystalline HAP is a very brittle ceramic (fracture toughness $\sim 1.3 \mathrm{MPa} \cdot \mathrm{m}^{1 / 2}$ ) and thus the material is removed by the brittle fracture mechanism, which creates cavities on machined surface. nHAP bioceramic has applications in human body as implant devices. It is essential that the machined surface is smooth and free of cavities and cracks. To achieve a smooth surface without strength degradation, the following two approaches should be considered in future investigations: ductile regime machining and laser assisted machining.

(A)Ductile Regime Machining: The advances in machining processes have enabled ductile machining of brittle materials. It is possible to machine brittle materials under certain conditions so that material removal will be realized through more plastic deformation. This transition of brittle to ductile mode can be explained by energy balance between strain energy and surface energy (28). Ngoi and Sreejith (2000) (28) reviewed the ductile regime machining for turning processes. A single point diamond tool is usually advised for this process. It has been observed that cutting speed and tool geometry are governing factors in achieving a smooth surface. Tool geometry is associated with depth of cut, which needs to be below a critical value. Higher negative rake angles improve the machining process. Tools with small rake angles improve the cutting mechanism. Critical depth of cut is considered as the governing parameter for ductile to brittle transition. Bifano et al. (6) showed that the critical depth of cut is a function of material and mechanical properties and can be calculated as $d_{c} \sim b^{*}(E / H) *\left(K_{c} / H\right)^{2}($ Bifano, 1991). Where $b$ is the constant of proportionality and is given as 0.15 . The elastic modulus (E) for nHAP is $108 \mathrm{GPa}$, the hardness $(\mathrm{H})$ is $2500 \mathrm{MPa}$, and the fracture toughness $\left(\mathrm{K}_{\mathrm{c}}\right)$ is 1.3 MPa.m ${ }^{1 / 2}$, which leads to a theoretical critical depth of cut of $\sim 1.75 \mu \mathrm{m}$ for the nHAP 
ceramic. Incorporating the above guidelines regarding cutting tool and the critical depth of cut, the effect of ductile regime machining on surface finish of nHAP should be tested.

(B) Laser Assisted Machining: Another approach to performing ductile machining of the nHAP can be laser assisted machining. Laser can be used to induce ductility into the nHAP material by localized heating. However, the absorptivity of the nHAP material depends on laser wavelength. Our initial experiments revealed that the nHAP is transparent to the laser irradiation at $940 \mathrm{~nm}$. Using shorter wavelengths may enhance absorption of the nHAP as suggested by Pioneer Surgical Technologies. Hence, proper wavelengths for laser heating should be identified in the future. In combination with the use of a sharp diamond cutting tool, machining nHAP could be performed in a more ductile manner as single point diamond inserts have a very small cutting edge radius. This should help to reduce the observed chipping effect, thus generating a cavity free machined surface. 


\section{Bibliography}

Abdel-Aal Ahmed $\mathbf{M}$ Cementless Total Hip Arthroplasty Basic Science [Online]// http://www.arthroclub.egydoc.com. - 10 12, 2011. - http://www.arthroclub.egydoc.com.

Akao M. Aoki H., Kato K. Mechanical properties of sintered hydroxyapatite for prosthetic applications [Journal]. - [s.1.] : Jouranl of materials science, 1981. - Vol. 16. - pp. 809812.

Benga G. Gingu O., Ciupitu I., Gruionu L., Pascu I., and Moreno J.C. Processing and Laser Micromachining of HAP Based Biocomposites [Book] / ed. L. Dudas. - [s.1.] : InTech, 2010.

Bertranda Ph. Baylea F.,Combea C., Goeuriotb P.,Smurova I. Ceramic components manufacturing by selective laser sintering [Journal]. - 2007. - 4 : Vol. 254. - pp. 989-992.

Best S.M. Porter A.E., Thian E.S., Huang J. Bioceramics: Past, present and for the future [Journal]. - [s.1.] : Journal of the European Ceramic Society, 2008. - Vol. 28. - pp. 13191327.

Bifano T.G., Dow T.A., Scattergood R.O. Ductile-Regime Grinding: a New Technology for Machining Brittle Materials [Journal]. - [s.1.] : Journal of engineering for industry, 1991. 2 : Vol. 113. - pp. 184-189.

Brehm R. Van Dun, Teunissen J.C.G. and Haisma J. Transparent single-point turning of optical glass: A phenomenological presentation [Journal]. - [s.1.] : Precision Engineering, 1979. - 4 : Vol. 1. - pp. 207-123.

Chelule K.L. Coole T. and Cheshire D.G. An investigation into the machinability of hydroxyapatite for bone restoration implants [Journal]. - [s.1.] : Journal of Material Processing Technology, 2003. - 135. - pp. 242-246.

Chelule K.L. Coole T. and Cheshire D.G. Machinability of advanced ceramics for CAD/CAM applications [Journal]. - [s.1.] : Society of Automotive Engineers 2001 World Congress Technical Papers, 2001.

Dabnun M.A. Hashmi M.S.J., El-Baradie M.A. Surface roughness prediction model by design of experiments for turning machinable glass-ceramic (Macor) [Journal]. - [s.1.] : Journal of Materials Processing Technology, 2005. - pp. 1289-1293.

Davis J.R. Handbook of Materials for Medical Devices [Book]. - [s.1.] : ASM International, 2003. 
Dorozhkin S.V. Calcium Orthophosphates as Bioceramics: State of the Art [Journal]. - [s.1.] : Journal of Functional Biomaterials, 2010. - Vol. 1. - pp. 22-107.

Enneking W.F. Eady J.L., Burchardt H. Autogenous Cortical Bone Grafts in the Reconstruction of Segmental Skeletal Defects [Journal]. - [s.1.] : The Journal of Bone and Joint Surgery, 1980. - Vols. 62-A.

Giannoudis P.S., Dinopoulos H.,Tsiridis E. Bone substitutes: An update [Journal]. - [s.1.] : Injury. International Journal of the Care of the Injured, 2005. - Vol. 36S. - pp. S20-S27.

HA Coated Standard (3.75) [Online] // http://osseosource.com. - OSSEOsource. - 10 12, 2011. http://osseosource.com/dental-implants/product_info.php?products_id=1019.

Hao L. and Lawrence J. Laser Surface Treatment of Bio-Implant Materials [Book]. - [s.1.] : John Wiley \& Sons, Ltd, 2005.

Health, United States [Report]. - [s.1.] : National Center for Health Statistics, 2010.

Keating J. F., McQueen M. M. Substitute for Autologous Bone Graft in Orthopaedic Trauma [Journal]. - [s.1.] : The Journal of Bone and Joint Surgery, 2001. - Vol. 83B.

Kokubo T Kim HM, Kawashita M. Novel bioactive materials with different mechanical properties [Journal]. - [s.1.] : Biomaterials, 2003. - 13 : Vol. 24.

Liu D. Savino K., Yates M.Z. Coating of hydroxyapatite films on metal substrates by seeded hydrothermal deposition. [Journal]. - [s.l.] : Surface and Coating Technology , 2011.

Martinetti R. Dolcini L., Mangano C. Physical and chemical aspects of a new porous hydroxyapatite [Journal]. - [s.1.] : Analytical and Bioanalytical Chemistry, 2005. - pp. 634-638.

Maximenko A.L. Van Der Biest O., Olevsky E.A. Prediction of initial shape of functionally graded ceramic pre-forms for near-net-shape sintering [Journal]. - [s.l.] : Science of Sintering, 2003. - Vol. 35. - pp. 5-12.

Montgomery D. C. Design and analysis of experiments [Book]. - [s.1.] : Wiley, 2001. 0471316490 .

Moore W.R, Graves S.E.and Bain G.I. Synthetic Bone Graft Substitutes [Journal] // ANZ Journal of Surgery. - 2001. - Vol. 71. - pp. 354-361.

Mudali U.K., Sridhar T.M. and Baldev Raj Corrosion of Bio-Implants [Journal]. - [s.1.] : Sadhana, 2003. - 3 \& 4 : Vol. 28. - pp. 601-637.

Navarro M.,Michiardi A.,Castañ O.and Planell J.A Biomaterials in orthopaedics [Journal]. - [s.1.] : The Royal Society Interface, 2008. - Vol. 5. - pp. 1137-1158. 
Newton C.D. and Nunamaker D.M. Textbook of Small Animal Orthopaedics [Book]. - [s.1.] : J.B. Lippincott Company, 1985.

Ngoi B.K.A. and Sreejith P.S. Ductile regime finish machining - A review [Journal]. - [s.1.] : International journal of advanced manufacturing technology, 2000. - Vol. 16. - pp. 547550 .

Oblak C. and Jevnikar P. The Strength and Hydrothermal Stability of Y-TZP Ceramics for Dental Applications [Journal]. - [s.1.]: International Journal of Applied Ceramic Technology, 2007. - 2 : Vol. 4.

Poitout D.G. Yamamuro T. Biomechanics and biomaterials in orthopedics [Book]. - [s.1.] : Springer, 2004. - pp. 22-33.

Ratner B. Biomaterials Science: An Interdisciplinary Endeavor [Journal]. - [s.l.] : Academic Press, Inc., 1996.

Reddy M.M. Gorin A. and Abou-El-Hossein K.A. Predictive Surface Roughness Model for End Milling of Machinable Glass Ceramic [Journal]. - [s.1.] : IOP Conference Series: Materials Science and Engineering (MSE), 2011. - Vol. 17.

Rooter H.M., Powers J.M., Graig R.G. Sintered hydroxyapatite ceramic for wear studies [Journal]. - [s.1.] : Journal of Dental Research, 1978. - 7-8 : Vol. 57.

Russias J. Saiz E., Nalla R.K., Gryn K.,Ritchie R.O., Tomsia A.P. Fabrication and mechanical properties of PLA/HA composites: A study of in vitro degradation [Journal]. - [s.1.] : Materials Science and Engineering: C, 2006. - 8 : Vol. 26. - pp. 12891295.

Singh G., Singh S., Prakash S. Post Heat Treatment of Plasma Sprayed Pure and AluminaTitania Reinforced Hydroxyapatite Coating on SS 304 Steel [Journal]. - [s.1.] : Journal of Minerals \& Materials Characterization \& Engineering, 2011. - Vol. 10. - pp. 173-184.

Spivak J.M. and Hasharoni A. Use of Hydroxyapatite in spice surgery [Journal]. - [s.l.] : European Spine Journal, 2001. - Vol. 10. - pp. S197-S204.

Tisdel C.L Goldberg V.M., Parr J.A., Bensusan J.S., Stailoff L.S., Stevenson S. The Influence of a Hydroxyapatite and Tricalcium-Phosphate Coating on Bone Growth into Titanium Fiber-Metal Implants [Journal]. - [s.1.] : The Journal of Bone and Joint Surgery, 1994. - Vols. 76-A. - 2.

U Kamachi Mudali T.M. Sridhar and Baldev Raj Corrosion of Bio-Implants [Journal]. [s.1.] : Sadhana, 2003. - Vol. 28. - pp. 601-637. 
Wenneberg A. and Albrektsson T. Suggested guidelines for the topographic evaluation of implant surfaces. [Journal]. - [s.l.] : The International Journal of Oral \& Maxillofacial Implants, 2000. - 3 : Vol. 15. - pp. 331-344.

Wennerberg A., Albrektsson T., Andersson B. Design and Surface Characteristics of 13 Commercially Available Oral Implant Systems [Journal]. - [s.1.] : he International Journal of Oral \& Maxillofacial Implants, 1993. - pp. 622-633.

Yoshikawa H. Myuoui A. Bone tissue engineering with porous hydroxyapatite ceramics [Journal]. - [s.1.] : The International Journal of Artificial Organs, 2005. - Vol. 8. - pp. 131-136.

Zhongkui Hong Peibiao Zhang, Chaoliang He, Xueyu Qiu, Aixue Liu, Li Chen, Xuesi Chen, Xiabin Jing Nano-composite of poly(L-lactide) and surface grafted hydroxyapatite: Mechanical properties and biocompatibility [Journal]. - [s.l.] : Biomaterials, 2005. - Vol. 26. - pp. 6296-6304. 


\section{Appendix I: Ra values of 5 level CCD}

\begin{tabular}{|c|c|c|c|c|c|}
\hline $\begin{array}{c}\text { Standard } \\
\text { Order }\end{array}$ & $\begin{array}{c}\text { Run } \\
\text { Order }\end{array}$ & $\begin{array}{c}\text { Speed } \\
(\mathbf{m} / \mathbf{m i n})\end{array}$ & $\begin{array}{c}\text { feed } \\
(\mathbf{m m} / \mathbf{r e v})\end{array}$ & $\begin{array}{c}\text { DOC } \\
\mathbf{( m m})\end{array}$ & $\mathbf{R}_{\mathbf{a}}$ \\
\hline 16 & 1 & 135.47 & 2.47 & 0.068 & 0.90 \\
\hline 13 & 2 & 77.50 & 1.26 & 0.068 & 0.98 \\
\hline 18 & 3 & 135.47 & 1.26 & 0.120 & 0.66 \\
\hline 19 & 4 & 135.47 & 1.26 & 0.068 & 0.88 \\
\hline 20 & 5 & 135.47 & 1.26 & 0.068 & 1.02 \\
\hline 17 & 6 & 135.47 & 1.26 & 0.016 & 1.18 \\
\hline 14 & 7 & 193.44 & 1.26 & 0.068 & 0.75 \\
\hline 15 & 8 & 135.47 & 0.45 & 0.068 & 0.60 \\
\hline 5 & 9 & 135.47 & 1.26 & 0.068 & 0.68 \\
\hline 4 & 10 & 99.97 & 1.72 & 0.100 & 1.20 \\
\hline 3 & 11 & 170.97 & 0.89 & 0.100 & 0.72 \\
\hline 1 & 12 & 99.97 & 0.89 & 0.036 & 0.92 \\
\hline 2 & 13 & 170.97 & 1.72 & 0.036 & 1.06 \\
\hline 6 & 14 & 135.47 & 1.26 & 0.068 & 0.97 \\
\hline 7 & 15 & 170.97 & 0.89 & 0.036 & 0.86 \\
\hline 12 & 16 & 135.47 & 1.26 & 0.068 & 0.87 \\
\hline 11 & 17 & 135.47 & 1.26 & 0.068 & 1.12 \\
\hline 9 & 18 & 99.97 & 0.89 & 0.100 & 1.07 \\
\hline 10 & 19 & 170.97 & 1.72 & 0.100 & 1.14 \\
\hline 8 & 20 & 99.97 & 1.72 & 0.036 & 1.21 \\
\hline & & & & & \\
\hline
\end{tabular}




\section{Appendix II: $\mathbf{R}_{\mathrm{a}}$ values of $\mathbf{2}^{\mathbf{3}}$ factorial design}

\begin{tabular}{|c|c|c|c|c|}
\hline $\begin{array}{c}\text { Standard } \\
\text { Order }\end{array}$ & $\begin{array}{c}\text { Speed } \\
(\mathbf{m} / \mathbf{m i n})\end{array}$ & $\begin{array}{c}\text { feed } \\
(\mathbf{m m} / \mathbf{r e v})\end{array}$ & $\begin{array}{c}\text { DOC } \\
(\mathbf{m m})\end{array}$ & Ra \\
\hline 1 & 99.97 & 0.00053 & 0.1 & 0.80 \\
\hline 2 & 170.97 & 0.00053 & 0.1 & 0.60 \\
\hline 3 & 99.97 & 0.00147 & 0.1 & 1.06 \\
\hline 4 & 170.97 & 0.00147 & 0.1 & 0.75 \\
\hline 5 & 99.97 & 0.00053 & 0.2 & 1.39 \\
\hline 6 & 170.97 & 0.00053 & 0.2 & 0.44 \\
\hline 7 & 99.97 & 0.00147 & 0.2 & 1.28 \\
\hline 8 & 170.97 & 0.00147 & 0.2 & 0.53 \\
\hline \multicolumn{5}{|c|}{ Replication } \\
\hline 9 & 99.97 & 0.00053 & 0.1 & 0.66 \\
\hline 10 & 170.97 & 0.00053 & 0.1 & 0.57 \\
\hline 11 & 99.97 & 0.00147 & 0.1 & 0.74 \\
\hline 12 & 170.97 & 0.00147 & 0.1 & 0.83 \\
\hline 13 & 99.97 & 0.00053 & 0.2 & 0.36 \\
\hline 14 & 170.97 & 0.00053 & 0.2 & 0.53 \\
\hline 15 & 99.97 & 0.00147 & 0.2 & 0.59 \\
\hline 16 & 170.97 & 0.00147 & 0.2 & 0.46 \\
\hline
\end{tabular}




\section{Appendix III $-2^{3}$ CCD Analysis}

\section{Residuals in 3-level CCD}

\begin{tabular}{|c|c|c|c|c|c|c|}
\hline Obs & $\begin{array}{c}\text { Std. } \\
\text { Order }\end{array}$ & Ra & Fit & SE Fit & Residual & $\begin{array}{c}\text { Standard } \\
\text { Residual }\end{array}$ \\
\hline 1 & 1 & 1.66208 & 1.53896 & 0.07905 & 0.12312 & 1.56 \\
\hline 2 & 2 & 0.74792 & 0.93344 & 0.07905 & -0.18552 & -2.35 R \\
\hline 3 & 3 & 2.39125 & 2.3574 & 0.07905 & 0.03385 & 0.43 \\
\hline 4 & 4 & 1.78042 & 1.75187 & 0.07905 & 0.02854 & 0.36 \\
\hline 5 & 5 & 1.1825 & 1.2476 & 0.07905 & -0.0651 & -0.82 \\
\hline 6 & 6 & 0.76958 & 0.64208 & 0.07905 & 0.1275 & 1.61 \\
\hline 7 & 7 & 1.97417 & 2.06604 & 0.07905 & -0.09187 & -1.16 \\
\hline 8 & 8 & 1.49 & 1.46052 & 0.07905 & 0.02948 & 0.37 \\
\hline 9 & 9 & 1.11333 & 1.0475 & 0.0559 & 0.06583 & 0.68 \\
\hline 10 & 10 & 1.03333 & 1.0475 & 0.0559 & -0.01417 & -0.15 \\
\hline 11 & 11 & 1.03333 & 1.0475 & 0.0559 & -0.01417 & -0.15 \\
\hline 12 & 12 & 1.01 & 1.0475 & 0.0559 & -0.0375 & -0.39 \\
\hline
\end{tabular}

$\mathbf{R}$ denotes an observation with a large standardized residual.

\section{Residual Plot of 3 level CCD}

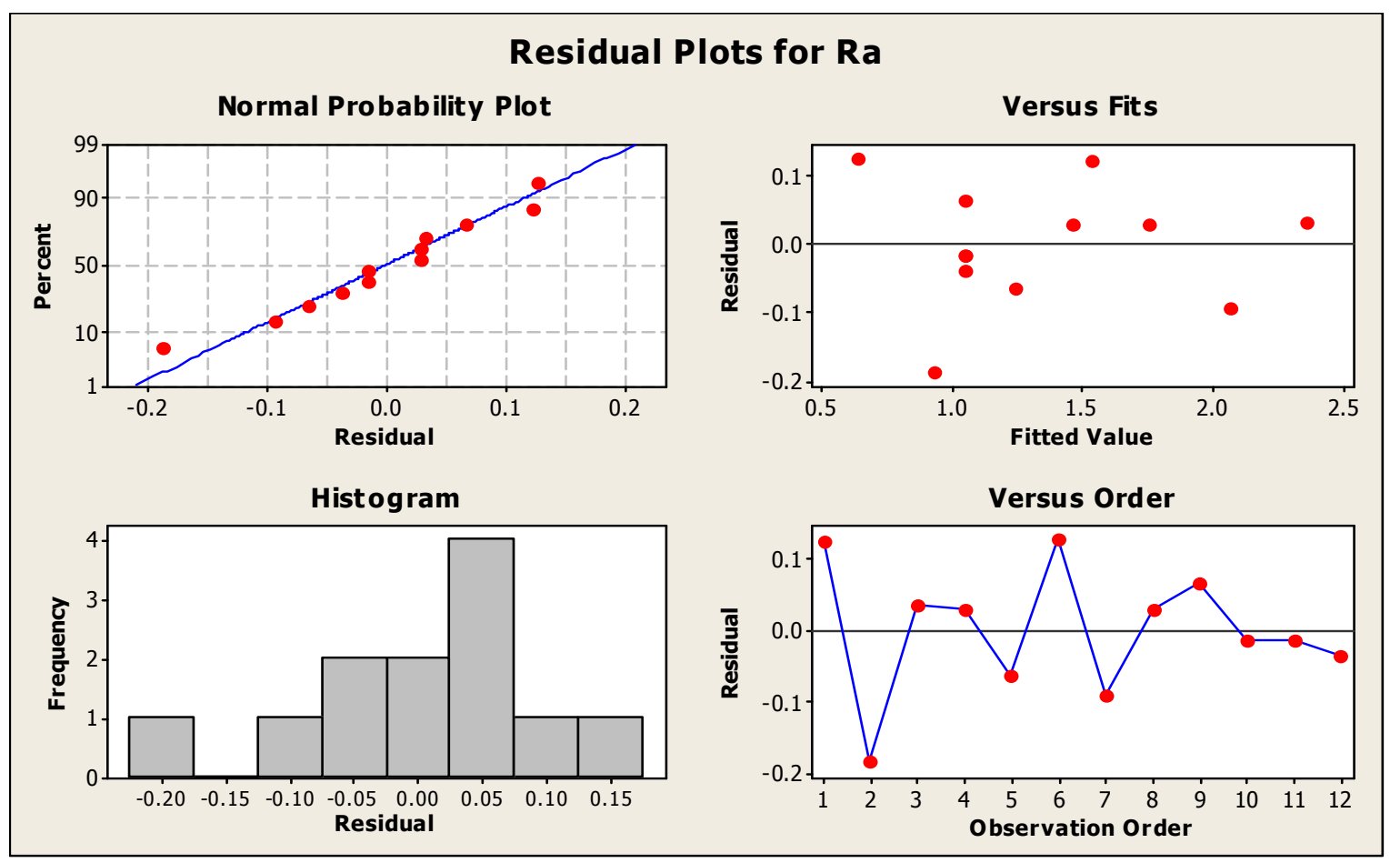




\section{Main effect plot and interaction plot of 3 level CCD}
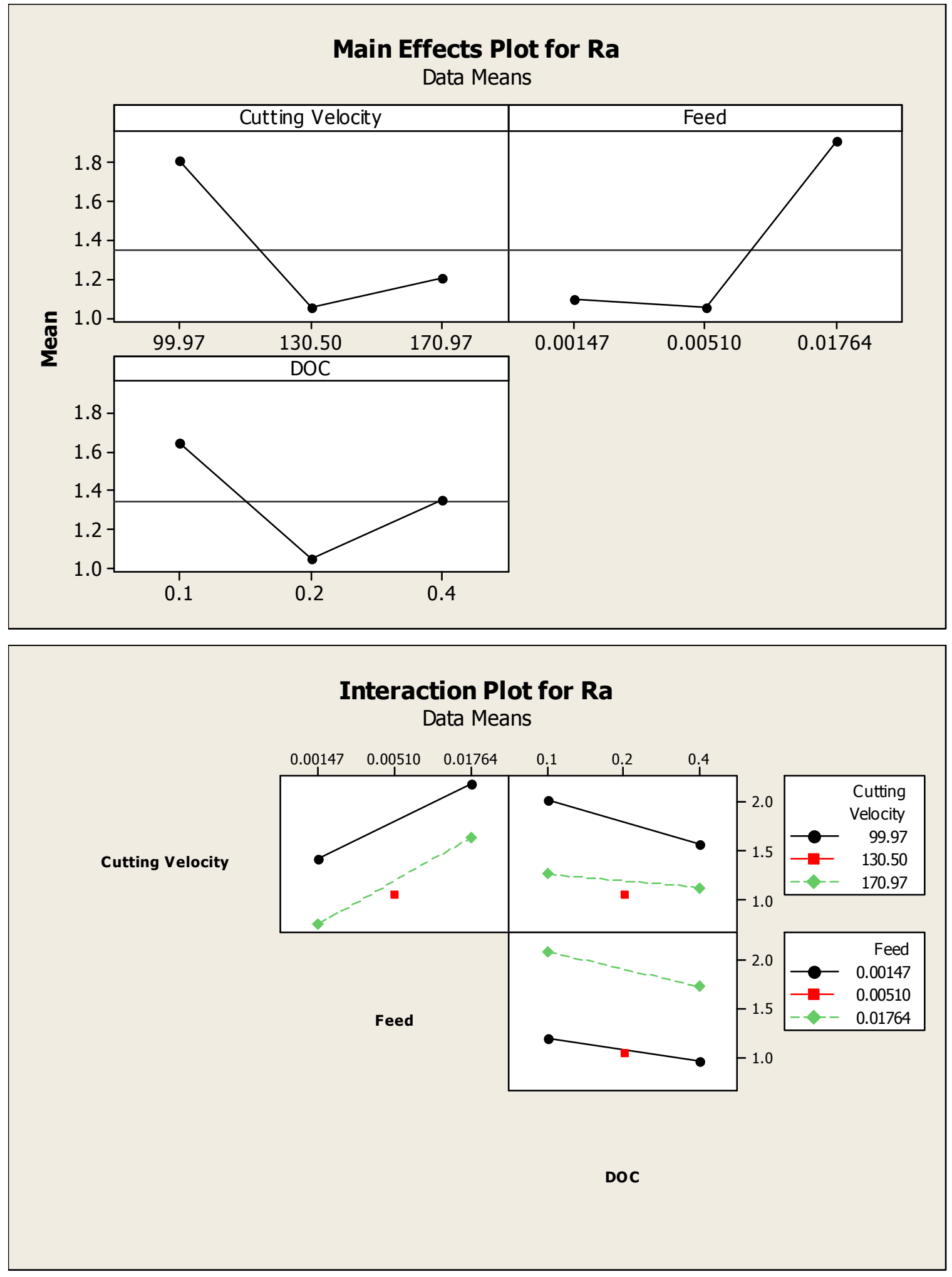


\section{Appendix IV.3D Surface plots and corresponding contour plots}

1. 3D surface plots and corresponding contour plots of 3-level CCD
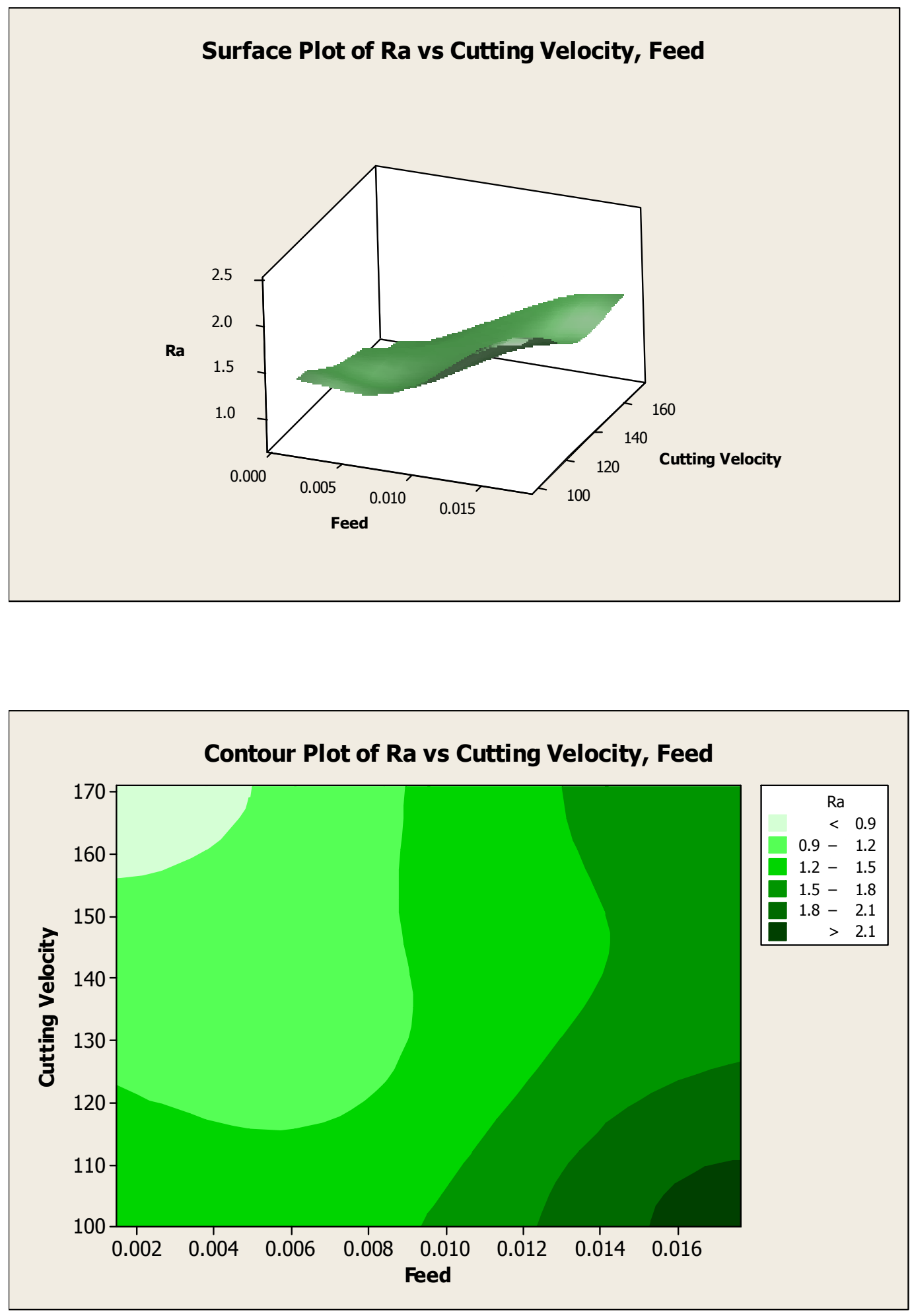

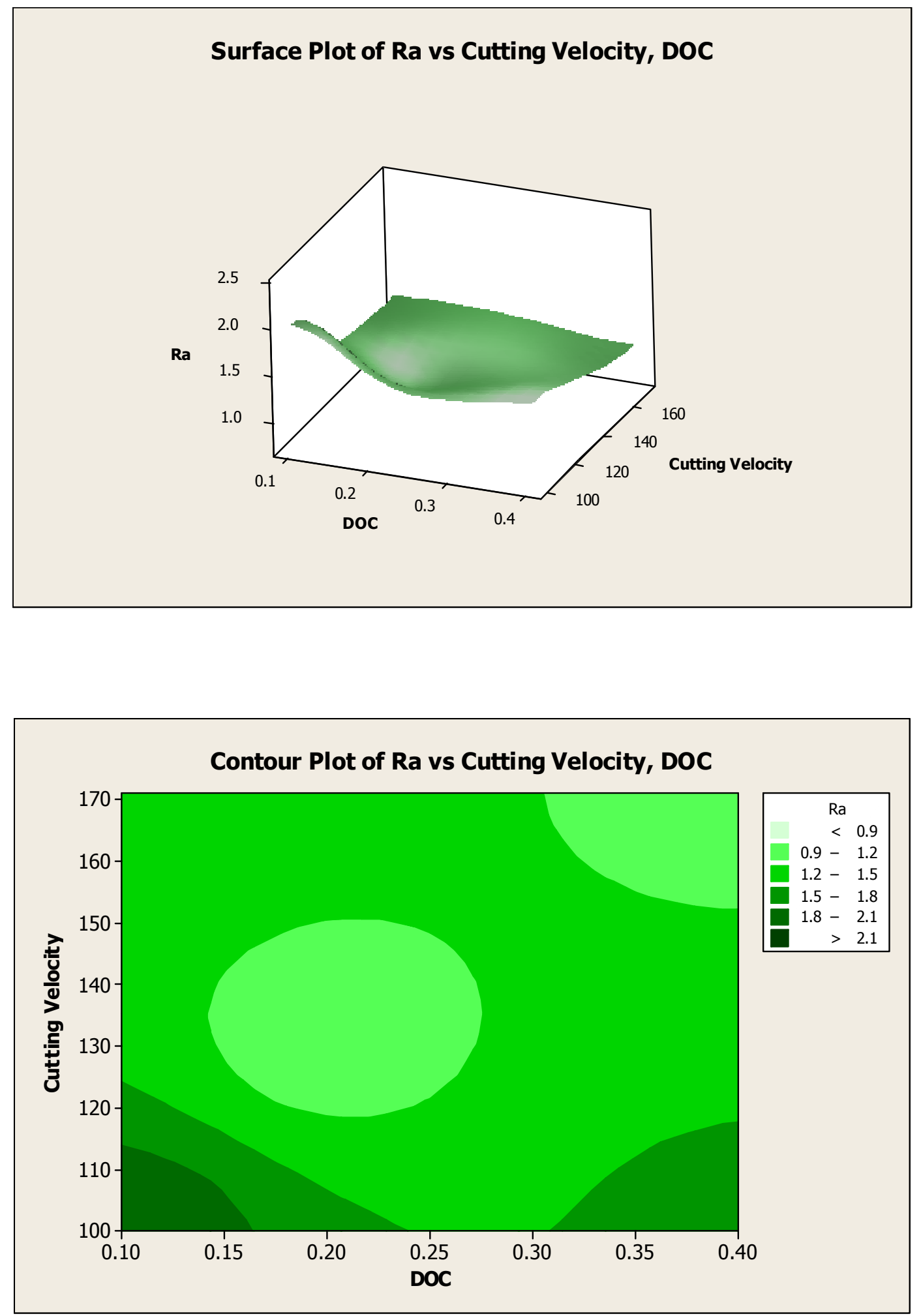

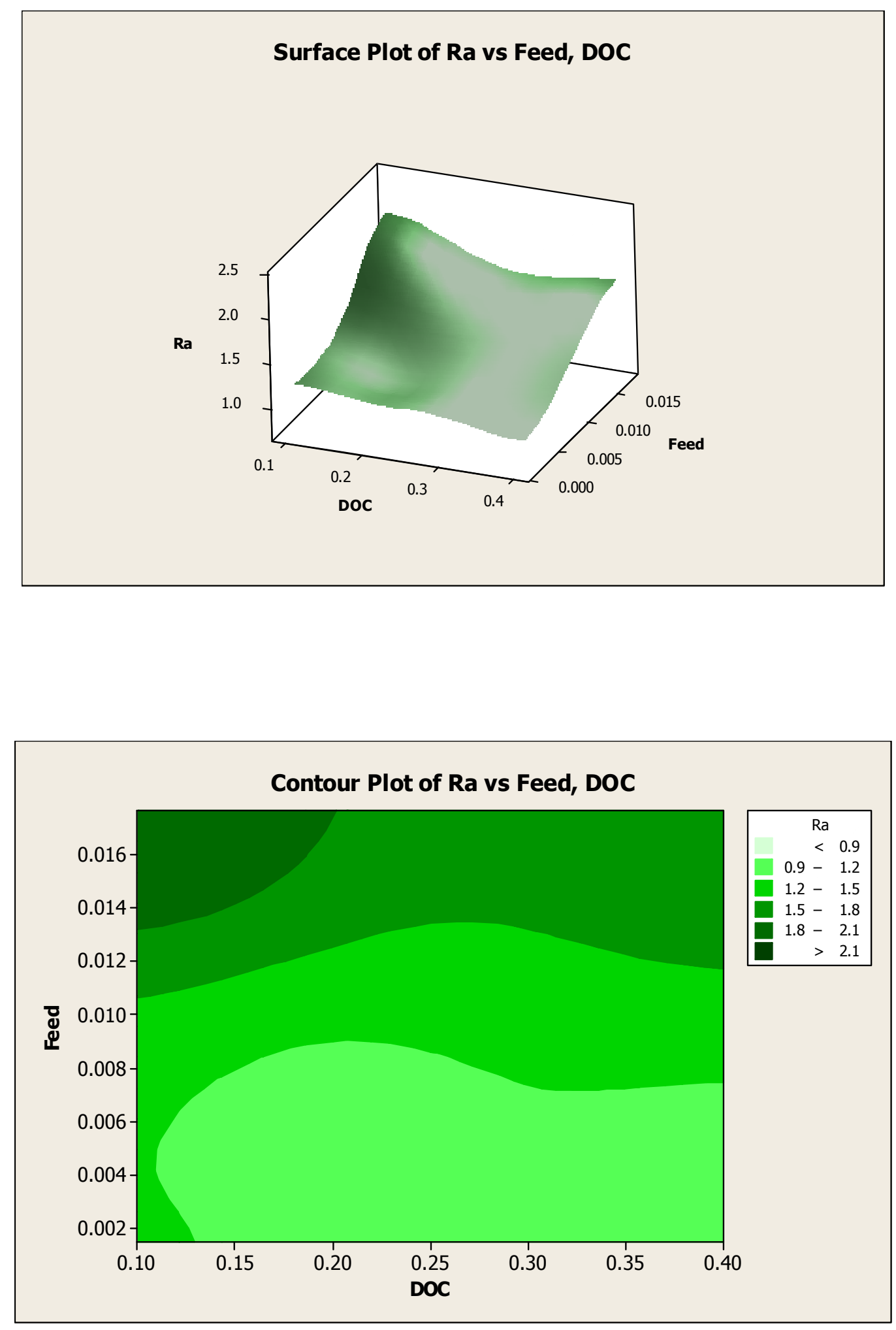